\title{
HYDRAULIC ANALYSIS OF UNDERGROUND BIORETENTION SYSTEMS
}

\author{
By \\ Sogol Bandehali \\ BEng., Ryerson University, Toronto, Canada, 2011
}

A thesis presented to

Ryerson University

in partial fulfilment of

the requirement for the degree of

Master of Applied Science

in the Program of

Civil Engineering

Toronto, Ontario, Canada, 2015

(C) Sogol Bandehali, 2015 


\section{Author Declaration}

I hereby declare that I am the sole author of this thesis. This is a true copy of the thesis, including any required final revisions, as accepted by my examiners.

I authorize Ryerson University to lend this thesis to other institutions or individuals for the purpose of scholarly research

I further authorize Ryerson University to reproduce this thesis by photocopying or by other means, in total or in part, at the request of other institutions or individuals for the purpose of scholarly research.

I understand that my thesis may be made electronically available to the public

I understand that my dissertation may be made electronically available to the public. 


\title{
Abstract \\ HYDRAULIC ANALYSIS OF UNDERGROUND BIORETENTION SYSTEMS
}

\author{
Master of Applied Science \\ Sogol Bandehali \\ Civil Engineering, 2015 \\ Ryerson University
}

The conventional practices of urbanization significantly increase the flooding and water pollution. This is due to reduction in pervious areas. To minimize the problem, various concepts of low impact development have been implemented such as underground bioretention cells. The main intention of this research was to review different aspects of Low Impacts Developments (LIDs) especially bioretention cells and develop a hydraulic model to predict the distribution of runoff throughout the bioretention cell under different scenarios.

In this study, the hydraulic simulation model was developed in Matlab in order to attain better understanding of bioretention systems. The hydraulic model was used to investigate the impacts of different design options on the distribution of flows over the entire bioretention cell. Understanding the effect of design options can be beneficial to improve the performance of bioretention systems and improving the water quality and quantity in developed areas. 


\section{Acknowledgements}

I would like to thank my supervisor, Dr. James Li and my co-supervisor Dr. Darko Joksimovic, who have provided me full support during my MSc. I am grateful to them for their valuable guide. Without their guidance and support, it was impossible to complete this thesis.

The author also acknowledges the financial support by City of Toronto and the useful suggestions of her colleague, Robin Luong at Environmental Research Lab at Ryerson University.

This thesis is dedicated to my family, especially my parents who sacrificed everything for me, as well as my kind sisters, Maygol and my brother Maziar. In addition, I would like to express my gratitude to my fiancé Amirhossein, and thank him for his love, patience and support. 


\section{Table of Content}

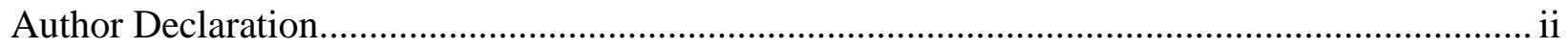

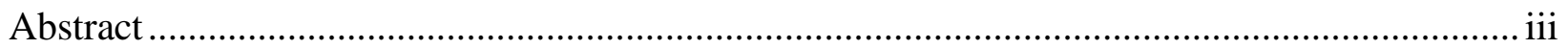

Acknowledgements ........................................................................................................ iv

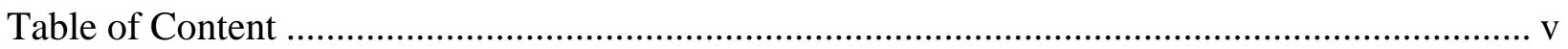

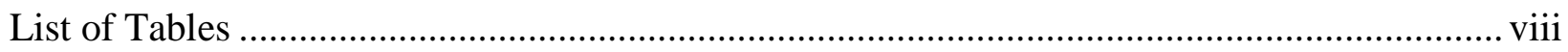

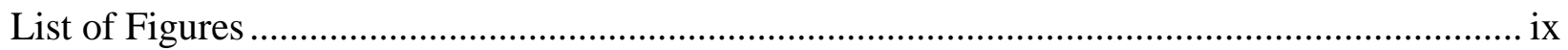

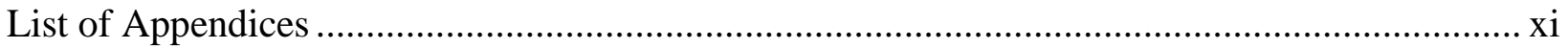

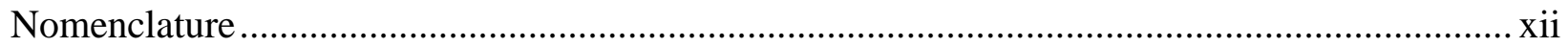

1 Chapter 1: Introduction and Motivations ........................................................................... 1

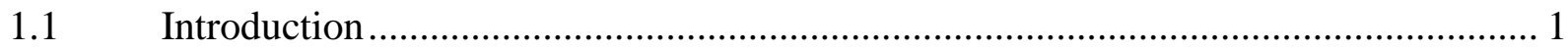

1.2 Application of the Underground Bioretention System ……....................................... 2

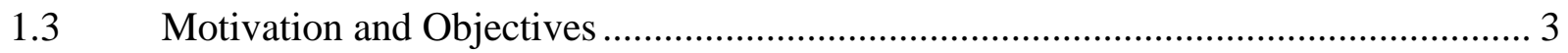

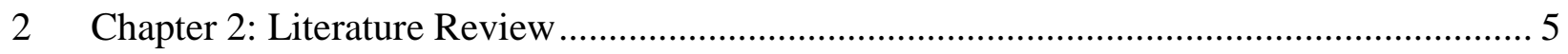

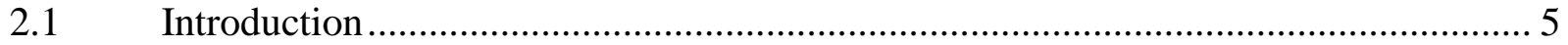

2.2 Best Management Practices (BMP) ………………............................................ 6

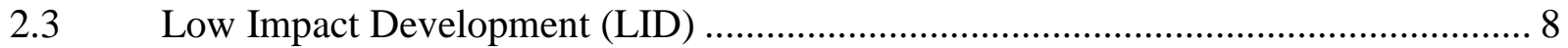

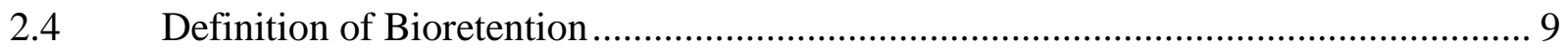

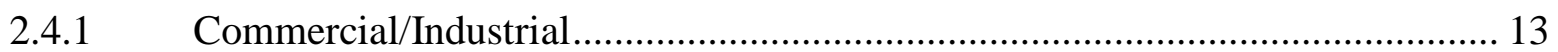

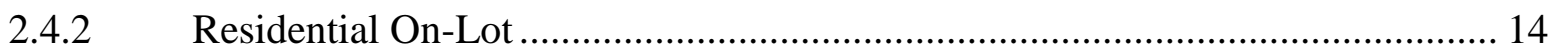

2.5 Bioretention Soil and its Functions ................................................................... 15

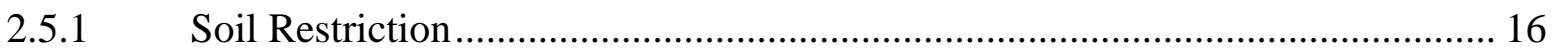

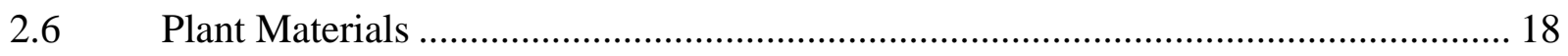

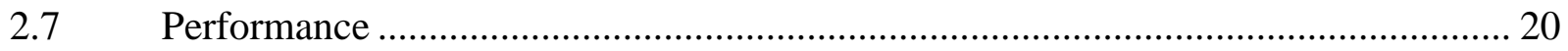




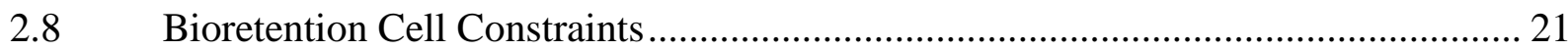

2.9 Modeling of Bioretention Hydrology .................................................................... 22

2.10 Underground Bioretention System.................................................................... 24

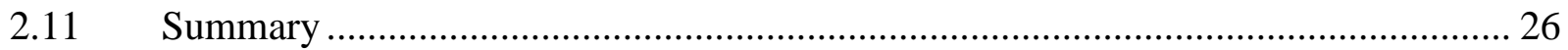

3 Chapter 3: Mathematic Modeling of the Underground Bioretention System........................ 27

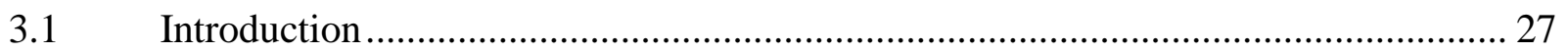

3.2 Mathematical Formulation of Underground Bioretention Cell................................ 27

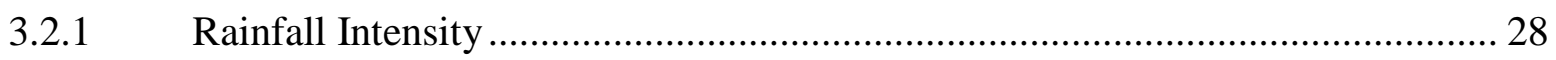

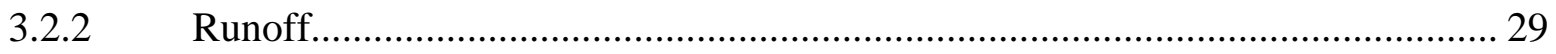

3.2.3 Mass balance at Catch Basin ................................................................................... 32

3.2.4 Mass Balance at the Distribution Pipe (P1) ..................................................... 34

3.2.5 Mass Balance at the Bioretention Cell ............................................................ 40

3.2.6 Mass Balance at the Flow Control Pipe (P2) ..................................................... 43

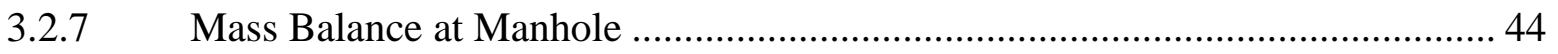

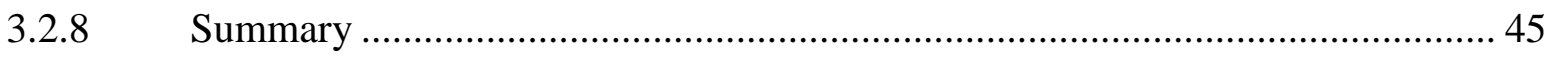

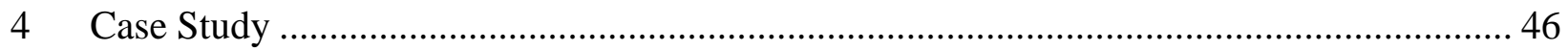

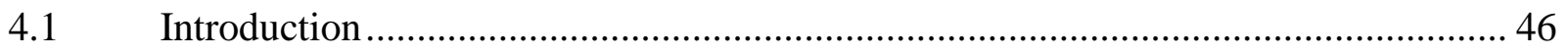

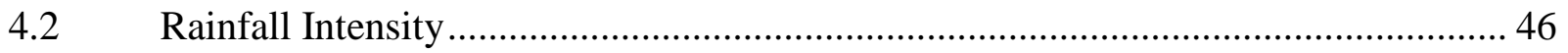

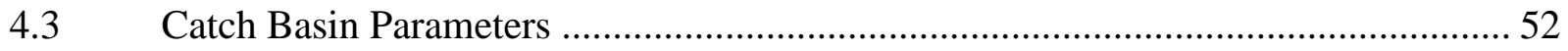

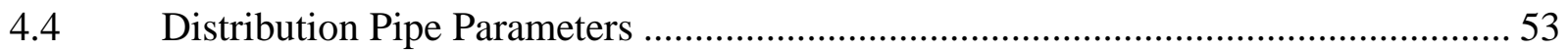

4.5 Bioretention Cell Parameters ............................................................................ 57

4.6 Flow Control Pipe and Manhole Parameters ……………………………............. 57

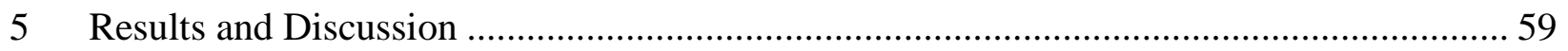

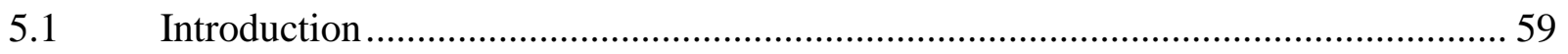

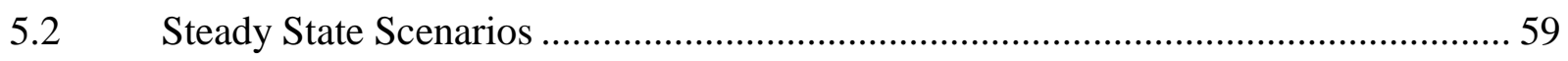




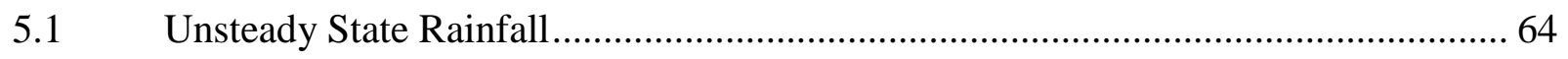

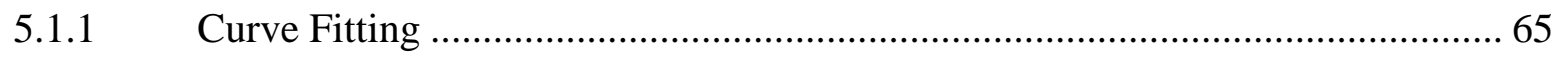

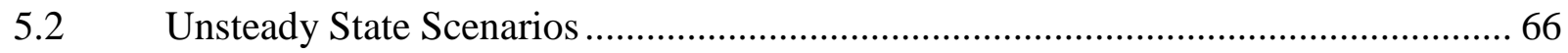

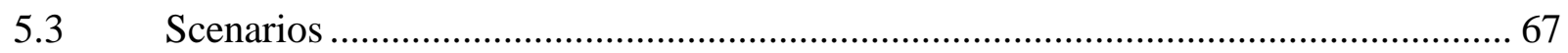

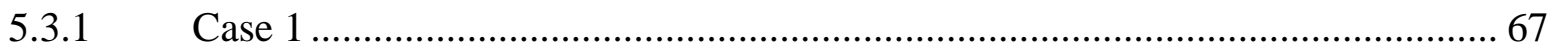

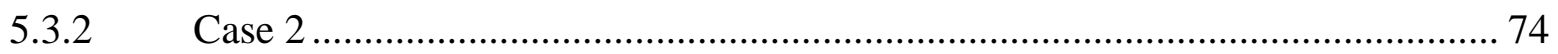

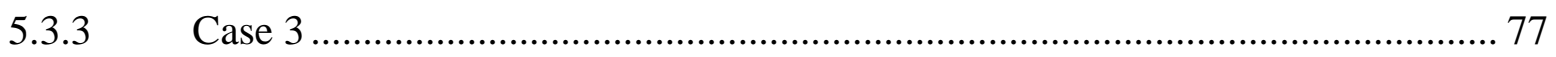

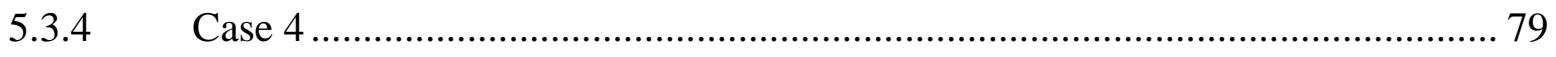

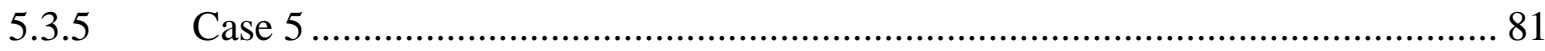

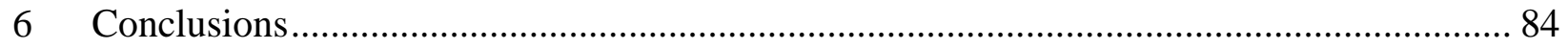

6.1 Recommendations and Future works ……………................................................ 85

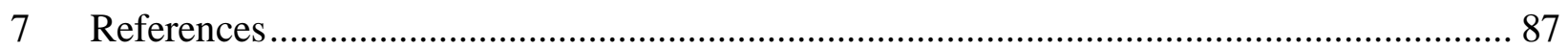

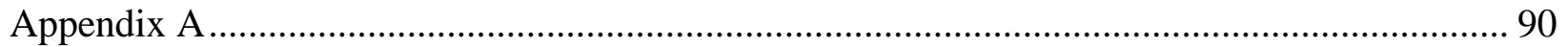




\section{List of Tables}

Table 1 Soil textural classification ................................................................................. 16

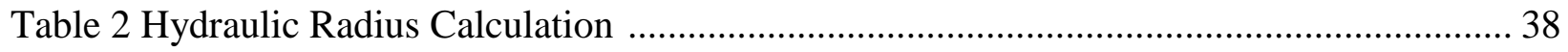

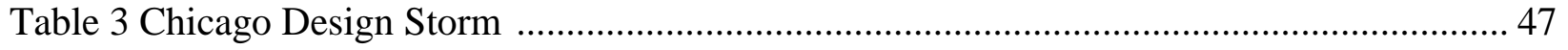

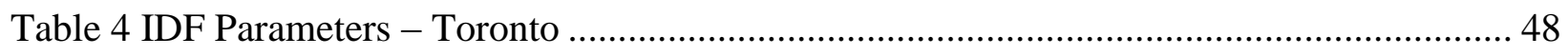

Table 5 Runoff Coefficient for Business and Areas ............................................................ 49

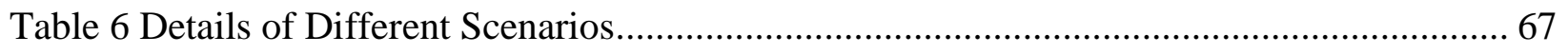




\section{List of Figures}

Figure 2-1 Changes to the storm hydrograph due to urbanization ......................................... 5

Figure 2-2 Bioretention facility conceptual cross-sectional layout ...................................... 10

Figure 2-3 Percent fines and hydraulic conductivity relationship ........................................ 17

Figure 2-4 Sustainable sidewalk with underground bioretention .......................................... 24

Figure 2-5 Installation of underground Bioretention System ............................................ 25

Figure 2-6 Sample of Underground Bioretention System ................................................. 25

Figure 3-1 Short duration rainfall intensity-duration- frequency data .................................... 29

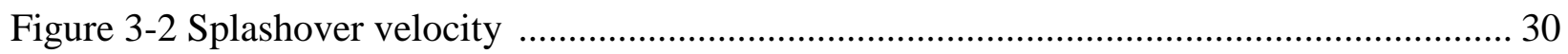

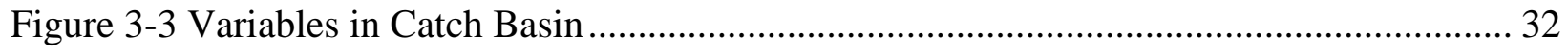

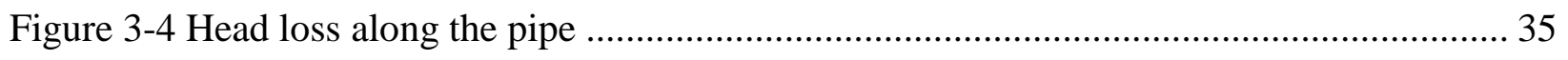

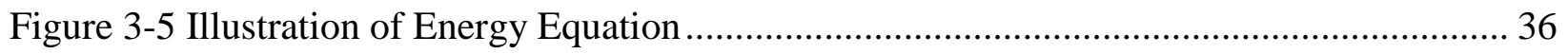

Figure 3-6 Different Variables of the Bioretention Cell ....................................................... 43

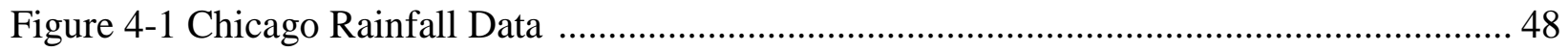

Figure 4-2 Continuous Chicago Design Storm Data ......................................................... 50

Figure 4-3 Grate Efficiency for Curved Vane Inlet Figure ................................................. 51

Figure 4-4 Layout of Orifices on the Distribution Pipe ........................................................ 55

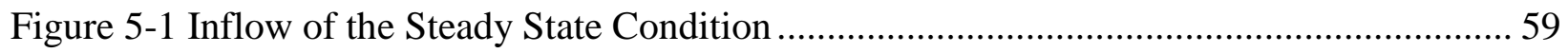

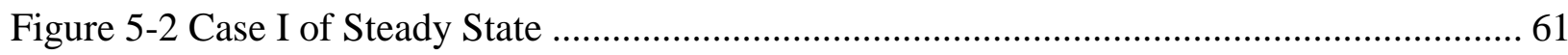

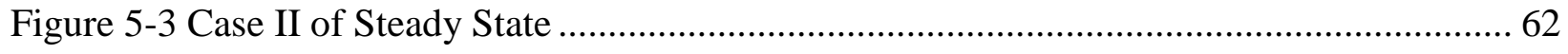

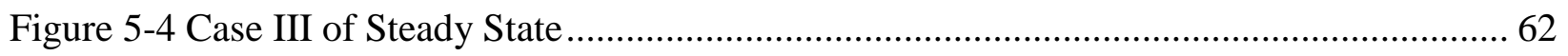

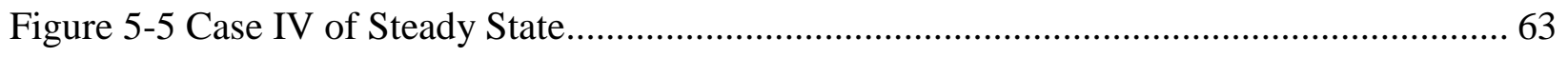

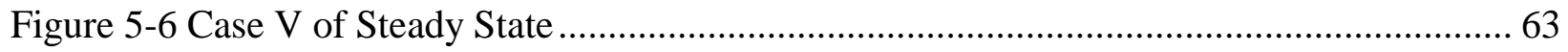

Figure 5-7 Water Profile in 5 Cases in Steady State Condition.............................................. 64

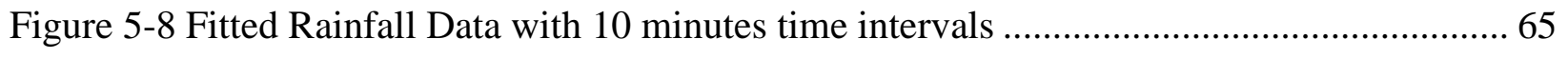

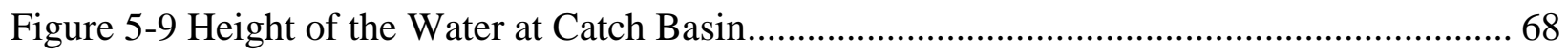


Figure 5-10 Height of Water in P1 for two Design Storms of 2 yrs and 10 yrs ....................... 69

Figure 5-11 Height of Water in P1 for two Continuous Design Storms................................... 69

Figure 5-12 Each Ring of Orifice Representation ........................................................... 70

Figure 5-13 Outflow of Each Ring of Orifices along the Pipe ............................................ 71

Figure 5-14 Outflow of Pipe for Chicago Design Storm of 2-yrs Return Period ....................... 72

Figure 5-15 Outflow of Pipe for Chicago Design Storm of 10-yrs Return Period ..................... 72

Figure 5-16 Height of Water in Bioretention Cell for two Design Storms of 2 yrs and 10 yrs .... 73

Figure 5-17 Height of Water in P2 Design Storm of 2 yrs and 10 yrs .................................. 74

Figure 5-18 Outflow of Each Ring of Orifices along the Pipe ............................................. 75

Figure 5-19 Outflow of Pipe for Chicago Design Storm of 2-yrs Return Period ....................... 76

Figure 5-20 Outflow of Pipe for Chicago Design Storm of 10-yrs Return Period ..................... 76

Figure 5-21 Outflow of Each Ring of Orifices along the Pipe .............................................. 77

Figure 5-22 Outflow of Pipe for Chicago Design Storm of 2-yrs Return Period....................... 78

Figure 5-23 Outflow of Pipe for Chicago Design Storm of 10-yrs Return Period ..................... 78

Figure 5-24 Outflow of Each Ring of Orifices along the Pipe ............................................... 79

Figure 5-25 Outflow of Pipe for Chicago Design Storm of 2-yrs Return Period ....................... 80

Figure 5-26 Outflow of Pipe for Chicago Design Storm of 10-yrs Return Period ..................... 80

Figure 5-27 Outflow of Each Ring of Orifices along the Pipe .......................................... 81

Figure 5-28 Outflow of Pipe for Chicago Design Storm of 2-yrs Return Period ....................... 82

Figure 5-29 Outflow of Pipe for Chicago Design Storm of 10-yrs Return Period ..................... 83 


\section{List of Appendices}

Appendix A Matlab Main Function.............................................................................. 102 


\section{Nomenclature}

\begin{tabular}{|c|c|c|c|}
\hline$A$ & Area & $H_{U}$ & Head in Upstream \\
\hline A_Coef 1 & Area of Orifices & $H_{d}$ & Head of Water in Pipe \\
\hline$A_{-}$Coef 2 & Parameter of Changing Area & $H_{o r f}$ & Invert Elevation of Orifice \\
\hline$C_{d}$ & Discharge Coefficient & $H_{\text {dead }}$ & Catch Basin Dead Storage \\
\hline$C N$ & Curve Number & $i$ & Intensity \\
\hline$d$ & Reduction Factor & $I_{a}$ & Initial Abstraction \\
\hline$d^{\prime}$ & Height of water in Pipe & $J$ & Objective Function \\
\hline$d \_s$ & Spacing of Ring of Orifices & $K$ & Arc Calculation Factor \\
\hline$D$ & Bioretention Dead Storage & $K_{f}$ & Conversion Factor \\
\hline$D_{p l}$ & Diameter of Distribution Pipe & $K_{s}$ & Conversion Factor \\
\hline$E$ & Grate Inlet Efficiency & $K_{n s}$ & Hydraulic Conductivity \\
\hline$f_{D}$ & Friction Factor & $L_{2}$ & Length of Bioretetion Cell \\
\hline$g$ & Gravitational Acceleration & $l$ & Length of Grate \\
\hline$h_{0}$ & Head Loss of Side Orifice & $n^{\prime}$ & Orifice Number \\
\hline$H_{1}$ & Height of Water at Catch Basin & $P 1$ & Distribution Pipe \\
\hline$H_{3}$ & Height of Water as Bioretention cell & $P 2$ & Flow Control Pipe \\
\hline$H_{4}$ & Height of Water in Flow Control Pipe & $P_{1}$ & Pressure of Upstream \\
\hline$H_{5}$ & Height of Water in Manhole & $P_{2}$ & Pressure of Downstream \\
\hline$H_{D}$ & Head in Downstream & $P_{w}$ & Wetted Perimeter \\
\hline
\end{tabular}




\begin{tabular}{|c|c|c|c|}
\hline$Q$ & Total flow of Gutter & $S$ & Storage \\
\hline$Q_{i n}$ & Inflow & $S^{\prime}$ & Factor Defining Wetted Perimeter \\
\hline$Q_{\text {out }}$ & Outflow & $S^{\prime \prime}$ & Max. Potential after Runoff Starts \\
\hline$Q_{\text {out,ring }}$ & Outflow or each Ring of Orifice & $S_{o}$ & Slope of Distribution Pipe \\
\hline$Q_{s}$ & Side Flow of Inlet & $S_{f}$ & Friction Slope \\
\hline$Q_{s i}$ & Side Flow Intercepted & $S_{x}$ & Cross Slope \\
\hline$Q_{\text {seepage }}$ & Outflow to Native Soil & $T$ & Total Spread of Water in Gutter \\
\hline$Q_{w}$ & Frontal Flow of Inlet & $t$ & Time \\
\hline$Q_{w i}$ & Frontal Flow Intercepted & $V$ & Velocity \\
\hline$Q \_h$ & Outflow of each Ring of Orifices & $V_{0}$ & Splash-over Velocity \\
\hline$Q \_h \_t i m e$ & Outflow of each Ring of Orifices in Time & $V_{D}$ & Velocity at Downstream \\
\hline$q_{\text {total }}$ & Average outflow of Distribution Pipe & $V_{U}$ & Velocity at Upstream \\
\hline$q_{\text {ring }}$ & Average outflow of One Ring of Orifice & $V_{c b d e a d}$ & Dead Storage of Catch Basin \\
\hline$R$ & Runoff & $W$ & Width of Bioretention Cell \\
\hline$R^{\prime}$ & Reduction Factor & $w$ & Width of Inlet \\
\hline $\operatorname{Re}$ & Reynolds Number & $w \_d \_m i n$ & Orifice Elevation at end of the pipe \\
\hline$R_{f}$ & Ratio & $w \_d \_$max & Orifice Elevation at the beginning of the pipe \\
\hline$R_{h}$ & Hydraulic Radius & $x$ & Location along Distribution Pipe \\
\hline$R_{s}$ & Ratio & $y_{D}$ & Elevation of water at Downstream \\
\hline$r$ & Radius of the Pipe & $y_{U}$ & Elevation of water at Upstream \\
\hline
\end{tabular}




\begin{tabular}{|c|c|c|c|}
\hline & Greek Symbols & $n$ & Time step $n$ \\
\hline$\varphi$ & Runoff Coefficient & $n+1$ & Time Step $n+1$ \\
\hline$\Delta$ & Change & orf & Orifices of Distribution Pipe \\
\hline$\theta_{n}$ & Angle of $n^{\text {th }}$ Orifice & orf 2 & Orifices of Flow Control Pipe \\
\hline$\theta_{1}$ & Angle of First Orifice & out & Outflow \\
\hline$\theta^{\prime}$ & Angle for Calculating Hydraulic Radius & $p 1$ & Distribution Pipe \\
\hline$\rho$ & Porosity & $p 2$ & Flow Control Pipe \\
\hline$\gamma$ & Unit Weight of Water & ring & Ring of Orifices \\
\hline \multicolumn{4}{|c|}{ Subscript } \\
\hline$b c$ & Bioretention & & \\
\hline catmt & Catchment & & \\
\hline$c b$ & Catch Basin & & \\
\hline$i$ & Factor Counting Orifices & & \\
\hline in & Inflow & & \\
\hline$j$ & Factor Counting Ring of Orifices & & \\
\hline$k$ & Maximum Number of Orifices & & \\
\hline$m$ & Maximum Number of Ring of Orifices & & \\
\hline$m h$ & Manhole & & \\
\hline
\end{tabular}




\section{Chapter 1: Introduction and Motivations}

\subsection{Introduction}

Development in urban areas is a concern in stormwater management and it is well known that urbanization affects the natural processes such as rainfall and runoff. By removing trees and natural lands and replacing them with buildings, roadways and other impervious areas, the risk of downstream flooding, erosion, and water pollution will increase significantly.

The problems associated with urbanization should not focus only on water quantity. Water quality is also impaired because of the build-up of pollutants during dry weather, which are related mostly to human activities. These pollutants are washed off by the runoff and are transferred to the receiving water bodies. Therefore, the major purpose of stormwater management is to capture and remove these pollutants from runoff and protect the receiving water bodies. To overcome the impacts of runoff water quality and quantity, new concepts of low impacts development are being used.

Conventional stormwater management practices depend on storing the stormwater at the downstream ends temporarily in order to control the quantity and quality of runoff [1]. Low impact development (LID) practices focus on on-site management of stormwater. LID covers a variety of stormwater management techniques such as bioretention, pervious pavers, rain gardens, etc. The necessity of implementing LID systems on-site in urban areas is growing due to the growth of development and continuous impairment of water bodies in urban areas using conventional stormwater ponds. Additionally, LID introduces redevelopment projects and builds on conventional design strategies by exploiting every surface in the infrastructures to perform a beneficial hydrologic function [2]. Three primary stormwater management objectives, which are used for LID practices, are:

- Stormwater volume control;

- Stormwater peak flow control; and

- Stormwater quality improvement, 
Most of the LID facilities discourse these three objectives at some level. Each LID has its specific requirements and considerations during the planning and design phases in order to ensure effective operation.

Bioretention system is one of the most common LID techniques. Bioretention systems absorb the stormwater runoff and infiltrate the stormwater in order to improve the quality and reduce the volume of runoff [1]. A bioretention cell removes the contaminants and sediments from stormwater runoff by filtering the water through porous media, which is normally soil, sing natural resources to control stormwater close to its source. Bioretention components include, inlet structure, distribution pipe, bioretention cell, and flow control pipe and outlet structure. These systems can be categorized differently. However, the main categories of bioretention systems are above ground and underground and this study focuses on underground bioretetion systems.

This study focuses primarily on the hydraulic flow distribution of stormwater runoff for underground bioretention systems. In underground bioretention systems, runoff enters the catch basin and feeds to an upper distribution pipe, which in turn dissipates the runoff water across the underground bioretention soil cell as uniformly as possible.

\subsection{Application of the Underground Bioretention System}

Bioretention systems can be optimized through minor design modifications to meet a wide range of climatic and environmental conditions. Typically, bioretention practices are best suited to small sites and highly urbanized places. Bioretention facilities can also be installed at commercial and institutional as well as residential places that were vegetated or pervious area before. One of the purposes of installing these facilities close to the impervious area is to reduce the amount of runoff produced from impervious zones such as parking lots, and buildings, as well as improving the water quality captured by the system. In existing development, which are having negative impacts on stormwater quality and quantity, bioretention cell would be beneficial to prevent further negative impacts $[1,3]$.

Additionally, bioretention systems are aesthetically pleasing by planting trees and vegetation on the top layer. It is also an effective way of removal of sediments, nutrients and heavy metals found in stormwater runoff. Bioretention systems also allow flexibility in design layout so it can be used 
in almost every landscaped areas and require relatively low maintenance cost compared to that of stormwater management ponds $[4,5]$.

Underground bioretention systems such as the Silva Cell system considered in this study are a relatively new concept, which has a great potential of stormwater runoff control along the rightof-way. Therefore, understanding the hydraulic characteristics and specification of underground bioretention systems are important to ensure their proper functioning and meeting of their design objectives. Most of the bioretention systems in North America and other parts of the world are typical lot-level bioretention cell. Having lack of literature and research on underground bioretention along the right-of-way, the author focuses on the analysis of water percolation and dissipating the runoff through the entire bioretention system. More research is needed at the local scale to ensure the technical conformity and performance before introducing large-scale project [6].

\subsection{Motivation and Objectives}

The main intention of this research is to develop a hydraulic design model of an underground bioretention system. Addressing the research gap on the performance of bioretention systems and improving on the detailed hydraulic design and mathematical simulation of these systems were the main motivations of this research. In the design of urban drainage infrastructure, peak flow rates are typically used using the Rational Method for sizing of pipes. Current trend of sizing LID practices focuses on a fixed depth of rainfall. However, the design of bioretention systems should also take into account the distribution of that depth over the whole system. In order to optimize the operation of a bioretention system, the captured runoff should be distributed uniformly throughout the cell.

The scope of this study focuses on the flow distribution pipe and the effect of changing each of the design variables on the distribution of runoff throughout the bioretention soil. Thus, the research approach is listed below:

- Review previous studies that dealt with the design and analysis of bioretention systems;

- Develop a hydraulic simulation model in Matlab to simulate the distribution of inflows resulting from a design storm through the distribution pipe; 
- Develop an analysis procedure to evaluate the bioretention systems with different properties (dimension and configuration of perforations); and

- Compare different flow scenarios of underground bioretention systems (i.e. steady and non-steady condition) in order to understand the effect of each design variable.

This thesis starts with a literature review of LID systems and definition of bioretention cells, their properties with its pros and cons, and previous flow distribution models developed for bioretention cell in Chapter 2. Details of the newly developed flow distribution model are provided in Chapter 3. A comprehensive analysis on the effect of each design variables on the distribution of runoff in the entire system is presented in Chapter 4. Lastly, Chapter 5 summarizes the conclusions and suggests future work. 


\section{Chapter 2: Literature Review}

\subsection{Introduction}

Precipitation from rain and snowmelt generates stormwater runoff over land, parking lots, building rooftops and other impervious surfaces in urbanized areas. These surfaces do not allow water to percolate into soil and will increase the discharge rate and volume of stormwater runoff. The flow of water collects debris, sediments and pollutants from the surface. These pollutants affect water quality of stormwater before reaching the receiving water bodies. Other pollutants that can be seen in the stormwater runoff are oil, grease, toxic chemicals, pesticides, nutrients, viruses, bacteria, road salts and heavy metals $[1,7]$. Therefore, urbanization escalates the diversity and amount of pollutants carried into water bodies, which in turn harm the wildlife populations, kill native vegetation and damage human lifestyle and usage of water. Other impacts of urbanization include reduction of groundwater levels and base flow conditions and peak flow increase. Considering the impacts mentioned above, the necessity of implementing LID techniques on developed areas is increasing.

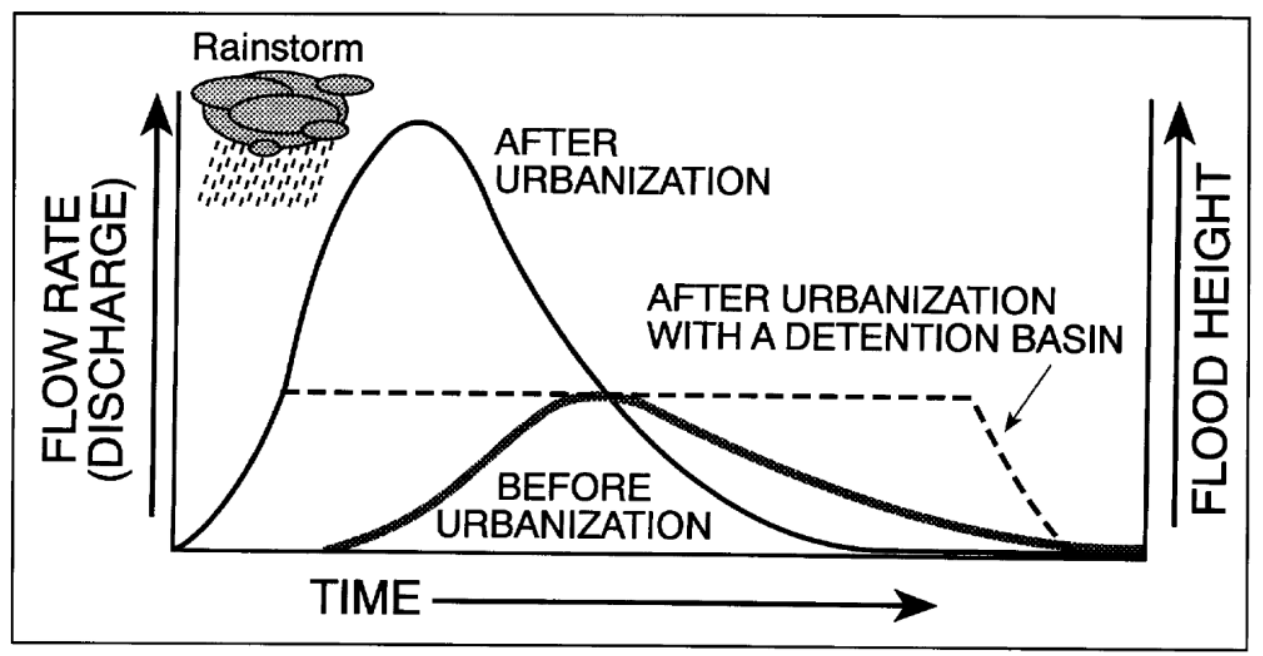

Figure 2-1 Changes to the storm hydrograph due to urbanization [8]

Best Management Practices (BMPs) control both the quality and quantity of runoff water. In general, BMPs emphasis is on water quality problems, which are caused by having more impervious areas from land development. BMPs techniques are to reduce the volume of runoff as 
well as its peak flow rate and pollution using natural processes such as evapotranspiration, detention, and filtration [2]. LID strategies allow land to be developed with minimum damage to the environment [8,9]. LID is a method that work with nature to collect stormwater as close to its source as possible. LID employs principles such as reconstructing natural landscape, decreasing effective imperviousness to create landscapes and site drainage that treat stormwater as a useful resource. Many LID practises and technologies have follows these principals such as bioretention cell, rain gardens, green roofs, etc. By implementing LID practices, storm runoff can be managed in a way that reduces the impact of human activities and pollution on natural resources such as water, soil and air. Using LID techniques in a large scale can maintain the hydrologic and ecological functionality of environment.

To overcome the impacts of existing problem of conventional development practices such as high volume peak flow and contamination of lands and amplified amount of runoff generated from rainfall, the usage of LID techniques are increasing significantly. LID design strategies address new development, retrofit and redevelopment project. For development project, topography and vegetative cover should be kept undisturbed as much as possible. LID techniques are compatible with existing buildings, roads, parking areas, site features, and stormwater management plans. Moreover, LID introduces redevelopment projects and builds on conventional design strategies by exploiting every surface in the infrastructures to perform a beneficial hydrologic function.

Bioretention is one of the acceptable urban BMPs in many countries especially in North America. "Bioretention is developed in the early 1990's by the Prince George's County, MD, and Department of Environmental Resources (PGDER)" [1,10]. Bioretention exploits soils and plants to remove impurities from runoff water. In this study, the literature review focuses on definition of bioretention systems and its soil and plants properties as well as its performance. In addition, the gap in a previously developed mathematical model of an underground bioretention system is discussed.

\subsection{Best Management Practices (BMP)}

The stormwater management has three main components to consider:

- Large volume of runoff, 
- High peak flow rate, and

- Increased concentration of pollutants in the runoff.

All these components are due to development and human activities in urbanized areas. These three components cause variations in both water quality and quantity. The water quality and quantity problems can increase the complications such as habitat modification and loss, flooding, and reduction in aquatic biological diversity. "In addition to chemical pollutants in stormwater, the physical aspects related to urban runoff, such as erosion and scour, can significantly affect a receiving water's fish population and associated habitat"[11]. The changes in characteristics of streams and rivers due to urbanization are listed below:

- Larger peak flow rates compared to undeveloped areas,

- Higher frequency and duration of bankfull flow, and

- Higher chance of flooding.

Conventional flood control as well as stormwater management count on the detention of the peak flow. By doing this the damages associated with development will be reduced. However, the US Environmental Protection Agency (EPA) endorses an approach that incorporates the control of stormwater peak flows and the protection of natural channels resulting the aquatic habitat untouched $[11,12]$. 


\subsection{Low Impact Development (LID)}

LID techniques are progressively popular method to reduce the hydrologic effects of urbanization on the watershed. The slight difference between natural scale processes and the LID techniques is that stormwater runoff will be directed to facilities which are man-made in a small scale. Several studies showed the affectedness of LID techniques and practices on hydrology and pollutant removal capabilities. Some of the most popular practices of LID in the urban areas are bioretention, grass swales, permeable pavements and vegetated rooftops. By using these practice the amount of Effective Impervious Area (EIA) will be diminished [11,13]. Based on the case studies, urbanization increased the impacts on hydrologic characteristics of the streams [14]. Also these studies provide evidences that show the negative effects of urbanization on watershed such as water quality problems as well as loss of local creatures, increases in water temperatures, sedimentation and loss of fish populations [14]. Overall, reducing the impervious surfaces can diminish the volume of runoff produces by rainfall. Numerous methods can be used to decrease the effect of losing pervious areas such as permeable pavement, permeable asphalt, green roofs, creation of more vegetation [13].

LID techniques are relatively new and not well known by public. Most of the data related to the LID practices and related literatures originate from Prince George's County, Maryland, that employed the LID first [1]. To use the LIDs more often, more long-term investigation is required to assess the accuracy and advantages of these techniques on watersheds and its properties. Some other benefits of LID techniques are as follows:

- Integrated into infrastructure,

- Aesthetically pleasing, and

- Economical. [15]

LID provides many opportunities to retrofit existing highly urbanized areas and discourse environmental matters in developed areas. LID techniques are valuable measures that can be used in so many different ways [14]. These techniques can be applied to diverse lot dimensions. As it was said in the US EPA's webpage, "the use of LID, however, may necessitate the use of structural BMPs in conjunction with LID techniques in order to achieve watershed objectives" $[9,14,16]$. The appropriateness of the practices at a site is dependent on conditions and limitations of the site. 
The runoff volume and rate are key parameters for design of hydrologic control systems and LID facilities. The smaller and more frequent storms characterise the majority of rainfall events in terms

of both the number of rain events and the total runoff volume. The LID approach controls runoff peaks and addresses stormwater runoff volume [15]. The conventional approach of stormwater management hardly provides the consideration of total runoff volume. By using the LID best management approaches, the volume of runoff generated from these storms will be captured and the transmission of pollutant will be reduced. The captured volume is effectively represented by rainfall depth since it is not possible to specify a finite runoff volume.

\subsection{Definition of Bioretention}

Bioretention is a popular water quality and quantity control practice and will be considered as one of the most popular LID practices. Bioretention cells can be divided into different types such as underground, on-lot rain garden etc. Characteristically, these systems contain four layers that water percolates:

- Plantings and aged mulch

- Topsoil

- Gravel drainage layer

- Underdrain

These layers can be changed depending on the location and type of bioretention. For underground bioretention system, these parts can be divided as follows:

- Inlet structure (e.g. catch basin)

- Distribution pipe

- Bioretention soil cell

- Flow control pipe (underdrain pipe)

- $\quad$ Outlet structure (e.g. manhole)

The processes used in a bioretention are related to the properties of plants and vegetation, microbes as well as the soil. Bioretention utilizes soils and plants to remove the pollutant from runoff in urban areas [5,13]. 
Some of the processes applied to stormwater runoff are adsorption, infiltration, sedimentation etc. Similar processes are used in different fields such as agricultural and wastewater treatment plants and alteration of nutrient and pollutants. In order to se bioretention in development areas, designers need to consider design parameters such as site conditions and constraints, land type, plants types, soil type and soil moisture condition.

Comparing to other LID practices, bioretention can be designed in a way to imitate the same conditions as the pre-development hydrologic conditions. Using bioretention system will provide landscape diversity and create a host of more habitat and increases real estate values. Bioretention facilities capture rainwater, infiltrate the water through the soil media, and treat the water so that the amount of the water reaching the end of pipe treatment facilities will be reduced significantly.

The suggested filter bed depth for an appropriate bioretention system is between 1 and $1.25 \mathrm{~m}$ with sandy or sandy loam soil as the majority of the soil media. The infiltration rate of the bioretention which is related to the soil media should be between $50-300 \mathrm{~mm} / \mathrm{hr}$ to filter runoff and sustain vegetation [2,17-19].Figure 2-2 shows a conceptual traditional bioretention facility implemented in a developed area to reduce the storm runoff.
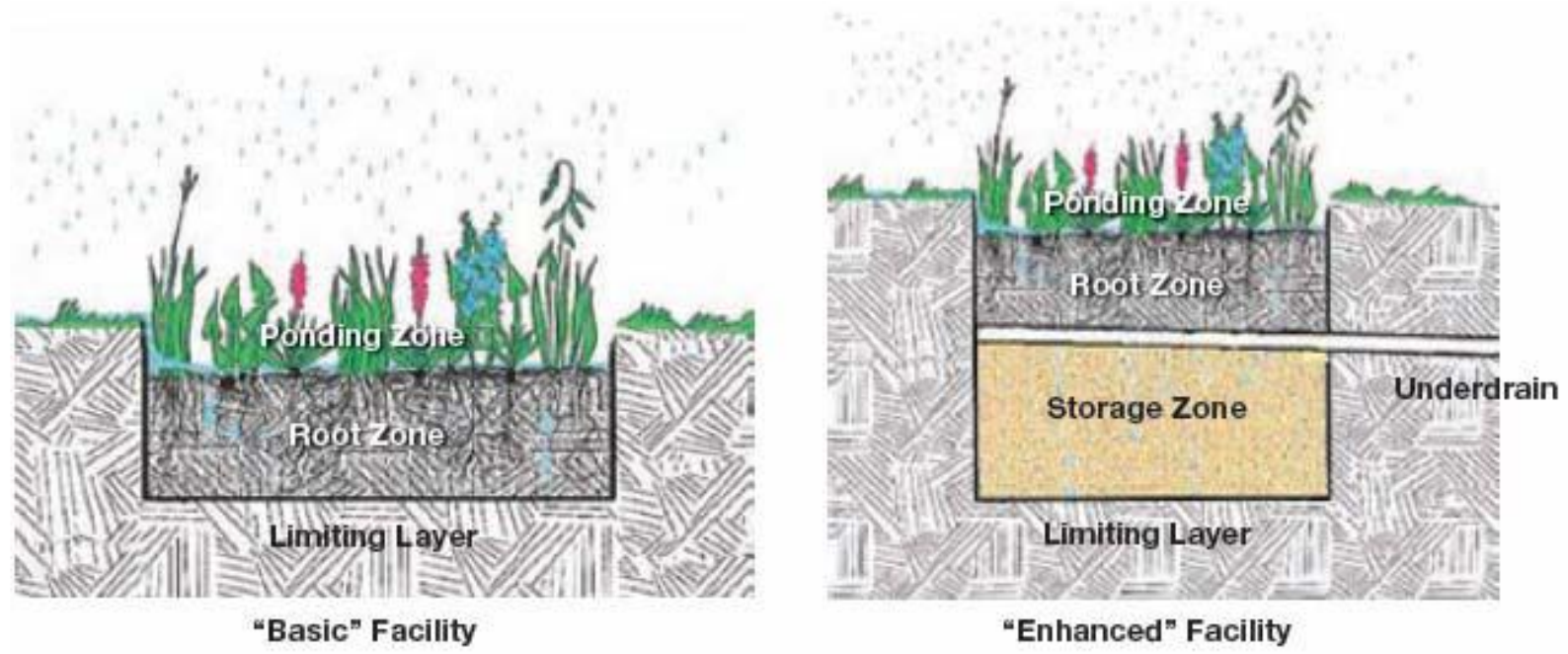

Figure 2-2 Bioretention facility conceptual cross-sectional layout [20]

A very important fact about bioretention practices is that unlike the traditional and conventional best management practices, which collect the runoff to the end of pipe treatment facilities, the 
runoff is treated on-site. Using bioretention facilities in urban areas will result in controllable watersheds in terms of water quality and quantity [11].

Some of the processes that take place in a bioretention are as follows:

- Interception: absorption and collection of runoff water by plants and soil

- Infiltration: the movement of runoff water downward through the soil and into the surrounding soils. This process can be done with or without underdrain system dependent on the site properties.

- Settling: the particles and pollutants settle on the surface of bioretention after the water has absorbed and percolated through the porous media.

- Evaporation: bioretention facilities have a shallow ponding area, a very small portion of the water will be evaporated by sunlight and the heat created in a developed area because of the cars and pollutions [14].

- Filtration: the pollutants and large particles are filtered as water moves to the layers of a bioretention facility.

- Absorption: the gap among soil particles and even the pores on the surface of the stones will absorb a very small portion of the water. Root hairs and their associated fungi implemented in a bioretention will absorb some portion of the water too.

- Evapotranspiration: the water absorbed by plants will exits through their leaves. This process happens daily.

- Nitrification/de-nitrification: This process is the conversion of ammonium ion to nitrogen gas. When the oxygen concentration is low in the soil, microorganism processes will use the nitrate and transform to volatile forms, which is a gas shape, which will be return to the air. One way of minimizing de-nitrification is the usage of an anaerobic zone in the bioretention facilities. [14]

- Degradation: This process is the resolving of chemical compounds in the porous media [8]

- Decomposition: This process is the breaking down of organic matters in the soil. This will be done by the fauna and fungi existed in the soil media [14] 
The mentioned processes will happen in different degree in bioretention facilities. These processes may vary depending on environmental conditions. By explaining the different processes that occur in a bioretention, it is obvious that this facility contains complex process.

According to Bioretention Manual [14,21], the removal rates of metals range from $70-97 \%$, for lead, 43-97\%, for copper and 64-98\% for zinc. Nutrient removal rates range from 0-87\% for phosphorus, 37-80\% for Total Kjeldahl Nitrogen, 0-92\% for ammonium and 0-26\% for nitrate. However, these rates can be different depending on the site characteristics and sections. A typical bioretention system contains the following parts:

- Grass buffer strips, which reduce the velocity of runoff.

- A sand bed, which provides proper drainage and aeration phase.

- A ponding area to store the runoff and provide the proper settling down of the particles.

- An organic layer, which helps to decompose the organic materials, provide a media zone for filtering the runoff too, and prevent soil erosion.

- Planting soil to help the plant to grow and provide the necessary nutrient for them

- Vegetation which absorb water and improve the aesthetic of the designated area

The name "bioretention" came from the idea of retaining nutrient by the biomass. Bioretention counts on the natural and regular cleansing processes that happen in the soil media. Appropriate design of bioretention allows natural processes and cycles to take place.

In addition to environmental benefits, there are economic advantages to use bioretention system in urban areas. Bioretention adjusts a developed site significantly to make it as close as possible to the original characteristics of that site. By capturing runoff in bioretention areas close to the source (on-site), the amount of the runoff can be reduced effectively. Therefore, the entire process of capturing and treating the runoff would be economical.

Main economic benefits of bioretention are as follows [22]:

- Significantly reduced stormwater management design costs and complications as well as installation costs by using a natural method to treat the stormwater runoff;

- Having less risk factor during construction, maintenance, and operations;

- Credit for subdivision landscaping; 
- Eliminated large-scale stormwater management treatment areas; and

- Homeowners would be the ones who maintain the stormwater management facilities.

However, the cost of the bioretention system depends on the design and complexity of the system implemented in each individual site. The structure of each bioretention area will be different depending upon the individual site characteristics and limitations. These limitations would be native soils, vegetation, location of bioretention facility, traffic and aesthetics aspects of the facility [11]. The application of bioretention systems can be divided into different land use groups as described in the following sections:

\subsubsection{Commercial/Industrial}

In the case of using bioretention system in commercial or industrial areas, because of having limited zoned, green areas around, complications may appear. However, considering the site conditions and characteristics, a bioretention system can help to obtain multiple credits for landscaping and creating green areas in commercial and industrial zones resulting in a positive impact. This type of bioretention can be divided into smaller groups such as Curbless Parking Lot, Curb parking Lot, Parking Lot Island and Median and Swale-side [14]

\subsubsection{Curbless Parking Lot Bioretention}

This type of the bioretention cells are next to the parking areas with no curbs. Because of not having the curbs, this kind has the lowest cost for the construction, operation and maintenance. As stated in Bioretention Manual [14] "this type of bioretention system should be used only where shallow grades allow for sheet flow condition over level entrance area”.

\subsubsection{2.2.1 Curbed Parking Lot Bioretention}

This type of bioretention is suitable for parking lots in urban areas. The water will be diverted to the bioretention system form the impervious section (parking lots) through the curb-cut entrance using an inlet deflector block. 


\subsubsection{Parking Lot Island and Median Bioretention}

For this type of the bioretention system, the size of the islands has its own specifications, which should obey to standard traffic island detail. These details are specified in the Prince George's County Landscape Manual [11].

In order to minimize the possibility of having runoff seepage to the native soil and pavement layers and frost heave action during cold seasons, a buffer and geotextile filter should be used. This type of bioretention can be used in areas with an underdrain system and high-porosity soil. This type also can exhibit very high hydraulic capacity.

\subsubsection{Swale-side Bioretention}

Another type of the bioretention is swale-side bioretention. Bioretention swales function by filtering stormwater runoff through the surface vegetation. The filtered water will percolate into filter media. Some biological uptake happens by the vegetation of the swale. In order to reach the main goal of the bioretention system in this type, the bioretention area should be graded in a way that the discharge and overflow moves toward the swales [20].

\subsubsection{Residential On-Lot}

The main concerns of bioretention systems in residential areas would be aesthetic and visibility. The soil drainage, the rate of the system to drain the runoff, aesthetic and other factors affect the residents of that area. Bioretention systems should be designed by considering native vegetation and wildlife of that area in order to balance the nature [8]. By considering the local building codes, bioretention can be used on any size residential lot.

\subsubsection{Landscaped Garden}

The simplest and most economical design of bioretention is a landscaped garden. This type employs communal flower gardens and planting trees [14]. To place the vegetation and do the landscaping, the elevation of bioretention should be lowered to intercept water. 


\subsection{Bioretention Soil and its Functions}

Bioretention areas are the combination of soil and plants devices which remove pollutants through numerous treatment processes [23]. Physically, bioretention facilities contain approximately $1 \mathrm{~m}$ of a porous media composed of soil/organic matters. This media layer is covered by a thin layer of standard hardwood mulch. Soil layer contains three phases of liquid, gas and solid particles. Each individual phase helps the process of treating the stormwater runoff. In order to have the reduction in the concentration of pollutant in the stormwater, the soil as one of the main parts of filtering process should be selected properly based on site constraints[24,25].

The top layer of the soil, which is mulch layer, has the greatest heading role in removing approximately all of the metal within the top few inches of the bioretention system. Heavy metals is collected by organic matter in this layer. Phosphorus removal rate increases linearly with depth of the soil layer and reaches a maximum of about $1 \mathrm{~m}$ depth [1].

The mechanism for the removal of the phosphorus is related to its attraction into aluminum, iron in the soil. TKN (nitrogen) removal also appears to be dependent on the soil depth [11]. Nitrate removal is variable among different types of bioretention systems. In addition, because of reduction in the velocity of the runoff in bioretention systems, solid particles will not be in suspension phase. In this situation, the chance of having sedimentation will be increased [26].

Based on the field studies done at the University of Virginia [17], the following removal rates of a bioretention system soil are [27]:

- $\quad$ Total Suspended Solids (TSS) removal=86\%

- $\quad$ Chemical Oxygen Demand (COD) $=97 \%$

- $\quad$ Oil and Grease removal $=67 \%$

Based on the above studies, a shallow bioretention with a thick mulch layer would be beneficial for treatment of runoff with high concentration of heavy metals. For residential areas in which the majority of the pollutants are nitrogen and phosphorous, the depth of the bioretention is the major parameter $[8,26]$. 


\subsubsection{Soil Restriction}

In order to have an effective LID for treating stormwater in an area, the soil that will be used should have a proper mix [8]. The purpose of the bioretention system is to distribute the water in the entire system and hold the water in a way that the large particles and pollutants stock with the soil particles. The result should be a much cleaner stormwater, which reduces the cost of treating the water at the end-of-pipe system. The type of bioretention soil should have the following characteristics:

- Offer a sufficient infiltration rate to facilitate surface water dewatering [14]

- Provide infiltration rates that increase the ability of pollutant removal in the soil [14]

- Deliver a media zone that supports plants and vegetation [14]

Based on the information provided in the Bioretention Manual [14], the gradation and soil type should be in a way to let the intercepted water leave the system in 48 hours and have an infiltration rate of $12 \mathrm{~mm} / \mathrm{hr}$. The soil recommended by the Bioretention Manual [14] is USDA soil textural classifications shown in Table 1.

Table 1 Soil textural classification [14]

\begin{tabular}{|c|c|c|}
\hline Texture Class & $\begin{array}{c}\text { Minimum Infiltration Rate } \\
(\mathrm{mm} / \mathrm{hr} .)\end{array}$ & Hydrologic Soil Group \\
\hline Sand & 210 & A \\
\hline Loamy Sand & 61.2 & A \\
\hline Sandy Loam & 25.90 & B \\
\hline Loam & 13.20 & A \\
\hline
\end{tabular}

Based on the studies done by Hinman et al. [25] which was focused on the bioretention soil mix guidelines, the hydraulic conductivity of bioretention soil is associated with the percent mineral aggregate passing the 200 sieve. In addition, the percentage of the fine aggregate should be less than five percent [28].

According to this research done by Hinman et al.[25], compaction, percent fines and how well the material is graded will influence the hydraulic conductivity of the bioretention soil mix. Based on 
the Bioretention Manual [14] "One value of relative compaction (85 percent of maximum dry density) was selected as representative of typical field conditions in bioretention areas that do not have regular foot traffic". By increasing, the percent of fine particles in the mixtures, the hydraulic conductivity of the soil will be reduced (Figure 2.3). The fine particles fill the pores and void in the soil resulting in a poor percolation of water through the mixture.

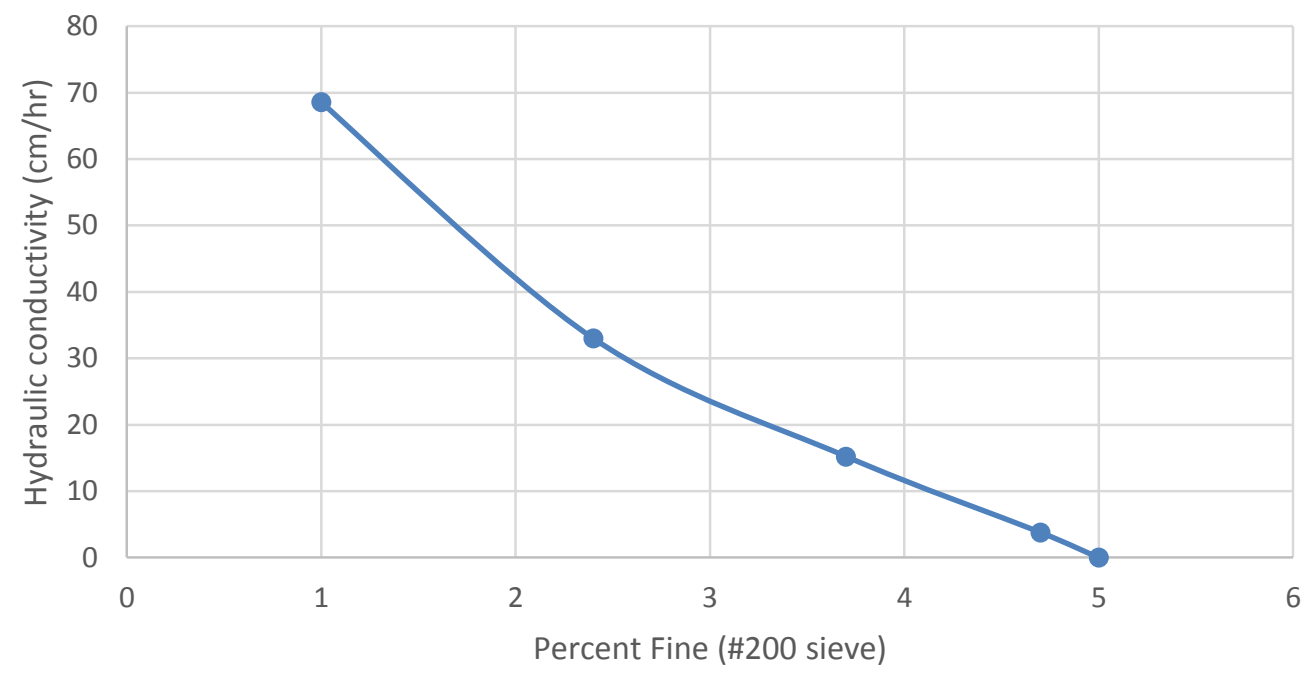

Figure 2-3 Percent fines and hydraulic conductivity relationship[2]

The importance of bioretention soil and the degradation are the least understood concepts of the designing bioretention for LID concepts [3,25,29].

The primary classification of soil material is based on the properties of soil. Three soil classifications such as loamy sand, sandy loam and loam are also differentiate the soil types. According to the Bioretention Manual [14], it is achievable to find a soil type, which has an infiltration rate of $13.2 \mathrm{~mm} /$ hour, which meet the required infiltration rate for bioretention systems. Although the hydraulic conductivity of sandy soil is $210 \mathrm{~mm} /$ hour, there is a concern related to dry soil and plant survival. The soil mixture recommended by Clar et. al. [3] is a mixture of $60 \%$ sand, $20 \%$ aged organic materials and $20 \%$ other materials such as aggregates.

The gravel bed at the bottom of the bioretention system protects the underdrain pipe and reduces the clogging. The characteristics of the gravel bed based on the specification mentioned in the Bioretention Manual [14,27] are: 
- Gavel size should not be greater than $12 \mathrm{~mm}$ to $40 \mathrm{~mm}$ diameter;

- The depth of this layer should not exceed $300 \mathrm{~mm}$; and

- Washed and river-run gravels are suggested.

Another important design concept of bioretention soil is the carbon content of the mixture. The performance of bioretention will be maximized if the soil has high carbon content and low fertility. According to the Bioretention Manual [14], a bioretention system should contain 50\% sand, 30\% topsoil and 20\% organic material [29]. Bratieres et al. [31] discovered that more organic matters to the mixture will enhance the phosphorus removal.

The mulch layer should be periodically replaced to increase the water quality performance of the bioretention system [10]. This layer pre-treats the intercepted runoff by removing TSS, preventing clogging of the porous media (soil), maintaining soil moisture and providing nutrients for vegetation [10]. Adding gravels to the mixture of the bioretention soil will increase the water storage and simplify the groundwater recharge.

\subsection{Plant Materials}

One of the factors affecting the performance of a bioretention system is the vegetation and plants used in the facility. In a bioretention system, soil and plants are cooperating to manage the amount of the runoff intercepted by the system and the quality of the filtered stormwater at the bottom of the system. This role is still unclear in so many aspects. The parameters that should be considered are the type and density of the plant and vegetation [14,32].

By having dense vegetation, the amount of the stormwater runoff intercepted will be decreased, the infiltration rate will be reduced, and most of the water will be absorbed by the roots. Based on the protocols mentioned in the Bioretention Manual [14], the suggested plant spacing should ensure that the $50 \%$ of the surface of the bioretention is unoccupied so that rainfall can be captured easily. However, the amount of unoccupied surface for bioretention system can be changed by knowing that the plants grow old and get mature. For solving the problem of having less unoccupied surface for bioretention systems, designers should know the size of the mature plants and consider the safety factor during the design process. 
Based on the research done by Lucas and Greenway [33], there are natural processes that are operative in restoring and enhancing infiltration rate of the soil. The existence of surface vegetation can result in infiltration rates more than that of the underlying soil properties.

It is also recommended to use the native plants and vegetation in the bioretention system which are compatible with the native weather condition and wildlife [28]. The crucial restrictions to study for selecting plants are the frequency of inundation, the drainage of the soils, aesthetics, and the expected shades from the sun. The suitable plants suggested by Prince George's County [1] are as follows:

- Blackhawk

- Winterberry

- Bitternut Hickory

- Button Bush

- Red Maple

- Northern Red Oak

- Green Ash
- Scarlet Oak

- Pawpaw

- Frosted Hawthorn

- American Elder

- Black Tupelo

- Eastern Red Cedar

- Shining Sumac

Most of these plants can be used in Toronto Area according to their suitable environmental conditions. These conditions can be pollutant loadings, soil texture and its $\mathrm{pH}$, variable rainfall events and soil moisture, etc. Vegetation improves heavy metal removal, nutrient removal, and infiltration to the porous media. Plant roots can absorb nutrients throughout the cold season [32]. Muthanna et al. [32] found that the usage of heavy metals by plants was between 2 to $7 \%$ of the total amount existed in the system.

Federal certified nurseries provide the details of the plants that should be used in a specified area for the bioretention systems [18]. In order to confirm diversity and balance the different species' infiltration rate, a minimum of three types of trees and shrubs should be designated for the bioretention system and these species should meet the requirement of LID bioretention system [11]. It is also suggested in the Bioretention Manual [14] that the plants, which need more maintenance, are not a good candidate for bioretention systems. 


\subsection{Performance}

Infiltration and evapotranspiration at bioretention systems help to reduce the amount of runoff. The infiltration and evapotranspiration processes will reduce the amount of runoff running on the surface by 50-90\% depending on different parameters [19]. DeBusk et al. [34] compared two different watersheds, one with and the other without bioretention systems. Comparison of these two watersheds concluded that the bioretention systems would be more environmentally friendly approach than the conventional stormwater practices for developed areas.

One of the benefits of using bioretention systems is that they reduce the peak flow rate. In the areas such as Greater Toronto Area (GTA) with hydrologic soil group A and B, the infiltration rates are more than other areas with different soil type. Area with a soil type of high infiltration rate would be beneficial to treat more runoff for each rainfall event [8]. Other factors and parameters such as rainfall event patterns, and amount would affect the water quantity performance of the bioretention system. Customization of a bioretention system will improve its water quality performance. These customizations include anaerobic zone, using different type of soil etc.

Usage of soil with less phosphorous index would increase the rate of phosphorous removal [10]. Based on the studies done in the laboratory, bioretention systems are effective with phosphorous removal of $60 \%$. Nitrogen removal is still varying for different sites and different conditions. Field studies on bioretention systems showed that the maximum nitrogen removal rate of $40 \%[8,10,25]$. The removal of suspended solids in the runoff intercepted by bioretention is associated with sedimentation and filtration in the porous media $[9,10,19]$. The percentage of removal of suspended solids is about $70 \%$.

Most of the bacteria in runoff will remain in the bioretention system because the water will drain and the cell will be dry. Exposing the system to the sun will kill most of the bacteria. In order to increase the usage of bioretention systems in developed areas, the long-term performance of the bioretention systems should be analysed in great cities [35].

Peltier et al. [36] conducted a three-year study of bioretention performance and proposed "improvements to the mulch material and vegetative establishment could potentially increase system performance". Based on this study, the performance of the system is as follows: 
- Removal of total suspended solids was close to 99\% [23]

- Removal of phosphorus was increasing in the range of 47\%-68\% [23]

- Ammonium Removal of first test starts at 2.3\% and reached 23\% at the last test [23]

Davis et al. [37] found that the rate of the infiltration did not decrease. As a result, a bioretention system is an economically and effective LID practice[38]. Based on the LID guide implement by City of Edmonton in 2011 [15], the overall observed removal efficiency (percentage) in LID facilities in USA and Canada is as follows:

- Annual Runoff Reduction: 50-90\%

- Total Suspended Solids reduction: 59-90\%

- Metals Removal: 80-90\%

- Total Phosphorus Removal: 5-65\%

- Total Nitrogen Removal: 45-50\%

The performance and effectiveness of bioretention systems can change due to the site-specific characteristics. The enhancement of these systems depends deeply on the design objective of the actual site and may varies from one site to another.

\subsection{Bioretention Cell Constraints}

LID practices contains constraints that depend on each type of the practice. The usage of LID practices and their importance has been increased by having more urbanization in cold climate region. However, cold winters may generate many problems for the LID practices such as increased flow (flooding), pollutant loadings and frost heave for the soil media. Muthanna et al. [32] conducted studies in Norway on bioretention systems and showed that the peak flow rate increased during winter time [38]. Snow melting in urban areas will increase the pollutant contents of the stormwater runoff. In order to eliminate the winter related problems, extending the filter bed should be extended and underdrain pipe below the frost should be used [35].

Selection of the vegetation that can be used in cold climate regions would be limited compared to regions with four seasons. By creating a deep ponding area, a bioretention system retains the trapped water over multiple days. This would create mosquito issues such as West Nile virus, 
which can cause aesthetical and health problems for the resident and the environment. Another important factor affecting the performance of the bioretention system is the native soil of the area. The infiltration rate and hydraulic conductivity of the soil are the important parameters in this case. High infiltration rate and high hydraulic conductivity of soil are helping to achieve water balance goal $[3,35]$.

A key factor of a bioretention system is the drainage area. Studies showed that the performance of bioretention systems is better with smaller drainage area compared to very large one. Based on the information provided in Bioretention Manual [14], the best drainage area for high performance bioretention systems is between $100 \mathrm{~m}^{2}$ to 0.5 hectares.

Some studies have shown that the performance of bioretention systems is bad and below expectation. Human errors (e.g. the compaction in the soil media, the huge wastes that clog the porous media or even the percentage of fine aggregates in the media) as well as the natural action in the ecosystem may be the primary cause of poor performance [40,41]. In summary, the disadvantages of bioretention systems can be listed as follows:

- Unable to treat large drainage areas compare to stormwater ponds

- The susceptibility to clogging by sediments is high

- Occupying a large space (5\% to $20 \%$ of the catchment area)

- Depending on the location and development type, construction costs can be relatively high

\subsection{Modeling of Bioretention Hydrology}

Many studies have evaluated the hydrologic effect of bioretention system on developed areas. James and Dymond [41] focused on a watershed located in Virginia, which used two modeled scenarios. This study stated that bioretention had the ability to improve the Virginia watershed hydrologic features. In this study, it was necessary to develop a single catchment model with no substructure for the entire watershed [41]. However, the single catchment model results can be quite different from a multi-catchment model. In order to calculate the runoff, the curve number of the model was assumed that of forested land cover. Forested land cover cannot be ideal for semi-developed areas and this would affect the results obtained from this model significantly. One 
of the outcomes of this study is that the bioretention systems can have an effect on watershed hydrology such as configuration of watershed and the amount of peak flows [41].

Akan [40] adopted a hydrologic storage equation to represent the variation of depth of the water in the ponding area of a bioretention system. The governing equation used to model the water movement in the soil cell of a bioretention system is the Green and Ampt equation. The advantage of this formulation is that the dimensionless parameters result in dimensionless final outputs that are scalable [40].

Dussailant et al. [42] reported that the Green and Ampt and Richards equations could simulate hydrologic performance of different rain gardens. In this study, the vertical movement of water was considered and lateral infiltration of water was neglected. In another study done by Z. He and A. Davis [43], a two dimensional flow model was used to simulate the runoff flow in the bioretention facilities [43]. This study also used the Richard's equation to simulate the twodimensional water flow in the bioretention system. This model compared to the one-dimensional model implemented by Heasom et al. [44] is more inclusive of the complexities of the site's characteristics.

One of the major aspects of studies done before related to bioretention systems is the mass balance concept. This tracks the amount of water entering and leaving the system. Knowledge about the water inflow and outflow can provide water storage at each individual part of the bioretention system, which is useful in modeling the distribution of water flow during the design process. This study is considering mass balance at each part of the system and provide more detail in formulation of mathematical model. 


\subsection{Underground Bioretention System}

Toronto Water has started a project to evaluate the performance of underground bioretention system installed in the Silva Cell [6]. Silva Cell Inc. is a technology provider that their products are related to tree care and stormwater management tools. Silva cells are flexible and sectional pavement system that uses soil to support large tree growth. These cells deliver dominant on-site stormwater management by absorption, evapotranspiration, and interception. Ryerson University and Deep Root Canada Corp started this performance evaluation project and Toronto Water installed an underground bioretention system underneath the sidewalk located on the north side of Queensway Avenue, a commercial area between Moynes and Berl Avenue as illustrated in Figures 2-4 and 2-5 [6].

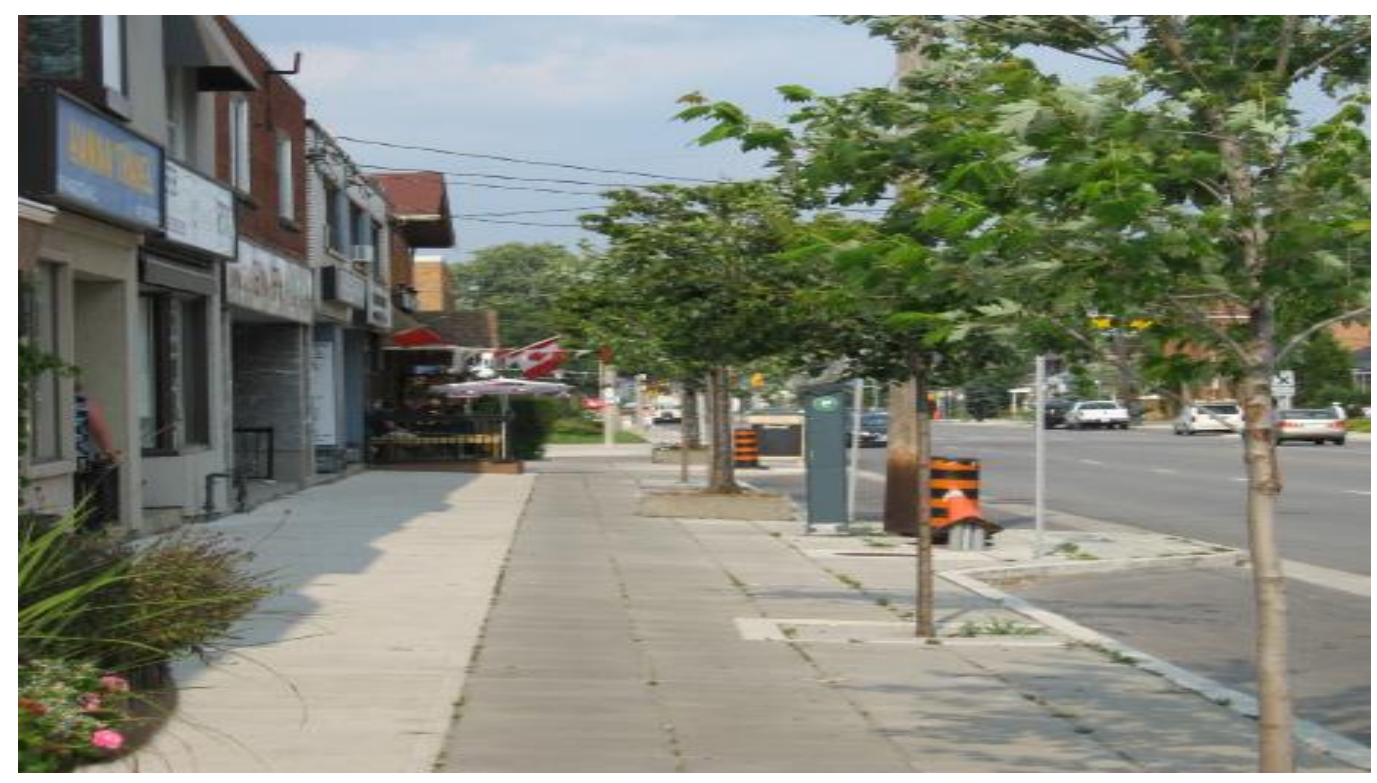

Figure 2-4 Sustainable sidewalk with underground bioretention [6] 


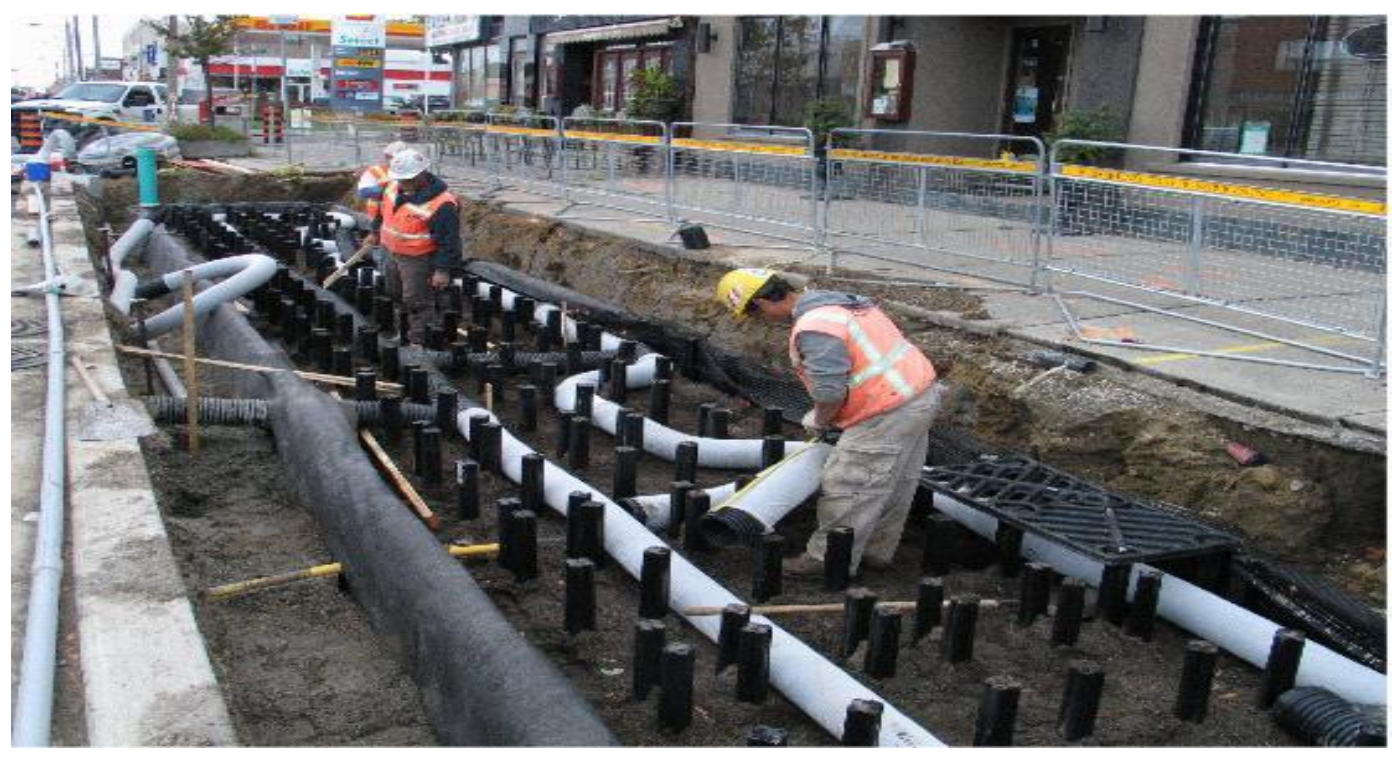

Figure 2-5 Installation of underground Bioretention System [2]

Two trenches for the two underground systems were excavated. The spots for trees were also marked during construction. The size of the bioretention systems excavated is $18.08 \mathrm{~m} \times 3.2 \mathrm{~m}$ with a depth $1.20 \mathrm{~m}$. The bottom of the trench was constructed by pouring concrete with a thickness of $15 \mathrm{~cm}$. The catchment area for both bioretention systems is about $385 \mathrm{~m}^{2}$. A catch basin will capture the runoff and distribute the captured water through the bioretention cell by a distribution pipe. Figure 2-6 shows the details of the installed practices underneath a sidewalk.

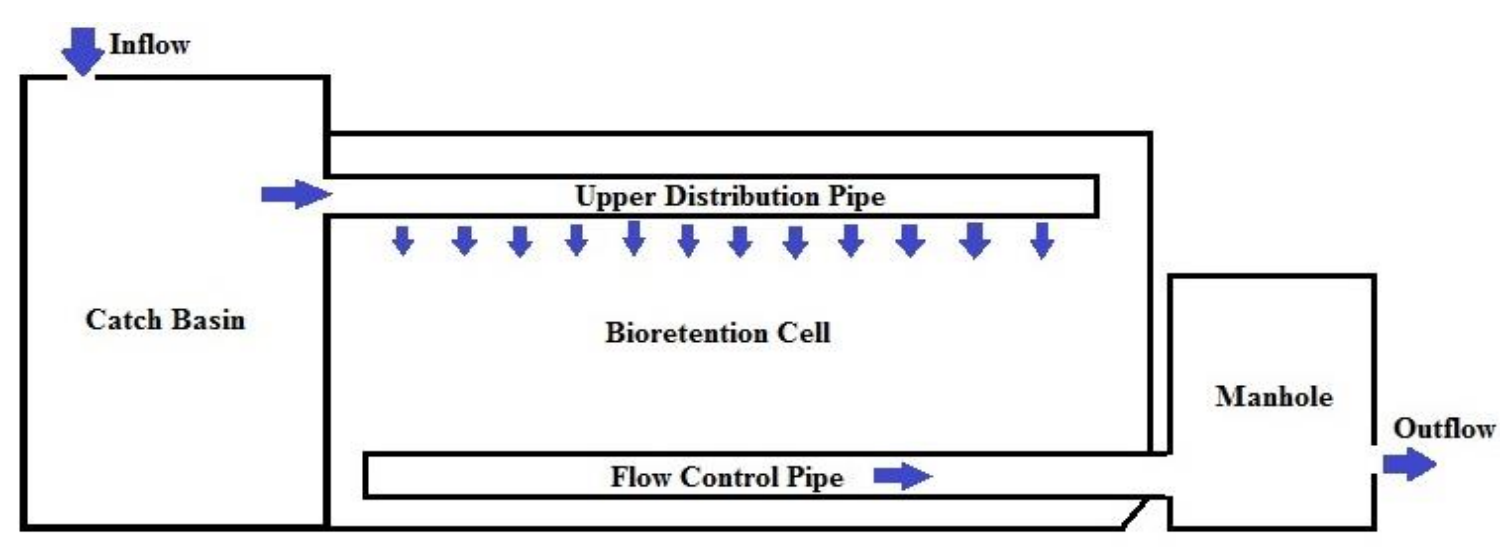

Figure 2-6 Sample of Underground Bioretention System 
A new concept of placing bioretention under the sidewalk is providing a suitable way to add sustainability design to existed development. Underground bioretention cells are still not really well known concept in literature. The processes that will happen in the underground bioretention cells are filtration, infiltration, evaporation etc. These processes reduce the volume of stormwater runoff and percolation of water through the soil [35]. The site located at downtown Toronto at Queensway Ave. was used as a case study for evaluating the simulation results of this study.

\subsection{Summary}

This chapter elaborated the urbanization's problems, LID practices and its necessity, BMP, definition of bioretention system, different types of bioretetion system and different mathematical model developed. Moreover, bioretention vegetation, soil media and its restrictions and performance were explained in detail. The next chapter is focused on the development of hydraulic design model for underground bioretention systems. 


\section{Chapter 3: Mathematic Modeling of the Underground \\ Bioretention System}

\subsection{Introduction}

In this chapter, the mathematic description of the hydraulic design of the underground bioretention system is presented. Formulation of the model is based on conservation of mass in the entire bioretention cell. Thus, mass balance is considered for each one of subsystems: 1) Catch basin, 2) Distribution pipe, 3) Bioretention cell, 4) Flow control pipe, 5) Manhole. Each individual subsystem has storage as well as some inlets (one or more depending on the various subsystem) and some outlets (one or more depends on the different subsystem). Accordingly, the change of water storage in each part of the system is considered.

\subsection{Mathematical Formulation of Underground Bioretention Cell}

To develop a hydraulic design model of an underground bioretention system the following inputs and system parameters must be known:

- Rainfall data modelled by Chicago design storms using the parameters specified for City of Toronto

- Catchment area, which is the area of land where water from rain and melting snow or ice joins to one point at a lower elevation.

- Bioretention characteristics and its decision variables, which will be:

$>$ catch basin dimensions,

$>$ size and length of distribution pipe

$>$ size, orientation and number of perforations along the distribution pipe

$>$ size of the bioretention cell (length, width and depth of the cell)

$>$ size of flow control pipe and implemented orifices to collect the treated water

$>$ size of the manhole to collect the treated water from flow control pipe 
The runoff will flow on roadways and only portion of that will be collected by the catch basin. The water inside the catch basin will rise up and after reaching specific height will flow to the upper distribution pipe. Water inside the distribution pipe will percolate to the soil cell. During this process, water will be treated. Water will be collected by flow control pipe at the bottom of the soil and will be diverted to the manhole and sewer system of the city.

Water will be seeped out from the soil cell to the native surrounding soil. In order to minimize the chance of contaminating the ground water, the bottom of the bioretention cell will be covered by a concrete layer. Thus, the water can only seep out from the side of the cell, which will be considered in modeling the water flow in the system.

As declared, the focus of this chapter is to develop a mathematical model using mass balance equations at different system components and hydraulic equations relating the various components of the system. The mass balance concept is applied for analyzing the flow condition of this bioretention system. The general conservation of mass balance is shown in Eq. 3-1 [17]:

$$
\Delta S=\left(\Delta Q_{\text {in }}-\Delta Q_{\text {out }}\right) \Delta t
$$

In order to develop an underground bioretention hydrologic model, the mass balance is used and the input and outputs of each parts of the system are based on hydraulic formulas.

\subsubsection{Rainfall Intensity}

Knowing the accurate amount of rainfall intensity would be beneficial to the calculation of runoff input to the underground bioretention cell. By installing rain gauges in the surrounding areas, the required data to estimate the inflow to the bioretention system can be obtained. In order to design the sewer infrastructures, the local Intensity Duration Frequency (IDF) curves are developed using historical rainfall data obtained from rain gauges. Figure 3-1 illustrates the IDF curve for the City of Toronto based on the data up to 2010. A Chicago design storm is used to model the rainfall of the case study in Section 2.10. The average intensity for Chicago design storm hyetograph can be generated by the following equation: 


$$
i=\frac{A}{\left(t_{C}+B\right)^{C}}
$$

where $A=$ drainage area $(h a), i=$ intensity of rainfall $(\mathrm{mm} / \mathrm{hr}), t_{c}=$ time of concentration $(\min )$ for the cumulative drainage area to the point of interest, $\mathrm{A}, \mathrm{B}$ and $\mathrm{C}=$ parameters function of the location and the frequency which is different for each location.

By knowing the parameters A, B, C and the area of catchment as well as time interval and the duration of the storm, the hyetograph can be generated for Chicago design storm of a specific location. As stated in the objective of the study, the design of a bioretention will be evaluated using the maximum runoff entering the system.

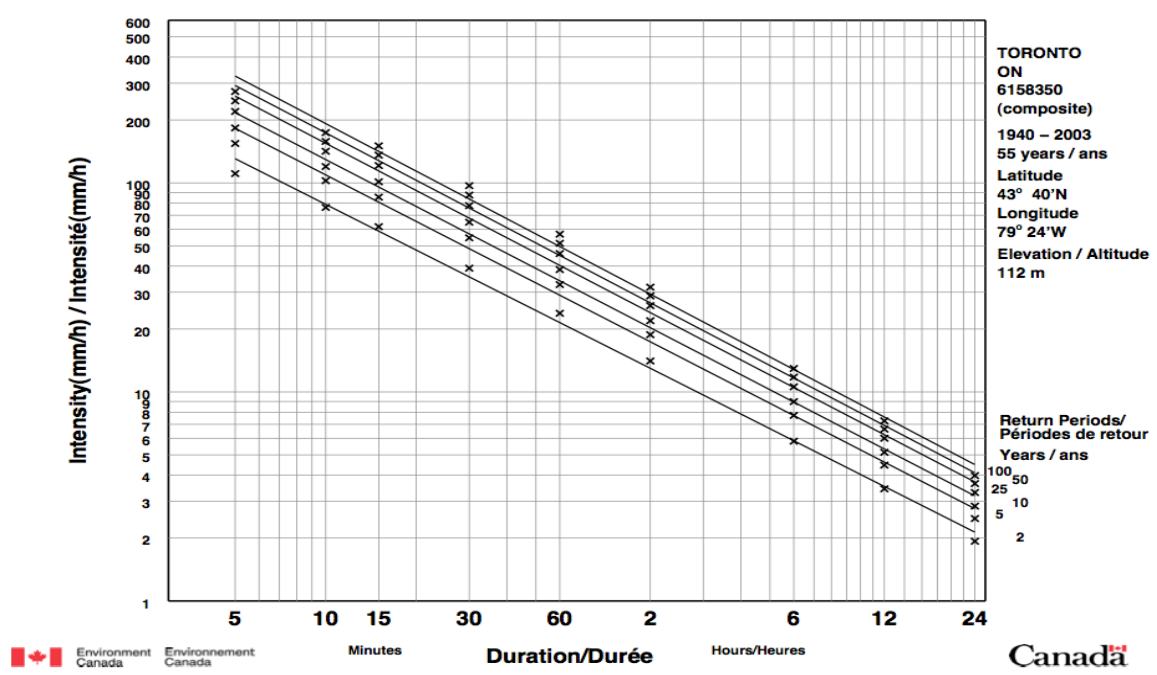

Figure 3-1 Short duration rainfall intensity-duration- frequency data [45]

\subsubsection{Runoff}

The Rational method is used to model the runoff of the Chicago design storm with different return periods. Only a portion of the runoff can be captured by the catch basin grate and become the actual inflow to the underground bioretention system. In this case, the efficiency of the grate (E) determines the amount of water passes through the grate. 
For low intensity and short duration rainfall, the grate splash over is minimal and most of the runoff enters the system. The efficiency of grate inlet has two parts: frontal flow and side flow [17].The frontal flow is the part of the total gutter flow and it is considered as follows:

$$
Q_{w}=Q\left[1-\left(1-\frac{w}{T}\right)^{2.67}\right]
$$

where, $Q_{w}$ is frontal flow, $Q$ is the total discharge flow in the gutter, $w$ width of the inlet, $T$ is total spread of water in the gutter. For side flow, the flow can be expressed as follow[17]:

$$
Q_{s}=Q-Q_{w}
$$

where, $Q_{S}$ is side discharge corresponding to the flow outside the width of the inlet (T-W).

The ratio of $R_{f}$ of frontal intercepted flow to total frontal flow is expressed as[17]:

$$
R_{f}=\frac{Q_{w i}}{Q_{w}}=1.0-K_{f}\left(V-V_{o}\right)
$$

For $V>V_{o}$ and $R_{f}=1.0$ and for $V \leq V_{o}$, where $K_{f}$ is conversion $\left(0.295 \mathrm{~s} / \mathrm{m}\right.$ in metric unit), $Q_{w i}$ is frontal flow intercepted, $V$ is average velocity of flow in the gutter, and $V_{o}$ is splashover velocity.

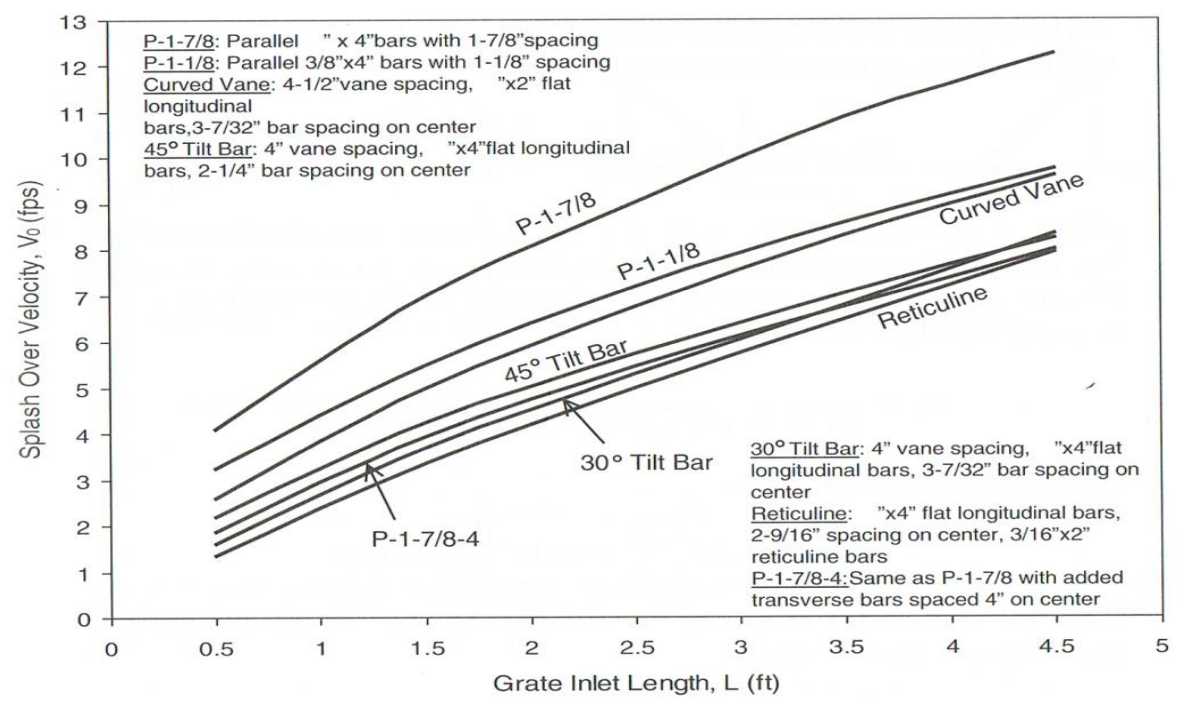

Figure 3-2 Splashover velocity [17] 
The ratio of intercepted side flow to total side flow $\left(R_{S}\right)$ is expressed as[17]:

$$
R_{s}=\frac{Q_{s i}}{Q_{s}}=\frac{1}{1+\left[\frac{K_{s} V^{1.8}}{\left(S_{x} l^{2.3}\right)}\right]}
$$

where, $Q_{s i}$ is side flow intercepted, $S_{x}$ is cross slope, $K_{s}$ is conversion factor $\left(0.0828 \mathrm{~m}^{0.5} / \mathrm{s}^{1.8}\right.$ for metric), and $l$ is length of grate. Therefore, the efficiency of grate inlet is given by $[17,46]$ :

$$
E=R_{f} \frac{Q_{w}}{Q}+R_{s} \frac{Q_{s}}{Q}
$$

By knowing the grate efficiency, the actual peak inflow of the bioretention system can be calculated .To calculate the runoff rate associated with specific intensity; the rational method is used as follows:

$$
R^{\prime}=\Phi i A_{\text {catmt }}
$$

which $\mathrm{R}^{\prime}$ is peak surface runoff rate $\left(\mathrm{m}^{3} / \mathrm{s}\right), \Phi$ is the runoff coefficient $(0.70-0.95$ for paved areas) $[17,47], \mathrm{i}=$ Rainfall intensity $(\mathrm{mm} / \mathrm{hr})$ and $\mathrm{A}_{\text {catmt }}=$ catchment area $\left(\mathrm{m}^{2}\right)$. The amount of water entering the system is equal to the runoff calculated by Rational method multiplied by $\mathrm{E}$ as follows:

$$
R^{\prime}=\Phi i A_{\text {catmt }} E
$$

Using the average measured rainfall at two different time steps of $n, n+1, R$ can be expressed by

$$
R=\Delta t \Phi A_{\text {catm } t}\left[\frac{i_{(n+1)}+i_{(n)}}{2}\right]
$$

Hereafter, average runoff flow volume entering the system at any given time step $\Delta t$, can be expressed by Eq. 3-11.

$$
R=\Delta t \Phi A_{\text {catmt }}\left[\frac{i_{(n+1)}+i_{(n)}}{2}\right] E
$$


There will be some portion of the rainfall intercepted as surface wetness, which is called initial abstraction ( $I_{a}$ ) given by:

- $Q_{i n, c b}=0$ if $i \Delta t \leq I_{a}$ and

- $Q_{\text {in,cb }} \geq 0$ if $i \Delta t \geq I_{a}$

where $I_{a}$ is the initial abstraction ( $\mathrm{mm}$ ) and $\mathrm{Q}$ (defined). The general mass balance equations is applied to different components of the system such as catch basin, distribution pipe (P1), bioretention cell, flow control pipe (P2) and sewer manhole.

\subsubsection{Mass balance at Catch Basin}

Once the runoff is greater than the initial abstraction, the runoff enters the catch basin through the grate inlet. Therefore, the inflow rate of the catch basin is modeled by the Rational method by:

$$
Q_{\text {in,cb }}=R=\Phi i A_{\text {catmt }} E
$$

Considering the different time steps, the average inflow volume of catch basin is modeled by

$$
\Delta Q_{i n, c b}=R \Delta t=\Delta t \Phi A_{c a t m t}\left[\frac{i_{(n+1)}+i_{(n)}}{2}\right] E
$$

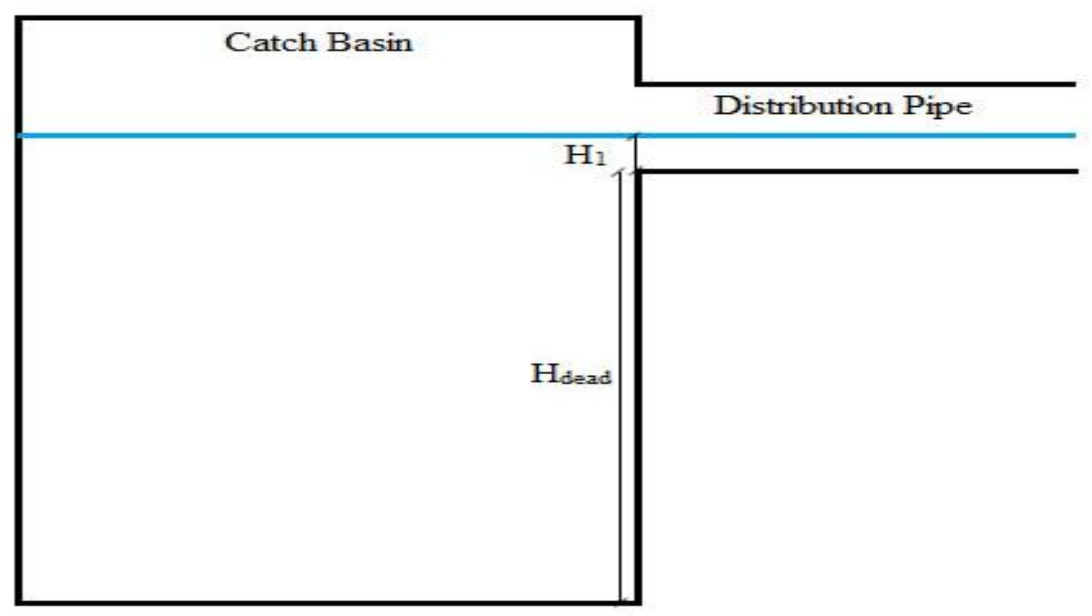

Figure 3-3 Variables in Catch Basin

The catch basin has a sump, which traps the gravel, sand and garbage and attenuates runoff entering to the distribution pipe. There will be no flow to the distribution pipe until the sump is filled with 
water. After the sump storage of the catch basin is filled, the water flows from the catch basin to the distribution pipe. The sump storage is calculated by:

$$
V_{c b d e a d}=A_{c b} H_{\text {dead }}
$$

where $A_{c b}$ is the cross sectional area and $V_{c b d e a d}$ is portion of the water in the catch basin in which is stored below the height of the bottom of the pipe 1 and $H_{\text {dead }}$ is the height of the water below the invert elevation of distribution pipe. The height of the water in the catch basin $\left(H_{1}\right)$ above the invert of the distribution pipe governs the flow equations for the outflow of the catch basin. $H_{1}$ varies between zero and the difference between the height of the water in catch basin and the invert of the distribution pipe:

- When $H_{1}<D_{p 1}$, the flow is weir flow: $Q_{o u t, c b}=A_{p 1} * \sqrt{2 g} * \frac{2 C_{d}}{D_{p 1}} * H_{1}^{1.5}$

- Otherwise, $H_{1} \geq D_{p 1}$, the flow is orifice flow: $Q_{o u t, c b}=A_{p 1} * C_{d} * \sqrt{2 g} * H_{1}{ }^{0.5}$

where $H_{1}$ is the depth of the water in the catch basin above the invert of the distribution pipe and $D_{p 1}$ is the diameter of distribution pipe, $A_{p 1}$ is the area of distribution pipe, $C_{d}$ is the discharge coefficient. Initially the flow does not submerge the distribution pipe, which can be modelled as weir flow. When the water submerge the distribution pipe, the flow can be modeled by orifice flow.

Hence, the average outflow volume of the catch basin between two time steps is given by

- Weir flow scenario:

$$
\Delta Q_{\text {out }, c b}=\frac{\Delta t}{2}\left[A_{p 1} \sqrt{2 g} \frac{2 C_{d}}{D_{p 1}} H_{1(n+1)}^{1.5}+A_{p 1} \sqrt{2 g} \frac{2 C_{d}}{D_{p 1}} H_{1(n)}^{1.5}\right]
$$

- Orifice flow scenario:

$$
\Delta Q_{o u t, c b}=\frac{\Delta t}{2}\left[A_{p 1} \sqrt{2 g} C_{d} H_{1(n+1)}^{0.5}-A_{p 1} \sqrt{2 g} C_{d} H_{1(n)}^{0.5}\right]
$$

Based on the mass balance equation, the storage for the catch basin can be written as follows: 


$$
\Delta S_{c b}=\left[\Delta Q_{i n, c b}-\Delta Q_{o u t, c b}\right]=A_{c b} H_{1}
$$

Therefore, the mass balance and change in the storage of the catch basin is given by

$$
\Delta S_{c b}=\left[\Delta Q_{i n, c b}-\Delta Q_{o u t, c b}\right] \Delta t=A_{c b}\left[H_{1(n+1)}-H_{1(n)}\right]
$$

For weir flow scenario, the mass balance is given by

$$
\begin{aligned}
A_{c b}\left[H_{1(n+1)}-\right. & \left.H_{1(n)}\right] \\
= & {\left[\frac{\Delta t}{2} \Phi A_{\text {catmt }}\left[i_{(n+1)}+i_{(n)}\right] E\right] } \\
& -\frac{\Delta t}{2}\left[A_{p 1} \sqrt{2 g} \frac{2 C_{d}}{D_{p 1}} H_{1(n+1)}^{1.5}+A_{p 1} \sqrt{2 g} \frac{2 C_{d}}{D_{p 1}} H_{1(n)}{ }^{1.5}\right]
\end{aligned}
$$

3-19 can be simplified as below:

$$
\begin{aligned}
A_{c b}\left[H_{1(n+1)}-\right. & \left.H_{1(n)}\right] \\
& =\frac{\Delta t}{2} \Phi E A_{\text {catmt }} i_{(n+1)}+\frac{\Delta t}{2} \Phi E A_{c a t m t} i_{(n)}-\frac{\Delta t}{2} A_{p 1} \sqrt{2 g} \frac{2 C_{d}}{D_{p 1}} H_{1(n+1)}{ }^{1.5} \\
& -\frac{\Delta t}{2} A_{p 1} \sqrt{2 g} \frac{2 C_{d}}{D_{p 1}} H_{1(n)}{ }^{1.5}
\end{aligned}
$$

For the orifice flow scenario, the mass balance is given by:

$$
\begin{aligned}
A_{c b}\left[H_{1(n+1)}-\right. & \left.H_{1(n)}\right] \\
& =\frac{\Delta t}{2} \Phi E A_{c a t m t} i_{(n+1)}+\frac{\Delta t}{2} \Phi E A_{c a t m t} i_{(n)}-\frac{\Delta t}{2} A_{p 1} \sqrt{2 g} C_{d} H_{1(n+1)} 0.5 \\
& -\frac{\Delta t}{2} A_{p 1} \sqrt{2 g} C_{d} H_{1(n)} 0.5
\end{aligned}
$$

\subsubsection{Mass Balance at the Distribution Pipe (P1)}

The inflow rate of the distribution pipe is equal to the outflow rate from the catch basin. In the weir flow scenario, the inflow rate of the distribution pipe is given by 


$$
Q_{i n, p 1}=Q_{o u t, c b}
$$

The inflow of the distribution pipe will be travelled a few meters of solid pipe in order to create a head before distributing throughout the pipe. Along the distribution pipe, perforations allow the flow to exit the pipe and infiltrate to the bioretention cell. The outflow from the orifices is modelled by the orifice equation.

In order to calculate the amount of water coming out of the orifices, the head of the water at each ring of orifices should be determined. Normally, the friction inside of the pipe should be considered in the head computation. After the sensitivity analysis of the head calculations between two sections, it was found that the head difference was minimal and could be assumed almost zero. Therefore, the uniform flow equation is used to model the flow of water between each ring of orifices (i.e $\mathrm{H}_{\mathrm{u} 2}$ is equal to $\mathrm{H}_{\mathrm{d} 2}$ ).

The concept of having uniform flow is illustrated in Figure 3-4. $\mathrm{H}_{\mathrm{u} 1}$ represents the head of the water at the upstream of Section 1 while $\mathrm{H}_{\mathrm{d} 1}$ represents the head of the water at the downstream of Section 1, which will be used to calculate the outflow of orifices in Section 1.

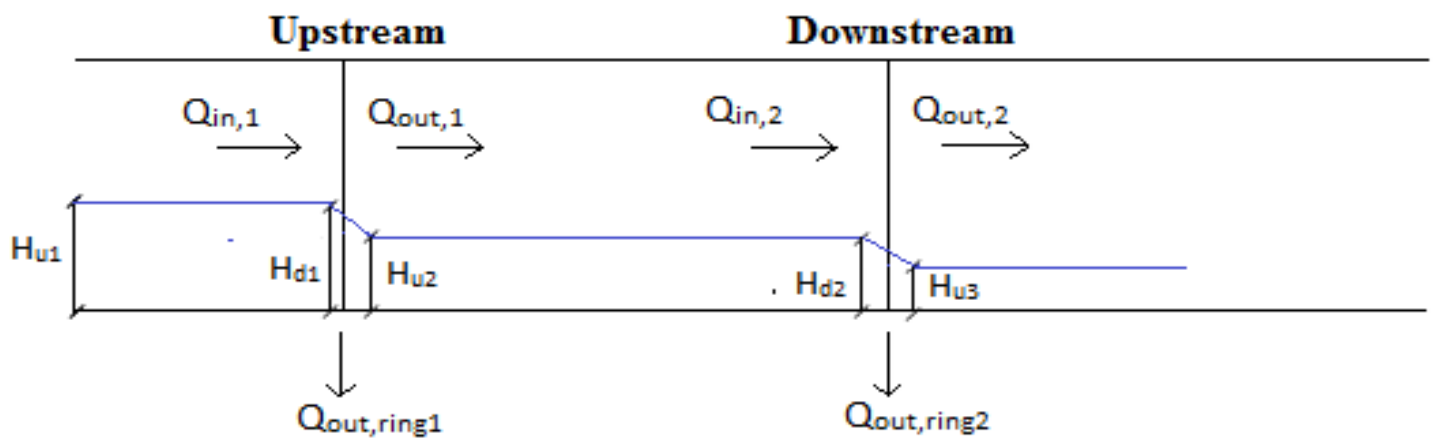

Figure 3-4 Head loss along the pipe

As shown in Figure 3-4, the flow passing through the upstream section is the difference of the flow entering the upstream section and the outflow of ring of orifices at upstream.

$$
Q_{o u t, 1}=Q_{i n, 1}-Q_{o u t, r i n g 1}
$$


In order to determine the depth of the water right after the orifices, the energy equation is used for a particular section like the first section of the orifices as follow:

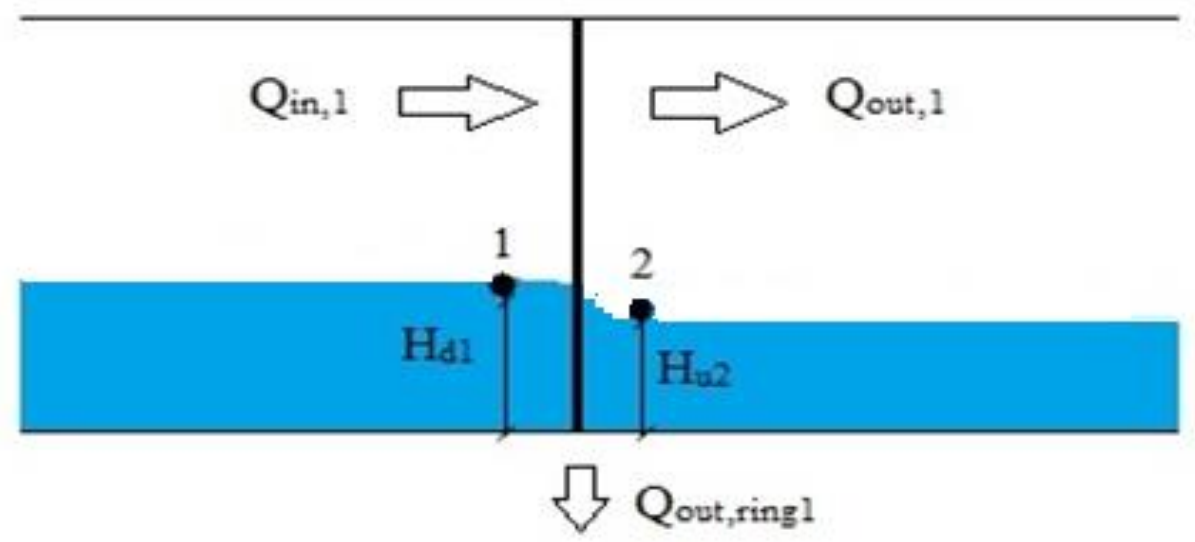

Figure 3-5 Illustration of Energy Equation

$$
H_{d 1}+\frac{P_{1}}{\gamma}+\frac{V_{1}^{2}}{2 g}=H_{u 2}+\frac{P_{2}}{\gamma}+\frac{V_{2}^{2}}{2 g}+h_{O}
$$

The flow of water inside of distribution pipe is considered as open channel flow. In that case, the term $\mathrm{P} / \gamma$ is equal to zero. $\mathrm{H}_{\mathrm{d} 1}, \mathrm{H}_{\mathrm{u} 2}$ are the elevation of water at point 1 and 2 , respectively, which $\mathrm{H}_{\mathrm{u} 2}$ is the variable that needs to be calculated in the equation. The term $Q_{\text {out,ring } 1}$ will be calculated by knowing the elevation of water before the perforations $\left(\mathrm{H}_{\mathrm{d} 1}\right)$. The velocity head at point 1 is known by knowing the flow and flow area at the upstream point. However, the velocity head at point 2 is unknown. The velocity at point 2 can be calculated by considering Eq.3-26. In this equation, $A$ is the flow area that is unknown and it is related to the depth of the water at point 2.

$$
\begin{gathered}
Q_{\text {out }, 1}=Q_{i n, 1}-Q_{\text {out }, \text { ring } 1}=Q_{i n, 2} \\
Q_{i n, 2}=V_{2} A_{2}
\end{gathered}
$$

The flow area $\left(\mathrm{A}_{2}\right)$ can be calculated by Table 2 using 3-27: 


$$
A_{2}=K \quad \text { or } \quad A_{2}=\pi r^{2}-K
$$

where $K$ is a variable based on the depth of the water right after the ring of orifices at each section $\left(\mathrm{H}_{\mathrm{u} 2}\right)$. Therefore, the flow area for the case that the depth of the water after each ring of orifices $\left(\mathrm{H}_{\mathrm{u} 2}\right)$ is less than the radius of distribution pipe is given by:

$$
A_{2}=K=\frac{r^{2}\left(\theta^{\prime}-\sin \theta^{\prime}\right)}{2}=\frac{r^{2}\left[\left(2 \cos ^{-1}\left(\frac{r-h}{r}\right)-\sin \left(2 \cos ^{-1}\left(\frac{r-h}{r}\right)\right)\right]\right.}{2}
$$

The simplified version of 3-28 is given by:

$$
A_{2}=\frac{r^{2}\left[\left(2 \cos ^{-1}\left(\frac{r-\left(2 r-H_{u 2}\right)}{r}\right)-\sin \left(2 \cos ^{-1}\left(\frac{r-\left(2 r-H_{u 2}\right)}{r}\right)\right)\right]\right.}{2}
$$

Therefore, by knowing the $\mathrm{Q}_{\mathrm{in}, 2}$ and $\mathrm{A}_{2}, \mathrm{~V}_{2}$ can be calculated.

$$
\begin{aligned}
& Q_{i n, 2}=V_{2} A_{2} \\
& =V_{2}\left[\frac{r^{2}\left[\left(2 \cos ^{-1}\left(\frac{r-\left(2 r-H_{u 2}\right)}{r}\right)-\sin \left(2 \cos ^{-1}\left(\frac{r-\left(2 r-H_{u 2}\right)}{r}\right)\right)\right]\right.}{2}\right]
\end{aligned}
$$

The same procedure can be applied for the case that the depth of the water right after the each ring of orifices (Hu2) is more than the radius of the distribution pipe. This can be seen in Eq.3-31.

$$
\begin{aligned}
A_{2}=\pi r^{2}-[K] & =\pi r^{2}-\frac{r^{2}\left(\theta^{\prime}-\sin \theta^{\prime}\right)}{2} \\
= & \pi r^{2}-\frac{r^{2}\left(2 \cos ^{-1}\left(\frac{r-h}{r}\right)-\sin \left(2 \cos ^{-1}\left(\frac{r-h}{r}\right)\right)\right)}{2}
\end{aligned}
$$

The simplified version of Eq.3-31is given by:

$$
A_{2}=\pi r^{2}-\frac{r^{2}\left(2 \cos ^{-1}\left(\frac{r-H_{u 2}}{r}\right)-\sin \left(2 \cos ^{-1}\left(\frac{r-H_{u 2}}{r}\right)\right)\right)}{2}
$$


$Q_{\text {in,2 }}$

$=V_{2}\left[\pi r^{2}-\frac{r^{2}\left(2 \cos ^{-1}\left(\frac{\left.r-\frac{H_{u 2, n+}\left(H_{u 2, n+1}\right)}{2}\right)}{r}\right)-\sin \left(2 \cos ^{-1}\left(\frac{\left.\left.r-\frac{H_{u 2, n+}\left(H_{u 2, n+1}\right)}{2}\right)\right)}{r}\right)\right]\right.}{2}\right]$

Table 2 Hydraulic Radius Calculation [48]

\begin{tabular}{|c|c|}
\hline If flow depth $\left(d^{\prime}\right)<$ radius of the distribution & If flow depth $\left(d^{\prime}\right) \geq$ radius of the distribution \\
pipe
\end{tabular}

Therefore, the velocity head $\left(\mathrm{V}_{2}\right)$ at 3-24 can be calculated using the procedure mentioned above. The term $h_{o}$ is the head loss due to the side orifices, which is assumed to be close to zero [30].Thus, by knowing the head loss and all the parameters of Eq.3-24, the depth of the water at point $2\left(\mathrm{H}_{\mathrm{u} 2}\right)$ can be calculated. Due to not considering the friction inside of the pipe, the depth of the water right after the ring of orifices is the same as the downstream head of the water for the next section $\left(\mathrm{H}_{\mathrm{d} 2}\right)$. Therefore, these procedures of calculating the height of the water before and after the perforations 
will apply to all section of orifices along the distribution pipe. These equations are solved using the built-in function of Matlab for each ring of orifices.

The amount of the flow coming out from each orifice is the function of different components. For instance, diameter of orifices is one of those characteristics. Increasing the diameter of orifices will increase the amount of outflow from each ring of orifices and in contrast decreasing the diameter of orifices will decrease the outflow of orifices. In addition, the orientation and the size of orifices along the pipe as well as the head of the water above the orifice can change the outflow from each of them. The outflow of each individual orifices is calculated using the head of the water above the orifice in the distribution pipe as $H_{d 1}$ and the invert elevation of orifices as $H_{\text {orf }}$ as follows:

$$
Q_{\text {out }, \text { orf }}=C_{d} A_{\text {orf }} \sqrt{2 g\left(H_{d 1-} H_{\text {orf }}\right)}
$$

The generalized equation of orifice outflow for multiple orifices and multiple rings along the distribution pipe is given by

$$
Q_{\text {out }, o r f, m, k}=C_{d} A_{\text {orf }, m, k} \sqrt{2 g\left(H_{d 1, m-} H_{o r f, m, k}\right)}
$$

In which, $Q_{\text {out }, \text { orf }, m, k}$ is the outflow of $\mathrm{k}^{\text {th }}$ orifice in the $\mathrm{m}^{\text {th }}$ ring of orifices. However, this equation only work if the $H_{d 1, m}>H_{o r f, m, k}$. Otherwise, the outflow of $\mathrm{k}^{\text {th }}$ orifice in the $\mathrm{m}^{\text {th }}$ ring of orifices is zero.The average outflow of water from the $\mathrm{k}^{\text {th }}$ orifice in section $\mathrm{m}$ to the bioretention cell between two consecutive time steps $(n$ and $n+1)$ is given by

$$
\begin{aligned}
\Delta Q_{\text {out }, \text { orf }, n, m, k} & =\frac{\Delta t}{2} C_{d} A_{\text {orf }, m, k} \sqrt{2 g}\left(\sqrt{\left(H_{d 1, n+1, m-} H_{o r f, m, k}\right)}\right. \\
& \left.+\sqrt{\left(H_{d 1, n, m-} H_{o r f, m, k}\right)}\right)
\end{aligned}
$$

As a result, the average outflow of all the orifices in one ring of orifices is given by 


$$
\begin{aligned}
\Delta Q_{\text {out }, \text { ring }, m, n} & =\sum_{i=1}^{k} \frac{\Delta t}{2} C_{d} A_{\text {orf }, m, i} \sqrt{2 g}\left(\sqrt{H_{d 1, n+1, m}-H_{\text {orf }, m, i}}\right. \\
& \left.+\sqrt{H_{d 1, n, m}-H_{\text {orf }, m, i}}\right)
\end{aligned}
$$

In which $i$ varies from one to the total number of orifices (k) at one ring.

By having the average outflow of each ring of orifices in Eq. 3-37, the outflow of distribution pipe can be modeled using $j$, which represents the number of orifices section along distribution pipe:

$$
\Delta Q_{o u t, p 1, n}=\sum_{j=1}^{m} \sum_{i=1}^{k} \frac{\Delta t}{2} C_{d} A_{\text {orf }, j, i} \sqrt{2 g}\left(\sqrt{H_{d, n+1, j}-H_{\text {orf }, j, i}}+\sqrt{H_{d, n, j}-H_{\text {orf }, j, i}}\right)
$$

The mass balance equation for the distribution pipe is given by

$$
\begin{aligned}
\Delta S_{p 1}=\left[\Delta Q_{i n, p 1}\right. & \left.-\Delta Q_{o u t, p 1}\right] \frac{\Delta t}{2} \\
& =\left[\left(\frac{\Delta t}{2}\left[A_{p 1} \sqrt{2 g} C_{d} H_{1(n+1)}^{0.5}+A_{p 1} \sqrt{2 g} C_{d} H_{1(n)}^{0.5}\right)\right.\right. \\
& -\left(\sum _ { j = 1 } ^ { m } \sum _ { i = 1 } ^ { k } \frac { \Delta t } { 2 } C _ { d } A _ { \text { orf } , j , i } \sqrt { 2 g } \left(\sqrt{H_{d 1, n+1, j}-H_{\text {orf }, j, i}}\right.\right. \\
& \left.\left.+\sqrt{H_{d 1, n, j}-H_{\text {orf }, j, i}}\right)\right]
\end{aligned}
$$

\subsubsection{Mass Balance at the Bioretention Cell}

It is assumed that all the water flow into the pipe and infiltrate to the bioretention cell. Therefore, the average inflow rate into the bioretention cell is equal to the average outflow from the distribution pipe P1 as follows: 


$$
\begin{aligned}
\Delta Q_{\text {in }, b c, n}=\Delta Q_{\text {out }, p 1, n} & \\
& =\sum_{j=1}^{m} \sum_{i=1}^{k} \frac{\Delta t}{2} C_{d} A_{\text {orf }, j, i} \sqrt{2 g}\left(\sqrt{H_{d, n+1, j}-H_{\text {orf }, j, i}}\right. \\
& \left.+\sqrt{H_{d, n, j}-H_{\text {orf }, j, i}}\right)
\end{aligned}
$$

where, $\Delta Q_{\text {in,bc }}$ is average inflow rate to the bioretention cell.

The soil in the bioretention is a porous medium, which absorbs water and works as a filter in the entire system. When the bioretention cell is empty of water in the beginning, the outflow from P1 is filling up the dead storage volume $\left(\mathrm{V}_{\mathrm{bcdead}}\right)$ in the soil. Once the dead storage volume of the bioretention cell is filled up, the outflow of the bioretention cell will be collected by flow control pipe (P2) located at the bottom of the bioretention cell.

By having length of bioretention cell $\left(L_{2}\right)$, as well as its width $(W)$, depth of water in the dead storage $(D)$ and the soil porosity $(\rho)$, the dead storage volume of bioretention cell may be calculated as follows:

$$
V_{b c d e a d}=L_{2} W D \rho
$$

The bottom of the bioretention cell the Queensway Ave., was finished by a thick concrete layer resulting in no infiltration at the bottom of the cell. However, the cell is connected to the native soil from four sides. Therefore, the amount of the water, which seeps out to the surrounding native soil is given by

$$
Q_{\text {seepage }}=2 K_{n s} R^{\prime} s\left(L_{2}+W\right)\left(H_{3}\right)
$$

- where, $H_{3}$ is saturated depth of water level into bioretention cell (m),

- $K_{n s}$ is the hydraulic conductivity of native soil $(\mathrm{m} / \mathrm{s})$,

- $R^{\prime}$ is reduction factor to account for clogging which depends on the number of years of use (assumed to be 0.8) [24],

- $\quad$ and $s$ is hydraulic gradient, assumed to be $1.0(\mathrm{~m}) / 1(\mathrm{~m})$ [24].

Therefore, average of seepage between $n$ and $n+1$ time step can be written as follows: 


$$
\Delta Q_{\text {seepage }, n}=\left(L_{2}+W\right) K_{n s} R^{\prime} s\left[H_{3(n+1)}+H_{3(n)}\right]
$$

The exfiltration of water from bioretention cell to the flow control pipe depends on the following parameters:

- Depth of water above the invert level of the inner layer of P2

- Size and number of perforations

The outflow of the bioretention cell to $\mathrm{P} 2$ is modeled in a manner similar to the orifice outflow from distribution pipe to the bioretention. Therefore, water will rise up in the bioretention cell (soil). The height of the water above invert elevation of lowest orifice indicate the head for orifice equation. This can be can be expressed accordingly:

$$
Q_{b c, o u t}=C_{d} A_{\text {orf } 2, m, k} \sqrt{2 g\left(H_{3, m-} H_{\text {orf } 2, m, k}\right)}
$$

However, in the case that $H_{3, m}<H_{\text {orf } 2, m, k}$, there is no outflow from bioretention cell to the flow control pipe and $Q_{b c, o u t}=0$

Otherwise, Eq. 3-44 is applicable for modelling the outflow of bioretention cell to the flow control pipe.

Thus, the average outflow from bioretention cell between two continuous time steps is given by

$$
\Delta Q_{o u t, b c, n}=\sum_{j=1}^{m} \sum_{i=1}^{k} \frac{\Delta t}{2} C_{d} A_{o r f 2, j, i} \sqrt{2 g}\left(\sqrt{H_{3, n+1, j}-H_{\text {orf }, j, i}}+\sqrt{H_{3, n, j}-H_{\text {orf } 2, j, i}}\right)
$$

The average mass balance equation at the bioretention cell can be written using $\Delta \mathrm{Q}_{\mathrm{bc}}$ in and $\Delta Q_{\text {seepage }}$ and $\Delta Q_{b c, o u t}$ :

$$
\Delta S_{b c}=\left[\Delta Q_{i n, b c, n}-\Delta Q_{\text {seepage }, n}-\Delta Q_{o u t, b c, n}\right] \frac{\Delta t}{2}
$$

The conservation of mass at the bioretention cell can be simplified to 


$$
\begin{aligned}
\Delta S_{b c}=\left[\left(\sum_{j=1}^{m} \sum_{i=1}^{k} \frac{\Delta t}{2} C_{d} A_{o r f, j, i} \sqrt{2 g}\left(\sqrt{H_{d, n+1, j}-H_{o r f, j, i}}+\sqrt{H_{d, n, j}-H_{o r f, j, i}}\right)\right)\right. \\
-\left(\left(L_{2}+W\right) K_{n s} r s\left[H_{3(n+1)}+H_{3(n)}\right]\right) \\
\quad-\left(\sum _ { j = 1 } ^ { m } \sum _ { i = 1 } ^ { k } \frac { \Delta t } { 2 } C _ { d } A _ { \text { orf } 2 , j , i } \sqrt { 2 g } \left(\sqrt{H_{3, n+1, j}-H_{\text {orf } 2, j, i}}\right.\right. \\
\left.\left.\left.+\sqrt{H_{3, n, j}-H_{\text {orf } 2, j, i}}\right)\right)\right]
\end{aligned}
$$

\subsubsection{Mass Balance at the Flow Control Pipe (P2)}

The inflow of the flow control pipe can be modelled based on the outflow of the bioretention cell because there are no other inflow sources. Therefore, the average inflow into P2 at two consecutive time steps is determined from the same equation as 3-45:

$$
\Delta Q_{\text {in, } p 2, n}=\Delta Q_{\text {out } b c, n}
$$

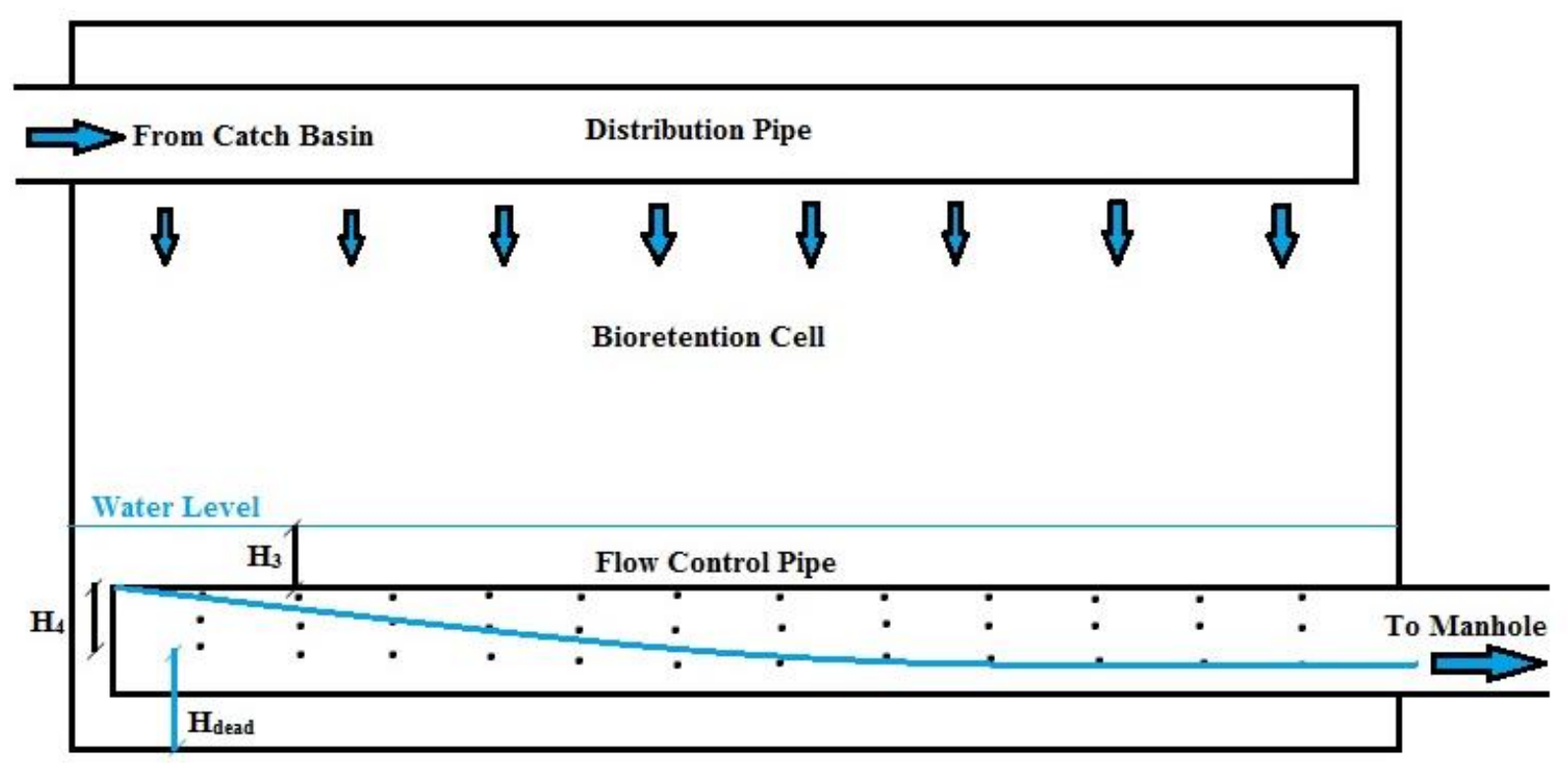

Figure 3-6 Different Variables of the Bioretention Cell 
The P2 is connected to a manhole of the city's sewer system. The water exiting from the bioretention cell will be collected until the water level reaches a certain level at the flow control pipe P2 then it flows through P2. Then the average outflow of water from P2 between two consecutive time steps is computed by weir flow equation as follows:

$$
\Delta Q_{\text {out }, p 2, n}=\frac{\Delta t}{2}\left[A_{p 2} \sqrt{2 g} \frac{2 C_{d}}{D_{p 1}} H_{4, n+1, m}^{1.5}+A_{p 2} \sqrt{2 g} \frac{2 C_{d}}{D_{p 1}} H_{4, n, m}{ }^{1.5}\right]
$$

where $\mathrm{H}_{4}$ is the height of the water inside the flow control pipe. Therefore, the conservation of mass balance equation at $\mathrm{P} 2$ of the bioretention system is given by

$$
\Delta S_{p 2}=\left[\Delta Q_{\text {in }, p 2, n}-\Delta Q_{o u t, p 2, n}\right] \frac{\Delta t}{2}
$$

Moreover, by substituting the values into the Eq.3-50:

$$
\begin{aligned}
& \Delta S_{p 2}=\frac{\Delta t}{2}\left(\sum_{j=1}^{m} \sum_{i=1}^{k} C_{d} A_{o r f 2, j, i} \sqrt{2 g}\left(\sqrt{H_{3, n+1, j}-H_{o r f, j, i}}+\sqrt{H_{3, n, j}-H_{o r f 2, j, i}}\right)\right) \\
& -\left(\left[A_{p 2} \sqrt{2 g} \frac{2 C_{d}}{D_{p 1}} H_{4, n+1, m}^{1.5}+A_{p 2} \sqrt{2 g} \frac{2 C_{d}}{D_{p 1}} H_{4, n, m}{ }^{1.5}\right]\right)
\end{aligned}
$$

\subsubsection{Mass Balance at Manhole}

The flow control pipe discharges percolated water from the bioretention cell to the sewer system through a manhole. The average inflow of water into the manhole is equal to the outflow from P2. Therefore, average inflow into manhole is:

$$
\Delta Q_{i n, m h, n}=\frac{\Delta t}{2}\left[A_{p 2} \sqrt{2 g} \frac{2 C_{d}}{D_{p 1}} H_{5, n+1, m}^{1.5}+A_{p 2} \sqrt{2 g} \frac{2 C_{d}}{D_{p 1}} H_{5, n, m}{ }^{1.5}\right]
$$


where $\mathrm{H}_{5}$ is the height of the water inside the manhole. Since the manhole is the last part of this bioretention system, the outflow of this part will be directed to the City's sewer system. Since the outflow from the manhole to the sewer system is small, the height of the water at the manhole will not reach the point that water move back to the flow control pipe for any circumstances.

\subsubsection{Summary}

In this chapter, the mathematical derivation of the hydraulic model for underground bioretention systems is presented. The focus is to determine the height of the water in each individual components. Using this model, the design of the upper distribution pipe can be optimized to dissipate the runoff as much as possible throughout the majority of the cell.

The modeling is based on the mass balance concept. The runoff entering the catch basin is calculated by the Rational method and grate efficiency of the inlet. Design storms with different return periods are used to generate the intensity in the catchment area. During a storm, the height of the water at the catch basin increases until it reaches the distribution pipe. The outflow of catch basin is modelled by the weir and orifice equations depending upon the water depth and the invert elevation of the distribution pipe. The outflow of catch basin is equal to the inflow of distribution pipe. The outflow of the distribution pipe is only from orifices along the pipe. The size and elevation of orifices along the pipe as well as the distance between each ring of orifices are the primary factors affecting the amount of water percolating through the soil cell. The outflow of P1 enters the bioretention cell, percolates through the soil, which fills the dead storage of the soil. Once the dead storage is filled up, the water will rise up in the soil until it reaches the invert elevation of first orifices along the flow control pipe. The water enters the flow control pipe at the bottom of the cell. Since the flow control pipe does not have any other outflow, its outflow will enter the manhole and exit to the city's sewer system. It should be noted that this chapter has highlighted the formulation of hydraulic design model for underground bioretention under a design storm condition. The next chapter demonstrate the mathematical model by selectively simulating certain combinations of design variables. 


\section{Case Study}

\subsection{Introduction}

In the mathematical model described in the previous chapter, certain parameters were used or introduced to formulate the model employed in this study. Some of these parameters may be adapted from literature while others will be considered as design variables for evaluating different design options. The designer can specify the desired value of the design variables and evaluate the performance of the bioretention system. In this chapter, all the input parameters and design variables considered in the hydraulic modelling are discussed in detail using a case study located at Queensway Ave.

\subsection{Rainfall Intensity}

The intensity and duration of a rainfall event happening in an area is relatively indeterminate and unknown until it has been measured locally by a rain gauge. In order to design a proper bioretention system for an area, a design rainfall event can be developed using the local intensity-duration frequency curves.

In this research, the Chicago design storms with two different return periods of 2 and10 years are used to generate the runoff hydrographs for the simulation. The reason of not considering 100-year return period is that typically the LID practices are fundamentally designed to operate under frequent events. The intensity values of Chicago design storm for different return periods are stated in Table 3 [2]. 
Table 3 Chicago Design Storm [2]

\begin{tabular}{|c|c|c|c|c|}
\hline \multirow{2}{*}{ Time } & \multicolumn{3}{|c|}{ Chicago Rainfall (mm/hr.) } \\
\cline { 2 - 5 } & 2 yrs & 10 yrs & 25 yrs & $\begin{array}{c}100 \\
\text { yrs }\end{array}$ \\
\hline 0:10:00 & 3.25 & 3.58 & 4.24 & 4.50 \\
\hline 0:20:00 & 3.56 & 3.99 & 4.98 & 5.05 \\
\hline 0:30:00 & 3.96 & 4.50 & 5.61 & 5.82 \\
\hline 0:40:00 & 4.52 & 5.21 & 6.45 & 6.83 \\
\hline 0:50:00 & 5.31 & 6.27 & 7.70 & 8.41 \\
\hline $1: 00: 00$ & 6.55 & 8.00 & 9.70 & 11.07 \\
\hline $1: 10: 00$ & 8.94 & 11.51 & 13.64 & 16.87 \\
\hline $1: 20: 00$ & 16.92 & 24.82 & 27.69 & 41.07 \\
\hline $1: 30: 00$ & 78.82 & 133.60 & 158.85 & 205.92 \\
\hline $1: 40: 00$ & 20.98 & 32.00 & 35.08 & 54.56 \\
\hline $1: 50: 00$ & 13.00 & 17.93 & 20.60 & 28.17 \\
\hline $2: 00: 00$ & 9.88 & 12.95 & 15.24 & 19.28 \\
\hline $2: 10: 00$ & 8.15 & 10.31 & 12.32 & 14.83 \\
\hline $2: 20: 00$ & 7.01 & 8.66 & 10.44 & 12.12 \\
\hline $2: 30: 00$ & 6.20 & 7.52 & 9.14 & 10.31 \\
\hline $2: 40: 00$ & 5.59 & 6.65 & 8.15 & 9.02 \\
\hline $2: 50: 00$ & 5.11 & 6.02 & 7.39 & 8.03 \\
\hline $3: 00: 00$ & 4.72 & 5.49 & 6.78 & 7.24 \\
\hline $3: 10: 00$ & 4.39 & 5.05 & 6.27 & 6.60 \\
\hline $3: 20: 00$ & 4.11 & 4.70 & 5.84 & 6.10 \\
\hline $3: 30: 00$ & 3.89 & 4.39 & 5.49 & 5.66 \\
\hline $3: 40: 00$ & 3.68 & 4.14 & 5.18 & 5.28 \\
\hline $3: 50: 00$ & 3.51 & 3.91 & 4.90 & 4.98 \\
\hline $4: 00: 00$ & 3.35 & 3.71 & 4.65 & 4.70 \\
\hline
\end{tabular}

Using this data, the hyetograph representing the above intensities for 4 hours design storms is illustrated in Figure 4-1.

The Silva Cell Inc. which designed the underground bioretention system at Queensway Ave assumed that the design rainfall event in Toronto would be $25 \mathrm{~mm}$ in 24 hours and fifty percent events of Toronto's annual precipitation would be less than $5 \mathrm{~mm}$ [6]. However, for this study the design storms of 2 and 10 years will be used to simulate the inflow to the bioretention system. 
The Chicago design storms were generated using the equation explained in Chapter 3 and the design storm parameters for city of Toronto shown in Table [49]:

Table 4 IDF Parameters - Toronto[49]

\begin{tabular}{|c|c|c|c|c|c|c|}
\hline Parameter & $2 \mathrm{yrs}$ & $5 \mathrm{yrs}$ & $10 \mathrm{yrs}$ & $25 \mathrm{yrs}$ & $50 \mathrm{yrs}$ & $100 \mathrm{yrs}$ \\
\hline $\mathrm{A}$ & 696.484 & 1022.724 & 1331.164 & 1606.048 & 1831.947 & 2031.456 \\
\hline B & 4.875 & 5.256 & 6.006 & 6.006 & 6.012 & 6.006 \\
\hline C & 0.81 & 0.826 & 0.847 & 0.85 & 0.856 & 0.857 \\
\hline
\end{tabular}

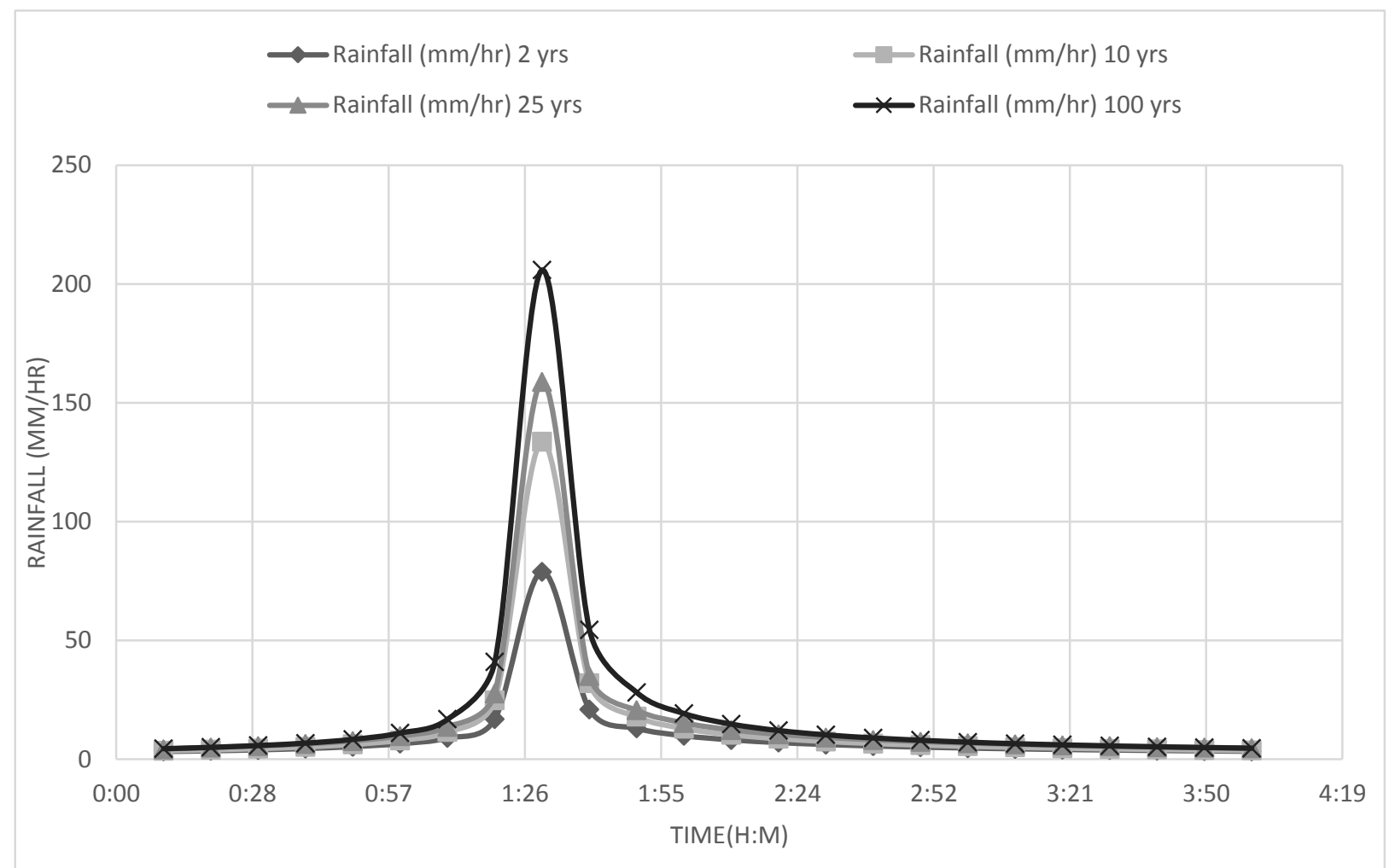

Figure 4-1 Chicago Rainfall Data [2]

The hyetograph for specific return periods were generated using PCSWMM software by specifying the IDF curve parameters mentioned in Table 4. Using the rainfall hyetographs, runoff hydrographs will be calculated using the Rational method. One important parameter of the 
Rational method is the Runoff Coefficient $(\Phi)$, which shows the percentage of rainfall that becomes runoff. The value of runoff coefficient is dependent upon the characteristics of the soil and land cover, which is usually 0.1 to 0.95 . Table 5 shows the runoff coefficient of urbanized areas:

Table 5 Runoff Coefficient for Business and Areas [47]

\begin{tabular}{|c|c|}
\hline Business: & \\
- Neighborhood Areas & $0.70-0.95$ \\
- Downtown Areas & $0.50-0.70$ \\
\hline Residential: & \\
- Single-family areas & $0.30-0.50$ \\
- Multi units, detached & $0.40-0.60$ \\
- Multi units, attached & $0.60-0.75$ \\
- Suburban & $0.25-0.40$ \\
\hline
\end{tabular}

Based on Table 5 and the characteristics of the site, which is located at downtown Toronto, the assumed runoff coefficient $(\Phi)$ in this project is 0.90 . Another important parameter of the Rational method is the catchment area. A measured area of $385 \mathrm{~m}^{2}$ is used by Z. Uddin [2]. Using the above parameters, the rainfall hydrograph for 2 years and 10 years return period is given by Figure 4-2. This figure illustrate the two graph which is fitted and linear interpolation of rainfall hydrograph for two continuous 2 years and 10 years return period. 


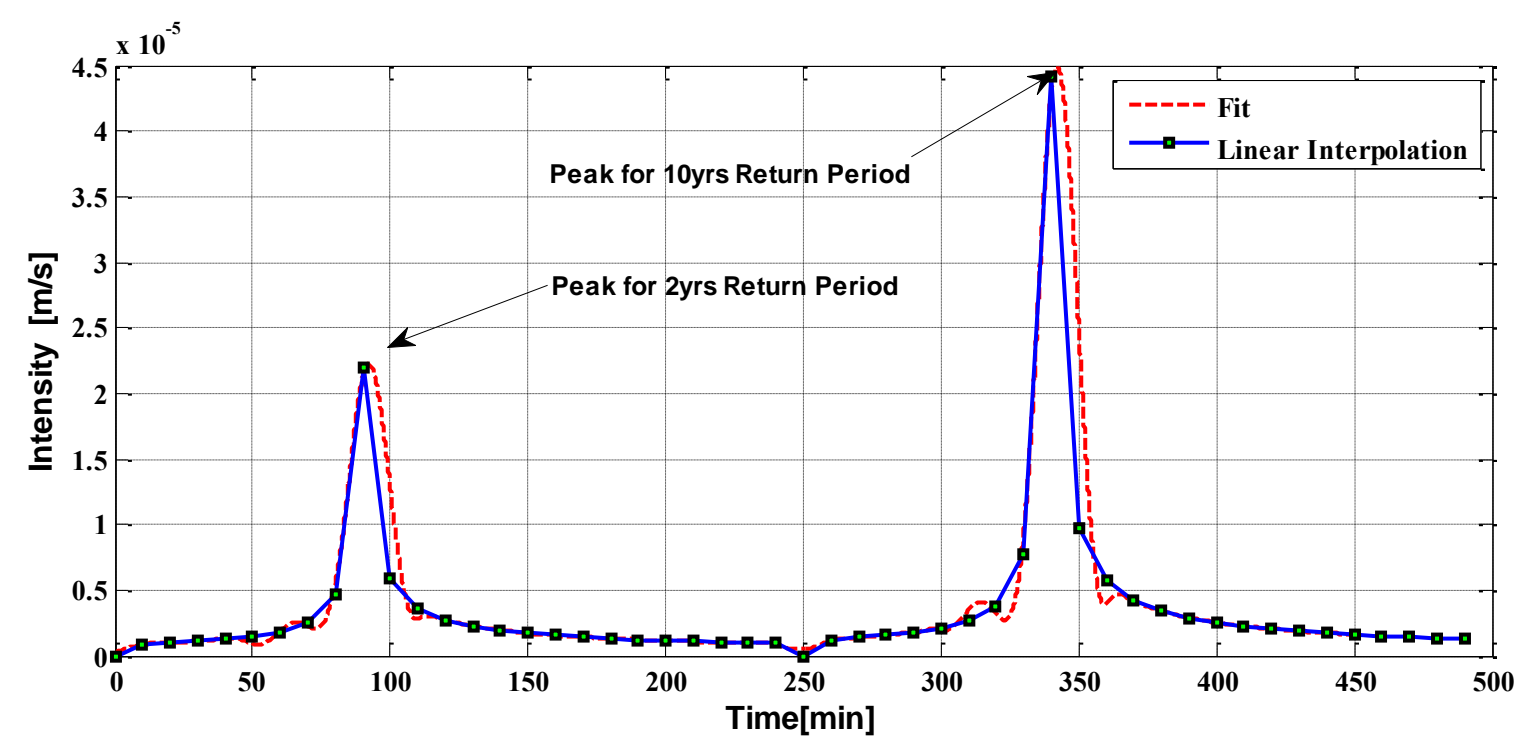

Figure 4-2 Continuous Chicago Design Storm Data [2]

The next important factor affecting the amount of runoff approaching the bioretention cell is the initial abstraction of the urban area $\left(\mathrm{I}_{\mathrm{a}}\right)$. This parameter was discussed and elaborated in details in the Journal of American Water Resources Association's paper [50]. Based on the research done, the initial abstraction of urban areas such as downtown Toronto can be calculated using the curve number $(\mathrm{CN})$ which is related to the properties of the land, soil moisture and other factors affecting runoff [47]. The curve number of this site in downtown Toronto was based on the soil type of sandy-sandy loam. For sandy-sandy loam soil and roads classified as paved with curbs and storm sewers, the curve number is assumed as 98. By knowing the curve number of the area [47], the initial abstraction is given by

$$
I_{a}=0.2 S^{\prime \prime}
$$

$S^{\prime \prime}$ is the maximum potential retention (m) after runoff initiates which can be calculated by the following equation:

$$
S^{\prime \prime}=\frac{1000}{C N}-10=\frac{1000}{98}-10=0.204
$$

Therefore, the initial abstraction value is $0.2 * 0.204=0.0408=4 \mathrm{~mm}$ using Eq.4-2 [47]. Runoff will occur after $4 \mathrm{~mm}$ of rainfall depth for the catchment area. 
Only a portion of runoff will enter the bioretention cell because of storm inlet grate. Inlet interception capacity is subject to the geometry of the inlet and its characteristics as well as the amount of the gutter flow. The efficiency of an inlet is the ratio of the discharge intercepted by the inlet to the total discharge coming to the inlet.

The efficiency of the inlet will be changed by the amount of the flow approaching to the cell. More gutter flow cause less flow passing through the inlet. By assuming the default inlet used in urban areas in City of Toronto, the experiments done by M. Gomez and B. Russo [51] and the literature related to the grate efficiency, the efficiency curve for curved vane inlet used would be curve number 2 in Figure 4-3. Curved vanes grates are the most popular inlets used on streets without sag and with medium amount of traffic. This type of inlets can be placed on grade and is efficient at intercepting flow from one direction only. Improper installation of the curved vane inlets would reduce the intercepting capacity of the inlet resulting in less runoff captured from the street.

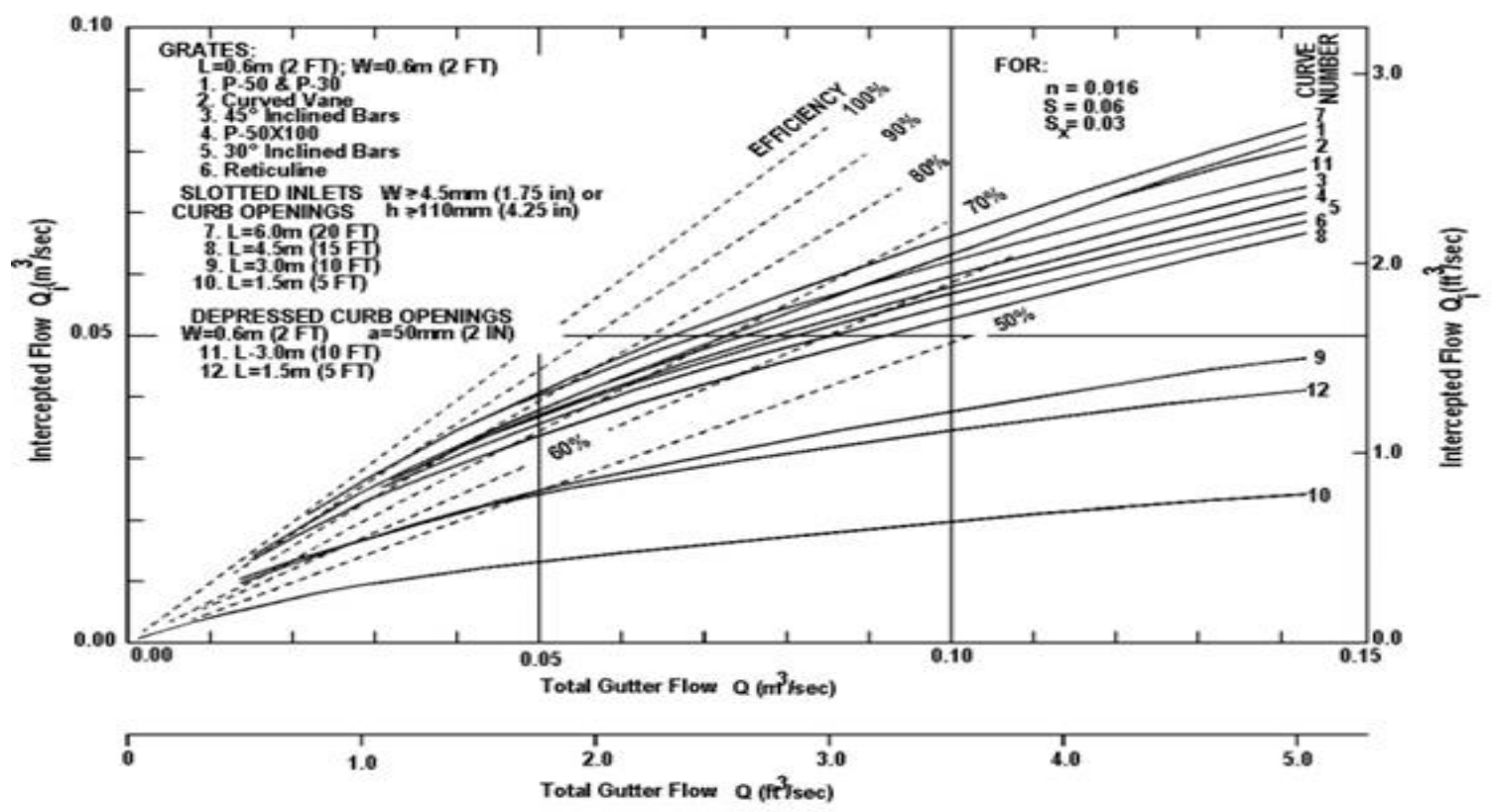

Figure 4-3 Grate Efficiency for Curved Vane Inlet Figure [27]

Based on the amount of water approaching the grate inlet, the efficiency will be selected and the actual amount of water passing through the grate will be used as the inflow to the bioretention system. 


\subsection{Catch Basin Parameters}

By knowing the parameters described above, the amount of water entering the catch basin of the bioretention cell can be determined. The dimension of the catch basin is another important factor in designing this system. Based on the actual site at Queensway Avenue and the dimension of the sidewalk, the cross sectional area of the catch basin used was $0.36 \mathrm{~m}^{2}(60 \mathrm{~cm} \times 60 \mathrm{~cm})$.

The height of the water above the invert of the distribution pipe in the catch basin was defined as $\mathrm{H}_{1}$ and this parameter can be calculated based on the amount of runoff captured and the catch basin area in the model.

Knowing the catch basin height of $1.2 \mathrm{~m}$ and a dead storage $\left(\mathrm{H}_{\text {dead }}\right)$, the height of the water entering the distribution pipe can be determined. In the case study at Queensway Ave., the dead storage height was assumed as $0.8 \mathrm{~m}$. However, in this design $\mathrm{H}_{\text {dead }}$ value is assumed small to minimize the capacity of the water in the catch basin. This would allow water to flow through the cell for filtering immediately. Therefore, the assumed value for dead storage instead of $0.8 \mathrm{~m}$ is $0.6 \mathrm{~m}$. In this case, the volume of water stored in the dead storage of the catch basin would be $0.216 \mathrm{~m}^{3}$. In addition, the discharge coefficient needs to be considered. The discharge coefficient for both weir and orifice flow is representing the loss of flow from catch basin to the distribution pipe, which is assumed to be 0.6 . 


\subsection{Distribution Pipe Parameters}

A very important and critical component of an underground bioretention cell is the distribution pipe and its characteristics such as pipe diameter and length, orifice sizes and orientation. The distribution pipe is designed to distribute the stormwater throughout the soil cell.

The water entering the distribution pipe can be modeled by the orifice and weir flow equations. The flow coefficients for both orifice and weir flow is assumed to be 0.6. The length of the distribution pipe is assumed $8 \mathrm{~m}$ for each individual bioretention cell. However, this parameter can be a variable for each specific design configurations. Based on $1 \mathrm{~m}$ of solid pipe at each end of the distribution pipe, the actual perforated length of the pipe is $6 \mathrm{~m}$.

Considering the structural stability of the PVC pipe used in the bioretention cell and the length of the perforated pipe, which is $6 \mathrm{~m}$, the number of rings of orifices is assumed to be 60 (every 10 $\mathrm{cm})$. This assumption can be changed for different scenarios in order to compare different outflow of orifices. This assumption was made based on the structural stability of the PVC pipe and the percentage of the orifices on a surface of the pipe $[52,53]$

Size of the pipe is a major factor effecting the flow in the distribution pipe. The pipe at the Queensway Ave. bioretention cell is $0.2 \mathrm{mPVC}$ pipe was not used in this study based on the results obtained from Z. Uddin [2]. Instead, the pipe size used in this study is $0.15 \mathrm{~m}$ diameter PVC pipe. The size of distribution pipe is changed subsequently to improve the bioretention performance. The total amount of Chicago Design Storm rainfall for the site in 4 hours for 2 years, 5 years and 10 years return period are $15.10 \mathrm{~m}^{3}, 21.46 \mathrm{~m}^{3}$ and $25.35 \mathrm{~m}^{3}$ respectively. These will generate an inflow rate of $1.048 \times 10^{-3} \mathrm{~m}^{3} / \mathrm{s}, 1.49 \times 10^{-3} \mathrm{~m}^{3} / \mathrm{s}$, and $1.76 \times 10^{-3} \mathrm{~m}^{3} / \mathrm{s}$ respectively. In this study, only two design storms (2 and 10 years) were considered due to multiple combinations of design variable and long duration of simulation of each scenario.

Only portion of runoff would enter the bioretention cell due to the inlet efficiency and the dead storage of the catch basin. According to the amount of water passes through the grate inlet, the design variables for the distribution pipe are:

- Orifice sizes

- Orientation of orifices 
- The distance between each ring of orifices

The height of the water in the entire distribution pipe is $\mathrm{H}_{2}$, which will be calculated by open channel flow equation explained in the previous chapter using $\mathrm{H}_{\mathrm{u}}$ and $\mathrm{H}_{\mathrm{d}}$ for each section of the orifices. By knowing the flow rate of the water and area of the pipe, the height of the water would be calculated as $\mathrm{H}_{\mathrm{u}}$ for the first section of the orifices. Assuming the head loss from each individual side orifices as zero would help to calculate the height of the water right after ring of orifices. The height of water right after the ring of orifices can be calculated using energy equation.

The size and orientation of orifices determine how far the flow will reach the distribution pipe. For this study, the number of orifices in each ring and the distance between each ring of orifices were not considered as the design variables of this system. The number of orifices along the distribution pipe defined as $m$ in Chapter 3 is assumed 8 not considering the two orifices at the bottom and top of the pipe. The reason for not considering the top orifice is that the pipe will be designed in a way that the water will not fill the pipe and prevent surcharging the pipe. The orifice at the bottom of the pipe has larger outflow due to having highest head above that. However, this orifice not recommended because orifices at the bottom will be clogged easily. In order to consider the effect of number of orifices, the following formula was considered.

$$
A_{\text {orifice }}=\left(A_{-} \text {Coef } 2 * x\right)+\left(A_{-} \text {Coef } 1\right)
$$

where $A_{\text {orifice }}$ is representing the area of orifices along the pipe, $A_{-}$Coef 2 and $A_{-}$Coef 1 are the coefficients defining the area of orifices along the pipe, which will be calculated in the simulation process and $x$ is the factor of changing area of orifices along the pipe in each run. By considering $x$, the area of the orifices in each section of the pipe would be determined. In this equation, $x$ is the location of the ring of the orifices at the pipe and Eq. 4-3 calculates the areas of orifices on that section. As explained earlier in this section, the number of ring of orifices would be 60 for every $10 \mathrm{~cm}$ of the distribution pipe. Therefore, the area of orifices on each section was calculated at each simulation using Eq.4-3.

The orientation of orifices is modelled based on the invert elevation of each individual orifices. The first meter of the pipe is solid with no orifices in order to help create a head inside of the distribution pipe. In addition, the height of the orifices will be investigated in different settings in 
order to determine the proper configuration of orifices along the pipe. This would ensure that the runoff is distributed through the entire cell and not short-circuiting the system. Therefore, the height of each individual orifice on a ring of perforations would be defined as an angle from the center of the pipe. This concept is defined in the Matlab simulation as an angle. The symmetric orientation of the orifices at each section is used to calculate the outflow of the orifices for each section. At each section of orifices, half of the pipe will be considered first and then the results will be multiplied by two for the entire system.

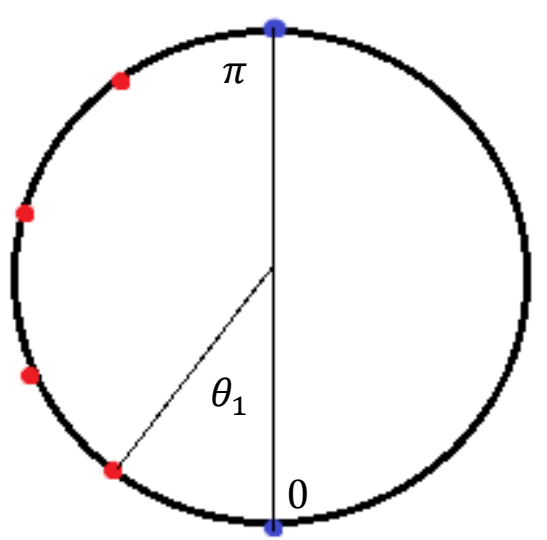

Figure 4-4 Layout of Orifices on the Distribution Pipe

In the Matlab simulation model, the minimum depth of the water in the distribution pipe is defined at the beginning of the simulation. A simple algebraic series equation used to calculate the angle of each orifice as follow:

$$
\theta_{n^{\prime}}=\theta_{1}+\left(n^{\prime}-1\right) d
$$

In which $\theta$ is the angle of each orifice, $n^{\prime}$ is the orifice number and $d$ is the reduction factor for an angle in order to make the angle between each orifice smaller. The reason of introducing the reduction factor in Eq. 4-4 is to have a parameter, which can decrease the angle between orifices. By decreasing the angle between the orifices, their elevation will be decreased too. Hence, water exit the pipe faster and prevent surcharging. Knowing the orifices number and the first angle based on the minimum dead storage of the pipe, the angle of the next orifice will be calculated. The value of the reduction factor is based on two known parameters: minimum depth of the water at the 
distribution pipe and the number of orifices. Using the summation format of algebraic series equation, [54] summation of all the angles calculated by Eq.4-4 is given by

$$
\frac{n^{\prime}}{2}\left(2 \theta_{1}+\left(n^{\prime}-1\right)\right) d=\pi
$$

The reason why Eq.4-5 is equal to $\pi$ is that half of the pipe (which is a half circle) is $\pi$. Using Eq. 4-5, the reduction factor (d) is calculated which in turn is used in Eq. 4-4 to find the angle of a specific orifice. By obtaining the size of the orifices for each ring and knowing the area of orifices in each ring, there is no need to determine the number of orifices along the pipe.

The minimum depth of the water at the distribution pipe was calculated in the Matlab simulation. The elevation of the orifices is different along the pipe in order to distribute the stormwater effectively. In order to investigate the performance of the system, different orifice orientation will be analyzed.

As indicated in Abdulwahid et al. [52], the size of the orifices should obey specific rules in order to dissipate the amount of runoff along the distribution pipe. The size of the orifices should be in the range of $0.001 \mathrm{~m}$ to $0.02 \mathrm{~m}$ based on the stability of the structure of pipe and the area of perforations. In addition, maximum diameter of the orifices should be 0.02 times of the inside diameter of the PVC pipe [55]. These recommended values are used as the lower and upper limit of the perforation size.

The distribution pipe size and the size and orientation of the orifices of the simulation model were specified based on the number of orifices, amount of rainfall and the maximum diameter of orifices as explained above. Therefore, it was obvious that the number of orifices would increase and the angle between them would decrease when more stormwater enters the system. However, in this study, the number of orifices is assumed as eight and only the angle between them is changed due to different minimum depth of the water at each section of the pipe. 


\subsection{Bioretention Cell Parameters}

The size of the bioretention cell of the Queensway Ave. project is used in this case study. The length $\left(\mathrm{L}_{2}\right)$ and the width $(\mathrm{W})$ of the bioretention cell are based on the properties of the site and sidewalk. Percolation of water from distribution pipe to the bioretention cell is described in the previous chapter in detail. However, the most important design parameters related to this part of the cell are the soil porosity and the dead storage.

The dead storage of the bioretention cell can be calculated by knowing the length, width, and soil porosity of the cell. The porosity for sandy soil is in the range of $0.25-0.5$. In this case study, the porosity is assumed as 0.35 based on the sandy loam soil inside of the cell [29]. The height of the dead storage at the bioretention cell is the invert elevation of the flow control pipe at the bottom of the cell, which is equal to the elevation of the first orifices of the flow control pipe.

Other parameters related to the seepage of the water from the cell to the surrounding native soil are explained in Chapter 3 except the hydraulic conductivity of the native soil. The hydraulic conductivity of the soil is a physical property, which measures the ability of transmitting water inside of the soil. A hydraulic conductivity $\left(\mathrm{K}_{\mathrm{ns}}\right)$ [2] is of 0.000018 is used the case study [2]. By knowing these parameters, the exfiltration of water from bioretention cell to the flow control pipe can be determined. The height of the water at the bottom of bioretention cell can be calculated based on the invert elevation of the orifices of flow control pipe (i.e. the dead storage of the cell).

\subsection{Flow Control Pipe and Manhole Parameters}

The water exfiltrated from the bottom of the bioretention cell is captured via a flow control pipe. For the flow control pipe, the pipe diameter and the number, size and orientation of the orifices are not as critical as those of the distribution pipe are. However, the same size and length as those of the distribution pipe are used in this case study to prevent any backwater to the soil. In order to prevent any backwater to the system, the larger orifices of the distribution pipe are used in the flow control pipe.

Water reaches the invert elevation of the first orifices of the flow control pipe and percolates to the pipe. The flow percolating into the pipe is dependent upon water level within the bioretention 
cell. In addition, the length of the pipe is a known parameter in the case study. The flow of water entering the flow control pipe determines the height of the water at the flow control pipe. The flow control pipe is attached to the manhole, which in turn is connected to the City's sewer system. The percolated water from the cell enters in the manhole and the height of the water at the manhole is calculated by the equations explained in Chapter 3. The size of the manhole is fixed because manholes are standard structures. The volume of water exiting from the bioretention system can be calculated and compared to the volume of water entering the bioretention system for mass conservation. 


\section{$5 \quad$ Results and Discussion}

\subsection{Introduction}

The mathematical model described in Chapter 3 is used to simulate the runoff distribution in the bioretention system in Toronto. One of the main objectives of this research is to determine the water depth in each component of the bioretention system. Other objectives are to simulate the water flow in the distribution pipe in order to dissipate the runoff through the entire cell. In addition, a general concept to optimize the parameters such as diameter of the pipe and area and orientation of orifices implemented on the pipe can be considered other objectives. In order to have a clear comparison among different design situations of the system, Matlab simulation results are presented and compared.

\subsection{Steady State Scenarios}

In order to test the mathematical model, the steady state simulation was conducted. Instead of introducing a hydrograph as an input to the model, a square pulse of constant inflow was used to represent the steady state conditions shown in Figure 5-1.

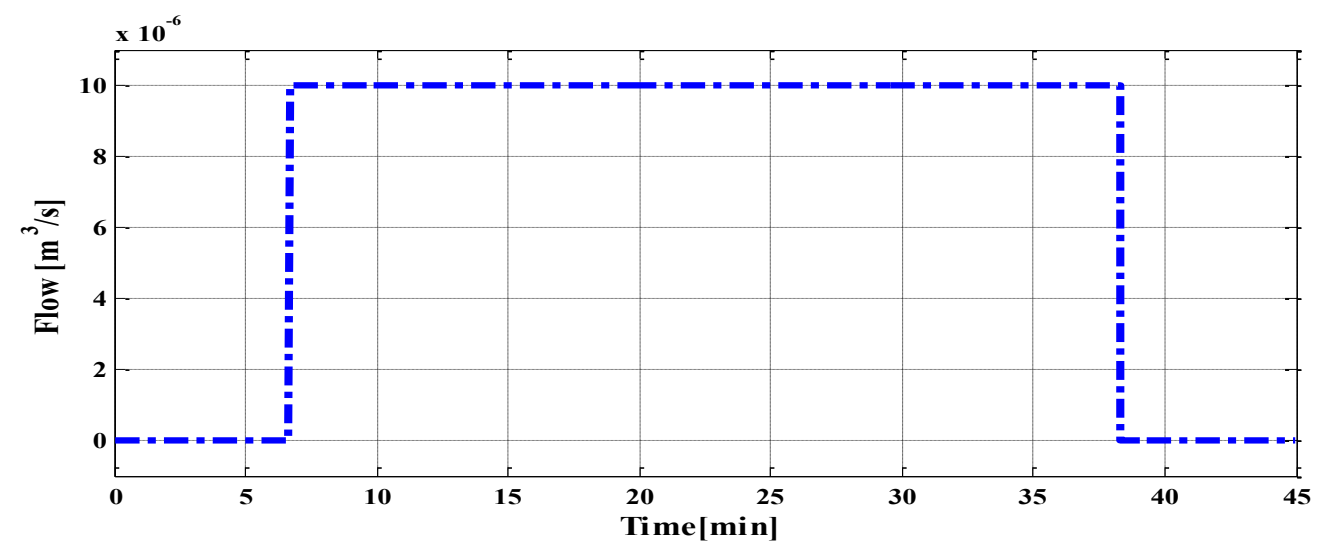

Figure 5-1 Inflow of the Steady State Condition

For this case, the inflow of the system is $10 \times 10^{-6} \mathrm{~m}^{3} / \mathrm{s}$ for 31.5 minutes. This selected steady state inflow rate was based on an arbitrary small flow (10 times smaller than 2 years, 5 years and 10 
years return period flow), which can show the amount of inflow and outflow of the distribution pipe only.

The steady state simulation is used to investigate the effect of different design parameters on the water depth of the distribution pipe. For original set of input values, the diameter of the distribution pipe equals $0.15 \mathrm{~m}$, the distance between each ring of orifices (d_s) equals $0.1 \mathrm{~m}$, the invert

elevation of orifices equals $\frac{D p 1}{8}$ and the orifice size (A_Coef1) equals $0.00001 \mathrm{~m}^{2}$ was used to represent as a reference scenario. Four other scenarios with the following input parameters are used to compare the effect of the number of section of orifices and the diameter of orifices on the water depth of the distribution pipe:

- Case I: d_s $=0.1(\mathrm{~m})$ and $\quad$ A_Coef $1=0.00001\left(\mathrm{~m}^{2}\right)$

- Case II: d_s=0.02 (m) and A_Coef1 $=0.00001\left(\mathrm{~m}^{2}\right)$

- Case III: d_s=0.05 (m) and A_Coef1 $=0.00001\left(\mathrm{~m}^{2}\right)$

- Case IV: d_s=0.1 (m) and A_Coef1 $=0.00002\left(\mathrm{~m}^{2}\right)$

- Case V: d_s $=0.1(\mathrm{~m})$ and $\quad$ A_Coef $1=0.00003\left(\mathrm{~m}^{2}\right)$

As shown in Figs. 5-2 to 5-6, a reduction of the distance between each ring of orifices and an increase of orifice diameter result in smaller flow depth along the distribution pipe. In Case 1 (Figure 5-2), the pipe is divided into 60 section of orifices at every $0.1 \mathrm{~m}$ interval. The areas of orifices on these rings of orifices are $0.00001 \mathrm{~m}^{2}$. The exfiltration starts at time $6.6 \mathrm{~min}$ with higher rate in the first 30 section of orifices and reduces subsequently until section 60th. Exfiltration would last until time $38 \mathrm{~min}$, which would be the end of pulse inflow, introduced to the system.

In the next two cases, the input parameters are similar to those of case I, except the number of ring of orifices. In case II, the d_s is changed to $0.02 \mathrm{~m}$. This would make 300 ring of orifices along the pipe (Figure 5-3). Only 100 of those rings will be used to exfiltrate the amount of runoff introduced to the system. By increasing just the ring of orifices along the pipe, the water would exit the pipe sooner than that of case I. In Case III, the d_s parameter is $0.05 \mathrm{~m}$, which is expected to produce a moderate result, compared to those of Case II and I. In this case, the rings of orifices are implemented in every $0.05 \mathrm{~m}$ along the pipe resulting in 120 rings of orifices. Water exfiltrates to the bioretention cell using 110 of these rings. By comparing the simulation results of these three scenarios, it is found that the number of rings of orifices along the pipe has a direct effect on how fast the water exfiltrates out of the distribution pipe. 
In Case IV, the area of orifices (A_Coef1), would be changed to $0.00002 \mathrm{~m}^{2}$ while the distance between each ring of orifice is not changed. As shown in Figure 5-5, the water exits the orifices faster than that of Case I. By comparing the simulation result of Case I and IV, it is found that water exits the pipe sooner in Case IV than that of Case I resulting in smaller flow rate at the end of the pipe. In Case V, A_Coef1 is changed to $0.00003 \mathrm{~m}^{2}$. By enlarging the area of orifices, it is found that water exit the distribution pipe sooner than that of Case I (Figure 5-6).

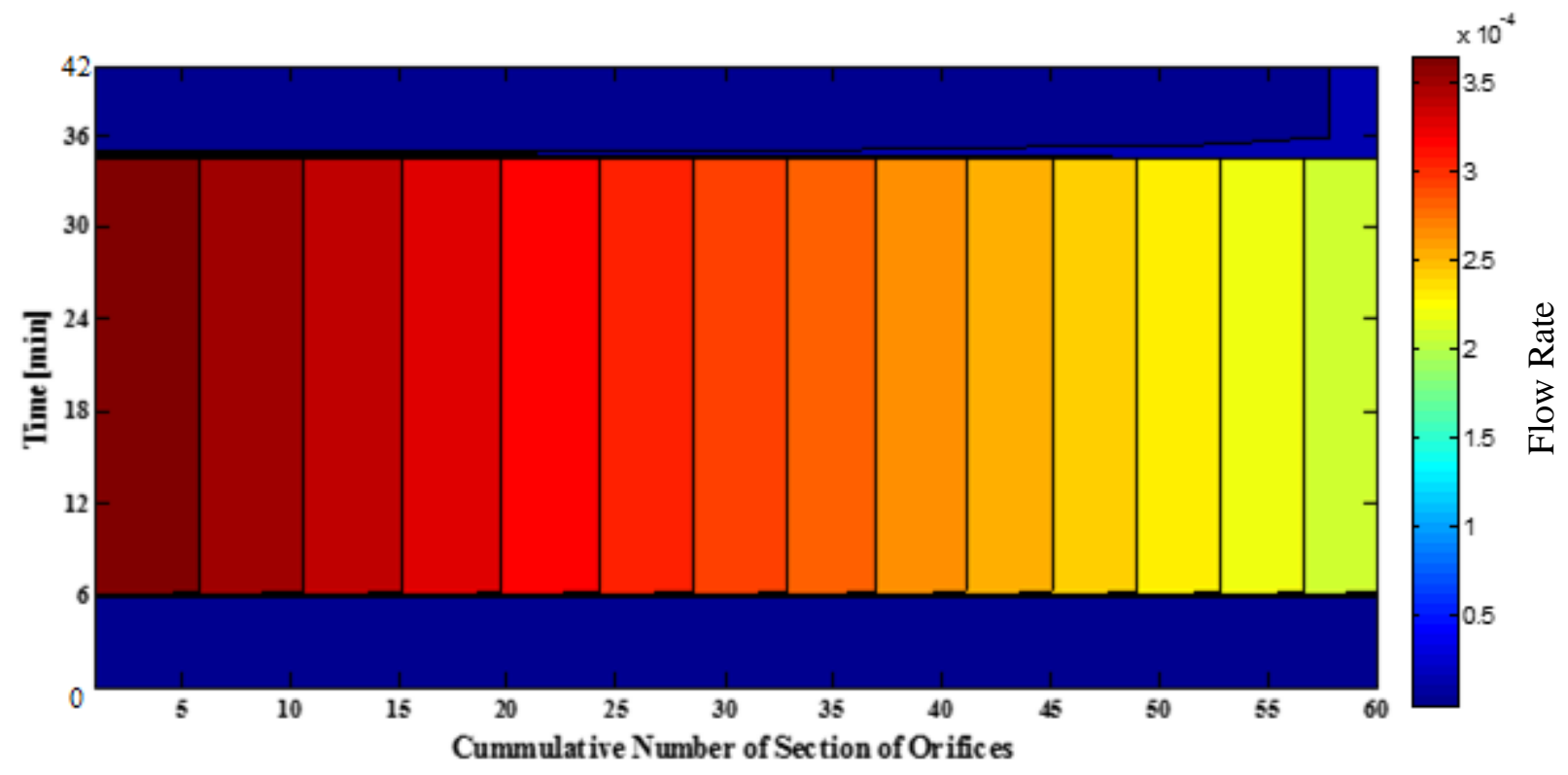

Figure 5-2 Case I of Steady State 


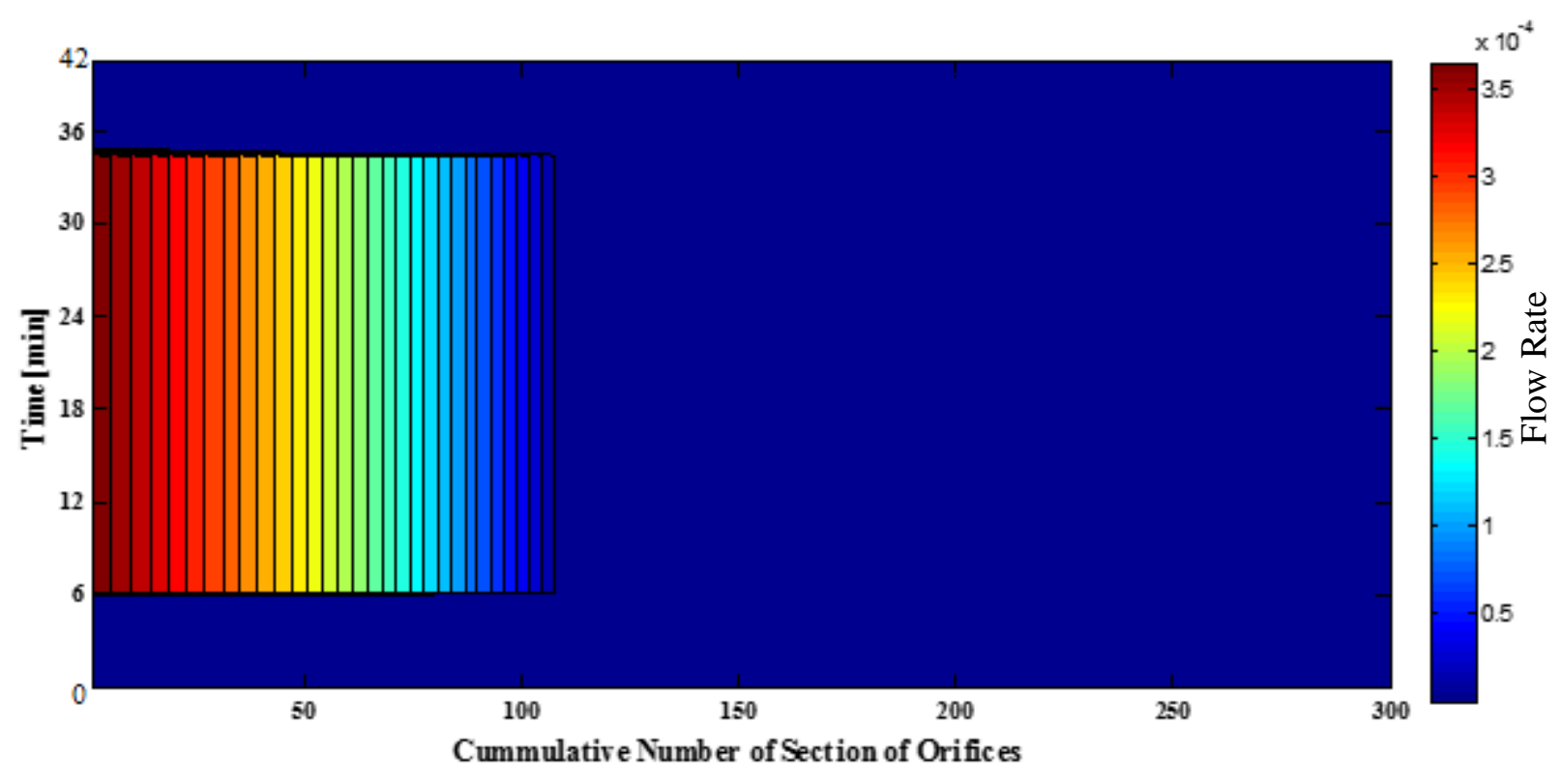

Figure 5-3 Case II of Steady State

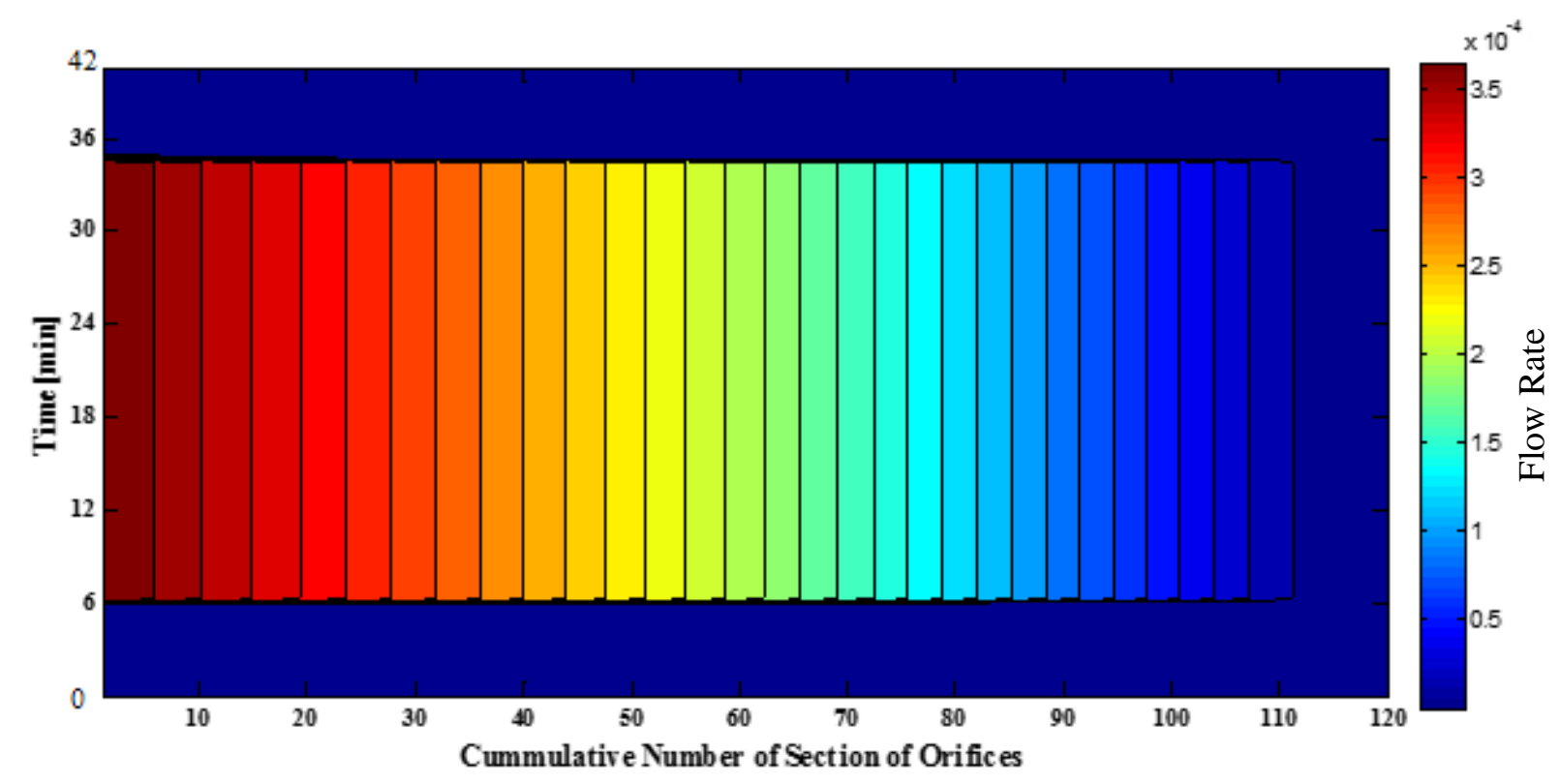

Figure 5-4 Case III of Steady State 


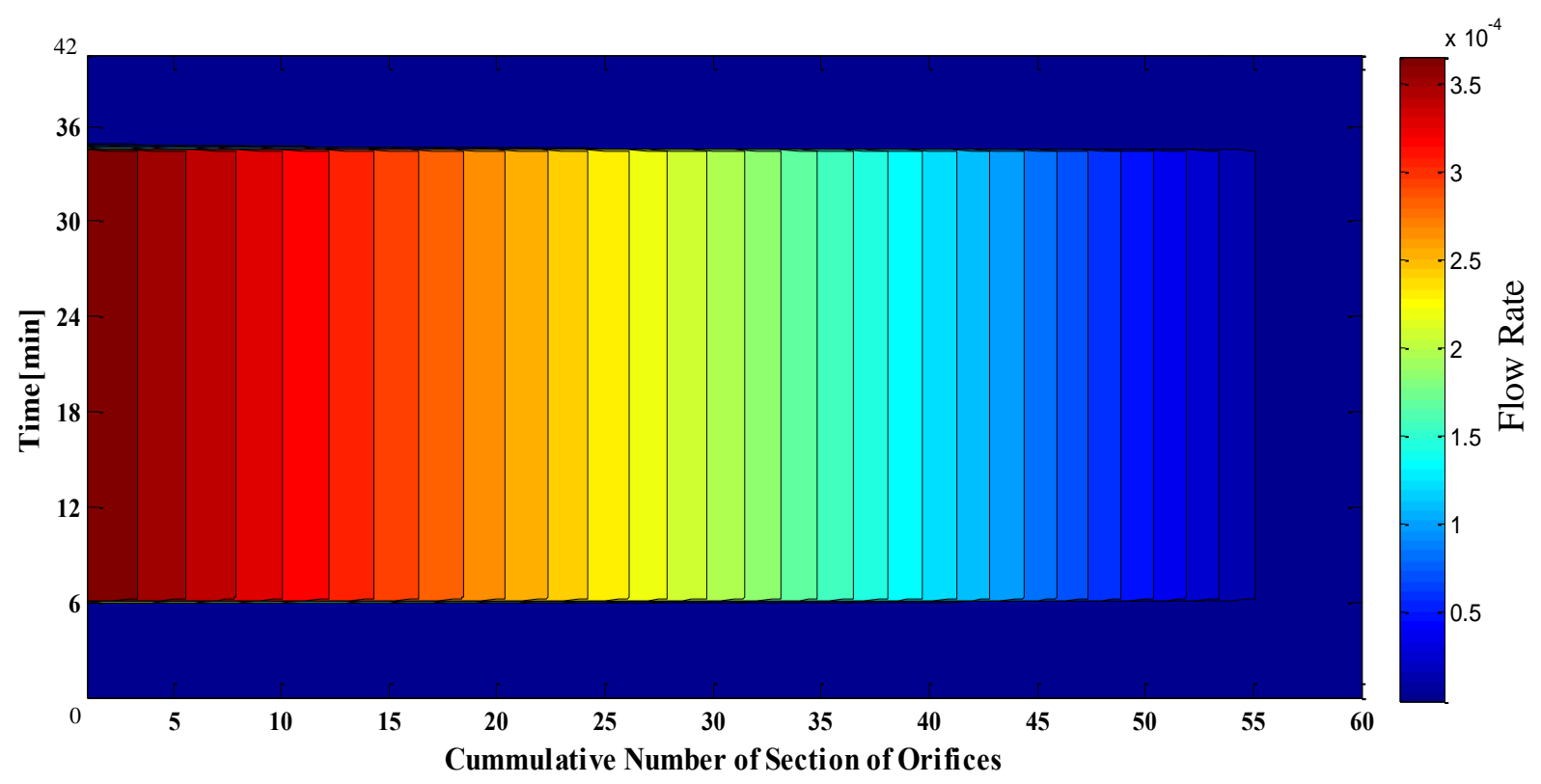

Figure 5-5 Case IV of Steady State

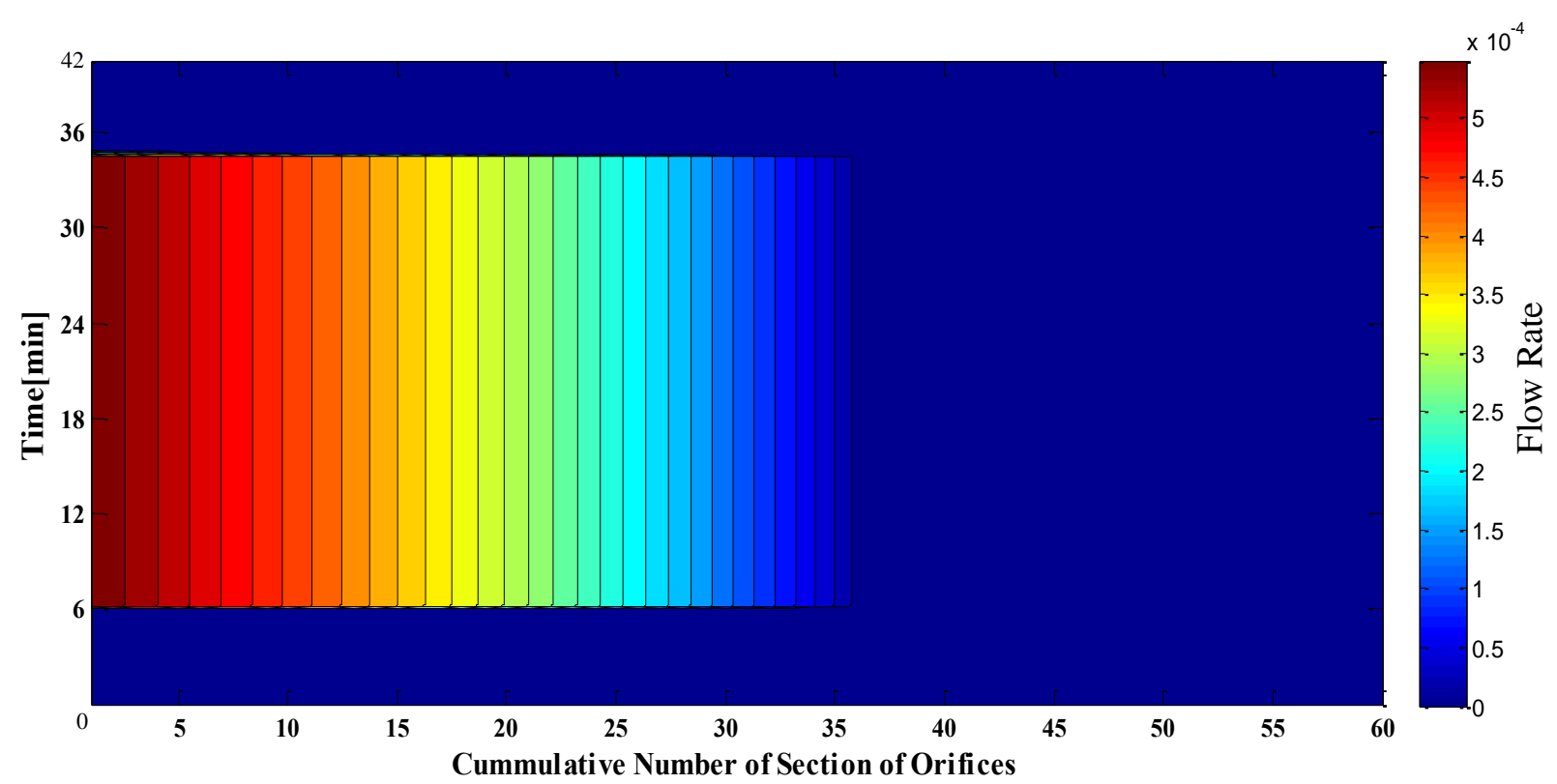

Figure 5-6 Case V of Steady State

Figure 5-7 summarizes the effect of the distance between each ring of orifices (d_s) and orifice size (A_Coef1) on the water depth of the distribution pipe. By reducing the distance between each ring of orifices, water would reach the $0.02 \mathrm{~m}$ depth (i.e. the invert elevation of the first orifices) 
and exit the pipe sooner. Doubling the area of the orifices along the pipe has similar effect on the water depth as seen in the Figure 5-7 (red and green curve).

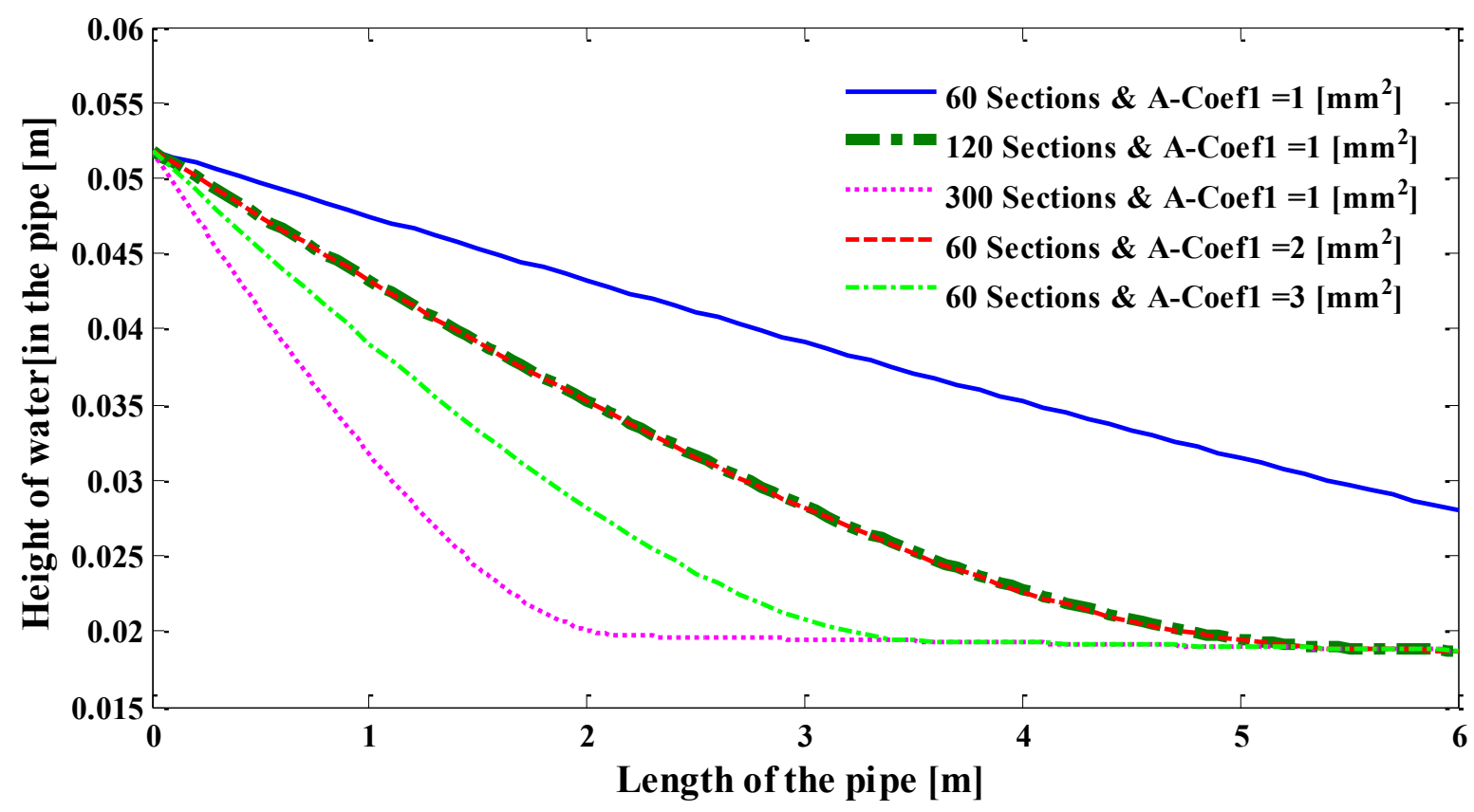

Figure 5-7 Water Profile in 5 Cases in Steady State Condition

\subsection{Unsteady State Rainfall}

In order to investigate the distribution of runoff at the bioretention system under unsteady state scenarios, the Chicago design storm was used. The rainfall intensity of the 4-hour Chicago storm was discussed in Chapter 4. In order to assess two back-to-back design storms with different return periods, the hyetographs of 2 years and 10 years return period are linked together as shown in Figure 5-8. Since the combined hyetograph is discretized at 10-minute interval, a curve fitting method (as discussed in next section) is used to develop the hyetograph on a shorter time step. 


\subsubsection{Curve Fitting}

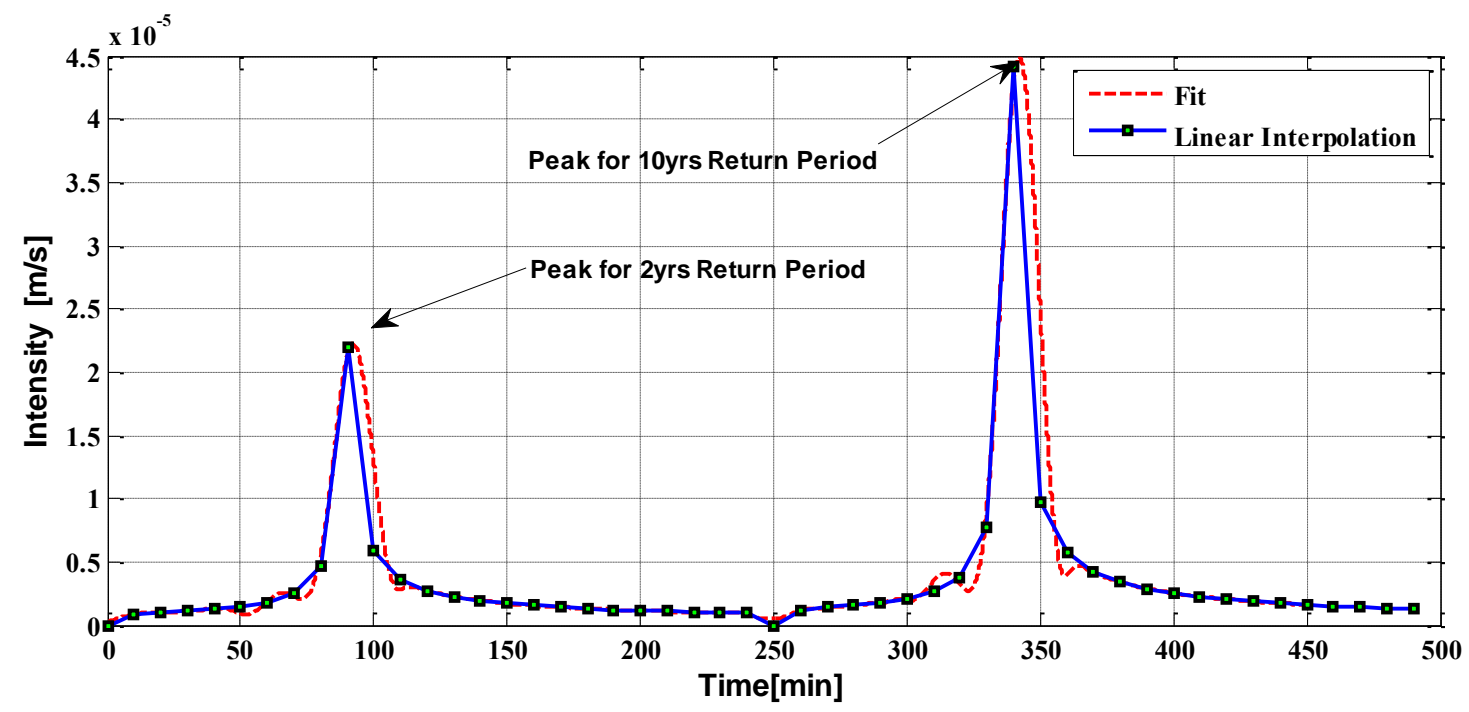

Figure 5-8 Fitted Rainfall Data with 10 minutes time intervals

Using the rainfall data of larger time steps, a functional curve fitting technique can be used to predict rainfall continuously over short time steps. The most common and practical approach of curve fitting is the least-squares regression which is also called regression analysis for a curve of discrete data.

Commonly, linear interpolation between two time steps would find the amount of rainfall at intermediate time steps. In this study, different types of interpolation were used because the linear interpolation method would not represent the actual rainfall data at that specific time step. Therefore, more details and sophisticated way of interpolation was used in this study.

Fitting one curve to the entire data would be impossible and inaccurate. In order to minimize this, multiple adjacent points would be selected and fitted to a curve. Therefore, the same step would be repeated for several adjacent points. However, the same problem appears to the interpolated points. In order to deal with this issue, at each individual procedure, the Matlab code reads one point before the first point of each level and one after the last point of that specific level and fits the curve, which is two orders larger than the total number of the points at that level of the procedure. In this case, the curve would be fitted without any significant jump at each time interval. 
In Figure 5-8, the fitted curves using two methods of interpolation method (i.e. linear regression and Matlab) are shown.

The data shown in Figure 5-8 is the rainfall entering the catch basin through a grate inlet with efficiency of $70 \%$. This rainfall graph, represents the fitted rainfall data for a 2 -year storm starting at time zero until 250 min followed by a 10-year storm of 4-hour duration, was used as an input for different simulation scenarios in Matlab. The peaks of these two design storms will happen at time $90 \mathrm{~min}$ and $340 \mathrm{~min}$, respectively. The outflow from each component of the bioretention system will be higher at these specified times due to a large volume of rainfall entering the system. The results of Matlab simulation will be plotted for each section of orifices individually.

\subsection{Unsteady State Scenarios}

In order to compare the effect of changing decision variables (e.g. distance between orifice ring, size of orifice) on the outflow of water from the distribution pipe and consequently the water depths at other components of bioretention system, five scenarios are investigated. In each scenario, each of the variables was changed under the unsteady rainfall condition. The details of these case studies are shown in Table 6 and the simulation results of these cases are discussed in the next section.

Listed below are four design variables, which are changed with a distribution pipe of $0.15 \mathrm{~m}$ :

- $\quad$ w_d_min $(m)$ is the invert elevation of orifices at the end of the pipe

- W_d_max (m) is the invert elevation of orifices at the beginning of the pipe

- A_Coef1 $\left(\mathrm{m}^{2}\right)$ is the area of each orifice along the pipe

- A_Coef $2\left(\mathrm{~m}^{2}\right)$ is the factor changing the area of orifices along the pipe according to its location

In each case, the Matlab simulation generated six outputs in which five of those represent the water

depth at each component of the bioretention system and the last one represents the outflow of each ring of orifices along the pipe at different time steps. 
Table 6 Details of Different Scenarios

\begin{tabular}{|c|c|c|c|c|c|}
\cline { 2 - 6 } \multicolumn{1}{c|}{} & \multicolumn{5}{c|}{ Design Parameters } \\
\hline Scenario & D 1 (m) & w_d_min (m) & w_d_max (m) & A_Coef1 $\left(\mathrm{m}^{2}\right)$ & A_Coef2 (m) \\
\hline 1 & 0.15 & $1 / 8 \mathrm{D}_{\mathrm{p} 1}$ & $1 / 8 \mathrm{D}_{\mathrm{p} 1}$ & 0.00001 & 0.000 \\
\hline 2 & 0.15 & $3 / 8 \mathrm{D}_{\mathrm{p} 1}$ & $1 / 8 \mathrm{D}_{\mathrm{p} 1}$ & 0.00001 & 0.000 \\
\hline 3 & 0.15 & $1 / 8 \mathrm{D}_{\mathrm{p} 1}$ & $3 / 8 \mathrm{D}_{\mathrm{p} 1}$ & 0.00001 & 0.000 \\
\hline 4 & 0.15 & $1 / 8 \mathrm{D}_{\mathrm{p} 1}$ & $1 / 8 \mathrm{D}_{\mathrm{p} 1}$ & 0.0001 & 0.000 \\
\hline 5 & 0.15 & $1 / 8 \mathrm{D}_{\mathrm{p} 1}$ & $1 / 8 \mathrm{D}_{\mathrm{p} 1}$ & 0.00001 & 0.00002 \\
\hline
\end{tabular}

\subsection{Scenarios}

\subsubsection{Case 1}

According to Table 6, the size of the distribution pipe is $0.15 \mathrm{~m}$ and all the orifices are at the elevation of $0.02 \mathrm{~m}$ of the pipe with the area of $0.00001 \mathrm{~m}$. To have a clear understanding of the effect of changing each parameter, this case represents the original combination of parameters for the Queensway site. Results of other cases are compared to those of this case.

After simulating this scenario in Matlab, the depth of the water at each component is calculated. The first component of the bioretention system is the catch basin, which store the water until it reaches the invert elevation of the distribution pipe. Until the water has reached the invert elevation of the pipe, there is no outflow from both catch basin and distribution pipe. After filling the dead storage of the distribution pipe (storage below the lowest orifices), the water level at the catch basin and distribution pipe will increase. Therefore, by increasing the intensity of the rainfall, the amount of water entering the catch basin will increase proportionally and escalate the height of the water in the system. These results can be seen in Figure 5-9. 


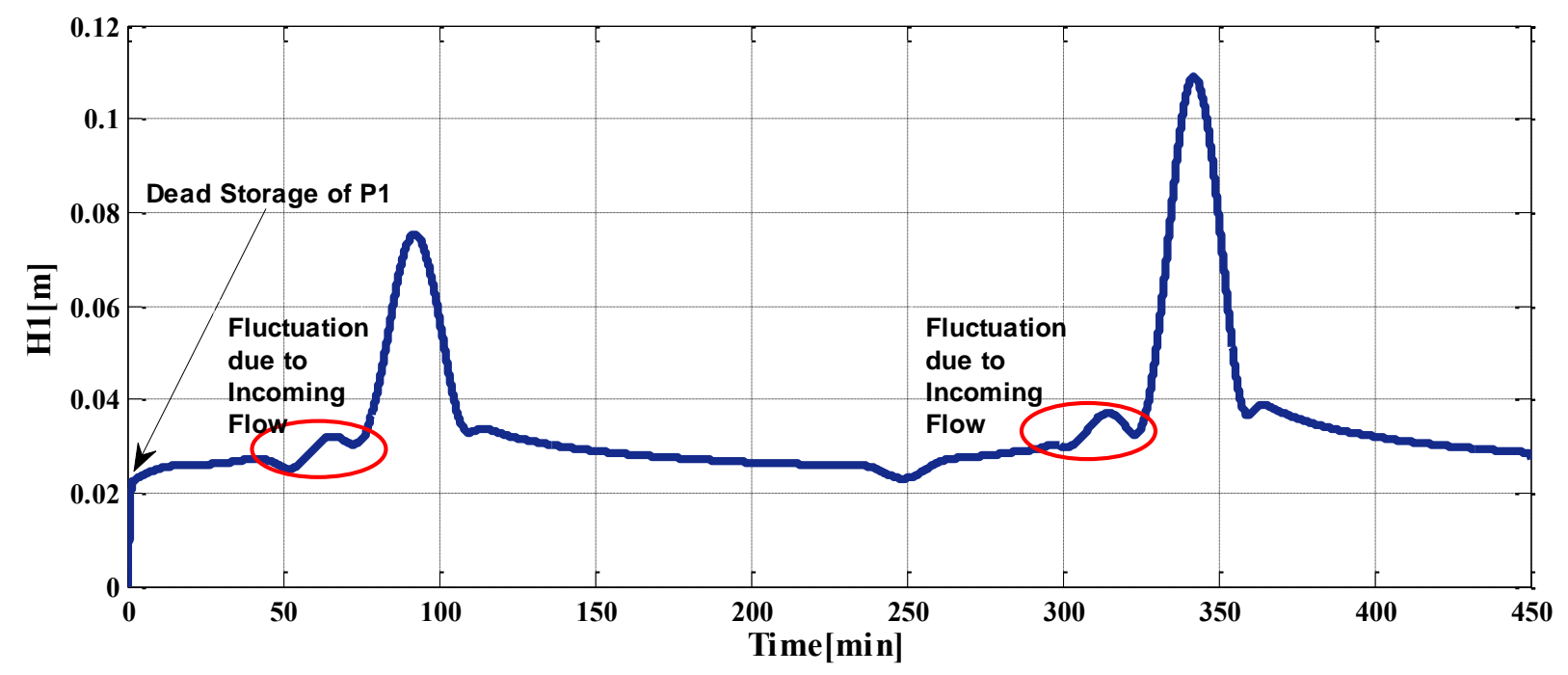

Figure 5-9 Height of the Water at Catch Basin

As shown in Figure 5-9, the water depth increases right after $0.02 \mathrm{~m}$. The change in water depth in the catch basin follows the same pattern as the intensity of the rainfall. However, the amount of water entering the catch basin is less than the amount of rainfall because of other factors such as hydrologic losses and inlet grate efficiency. After water has reached the invert elevation of the orifices at the distribution pipe, there is an outflow from the orifices along the pipe. The amount of outflow depends on the different characterises and physical properties of the orifices and pipe. The number of ring of orifices along the pipe is fixed at 60 in these simulations $(0.1 \mathrm{~m}$ distance between each ring). In addition, the number of orifices in each ring is also fixed at eight (four orifices at each side of the pipe). Therefore, 60 sections of orifices are implemented along the pipe and their outflow is illustrated in Figure 5-10. 


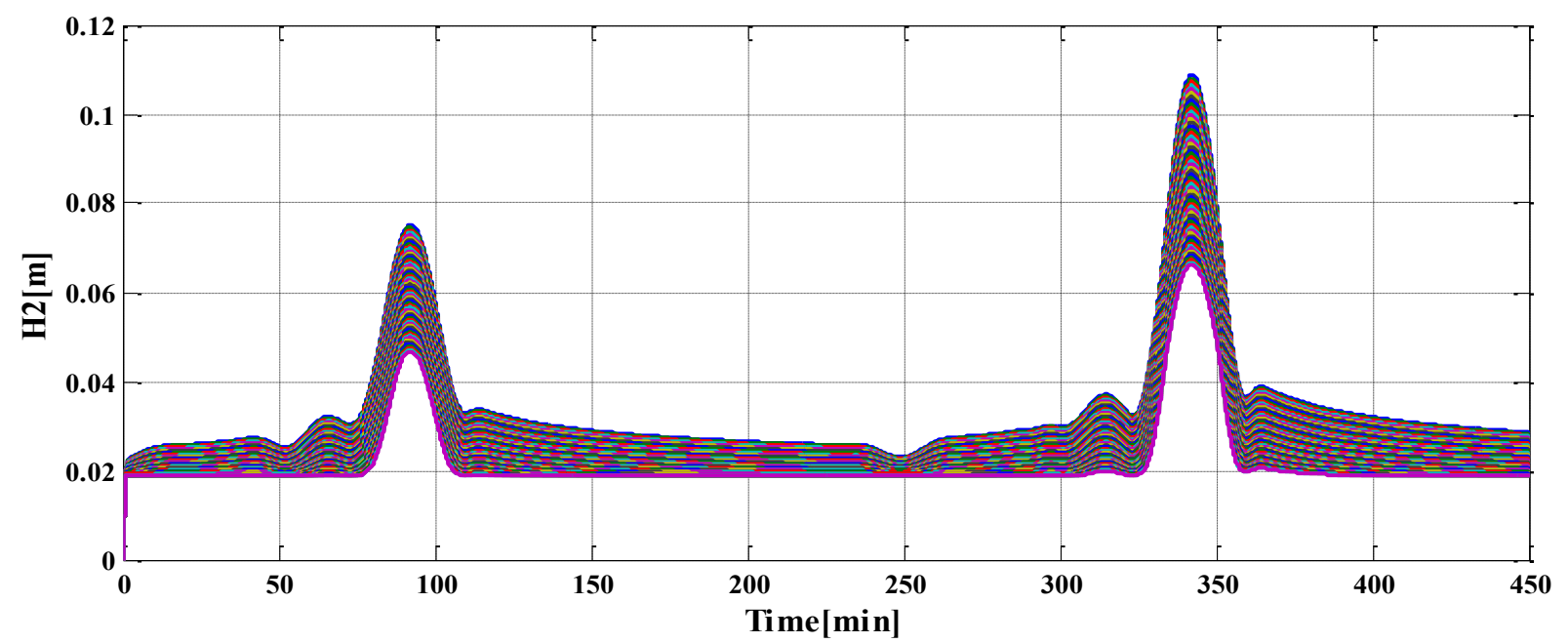

Figure 5-10 Height of Water in P1 for two Design Storms of 2 yrs and 10 yrs

Each curve with different color in Figure 5-10 represents one ring of orifices along the pipe. Each curve is shown by different color. The first curve from bottom of the graph is showing the depth of the water at the first ring of orifices and the last curve is showing the depth of the water at the last ring of orifices. It can be seen that, the height of the water for all 60 sections starts at $0.02 \mathrm{~m}$ and follows the same pattern as the incoming flow.

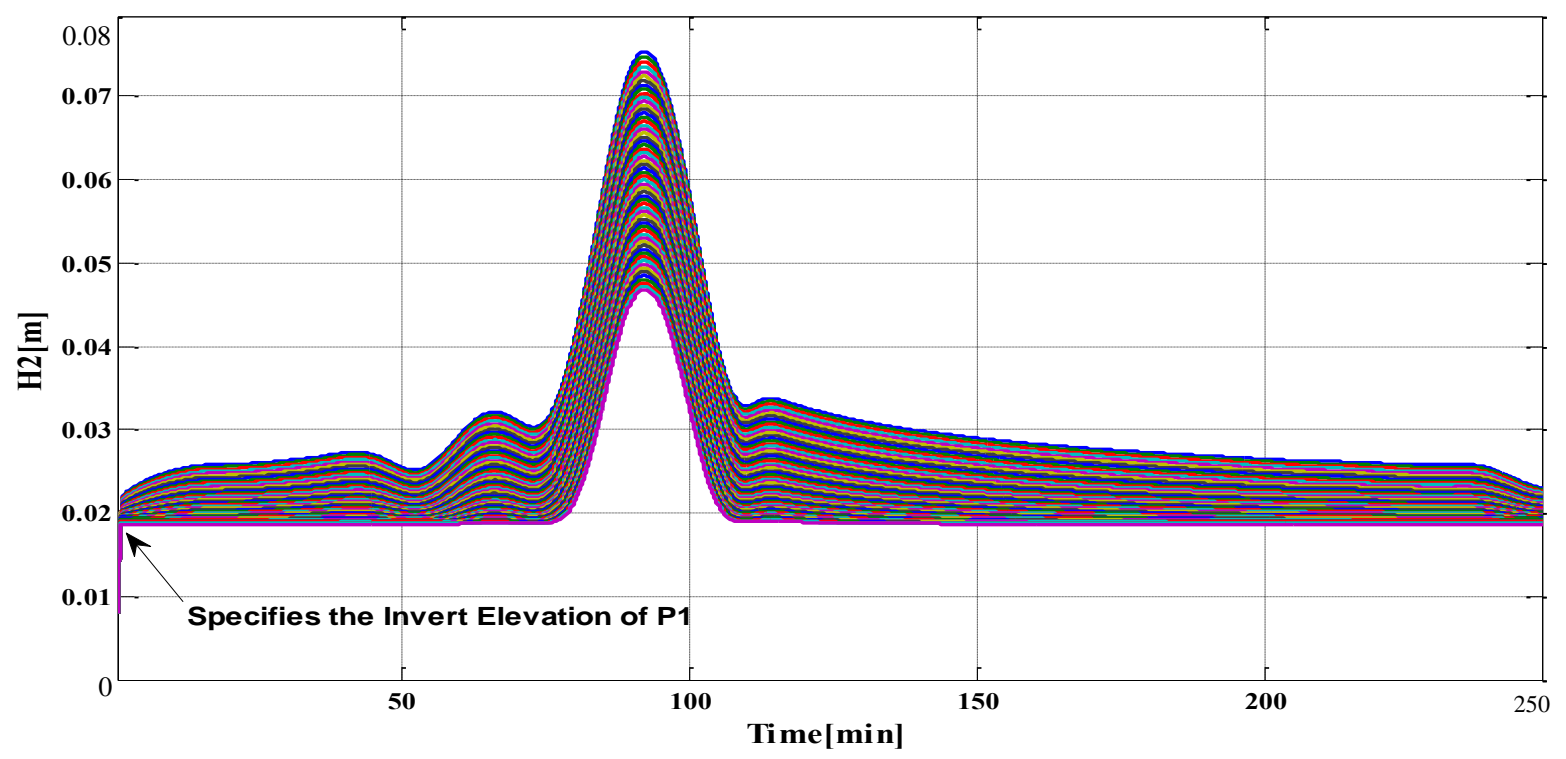

Figure 5-11 Height of Water in P1 for two Continuous Design Storms 
Figure 5-11, shows the depth of water at each ring of orifices for a 2 years Chicago design storm. The fluctuation and peak of the height of water in P1 correspond to fitted rainfall data in Figure 5-8. It can also be determined from Figure 5-11 that the progress of falling water height is following the same pattern for each ring of orifices. The more detail and zoomed figure to illustrate these 60 graphs will be shown in Figure 5-12. In this graph the height of water reaches $0.02 \mathrm{~m}$ which is the invert elevation of first orifice in distribution pipe.

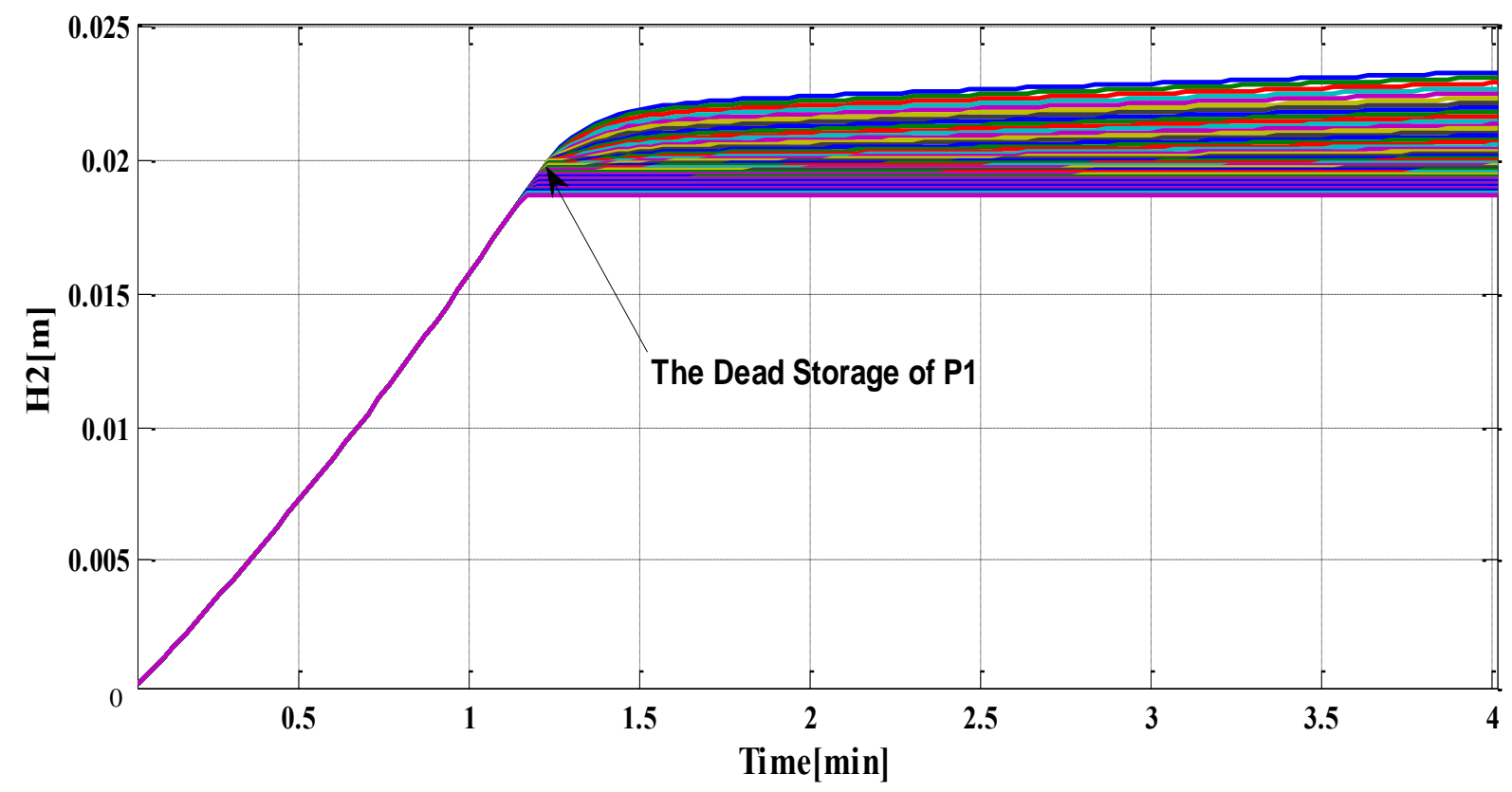

Figure 5-12 Each Ring of Orifice Representation

The outflow from each ring of orifices along the pipe length at each time steps is shown in Figure 5-13. 


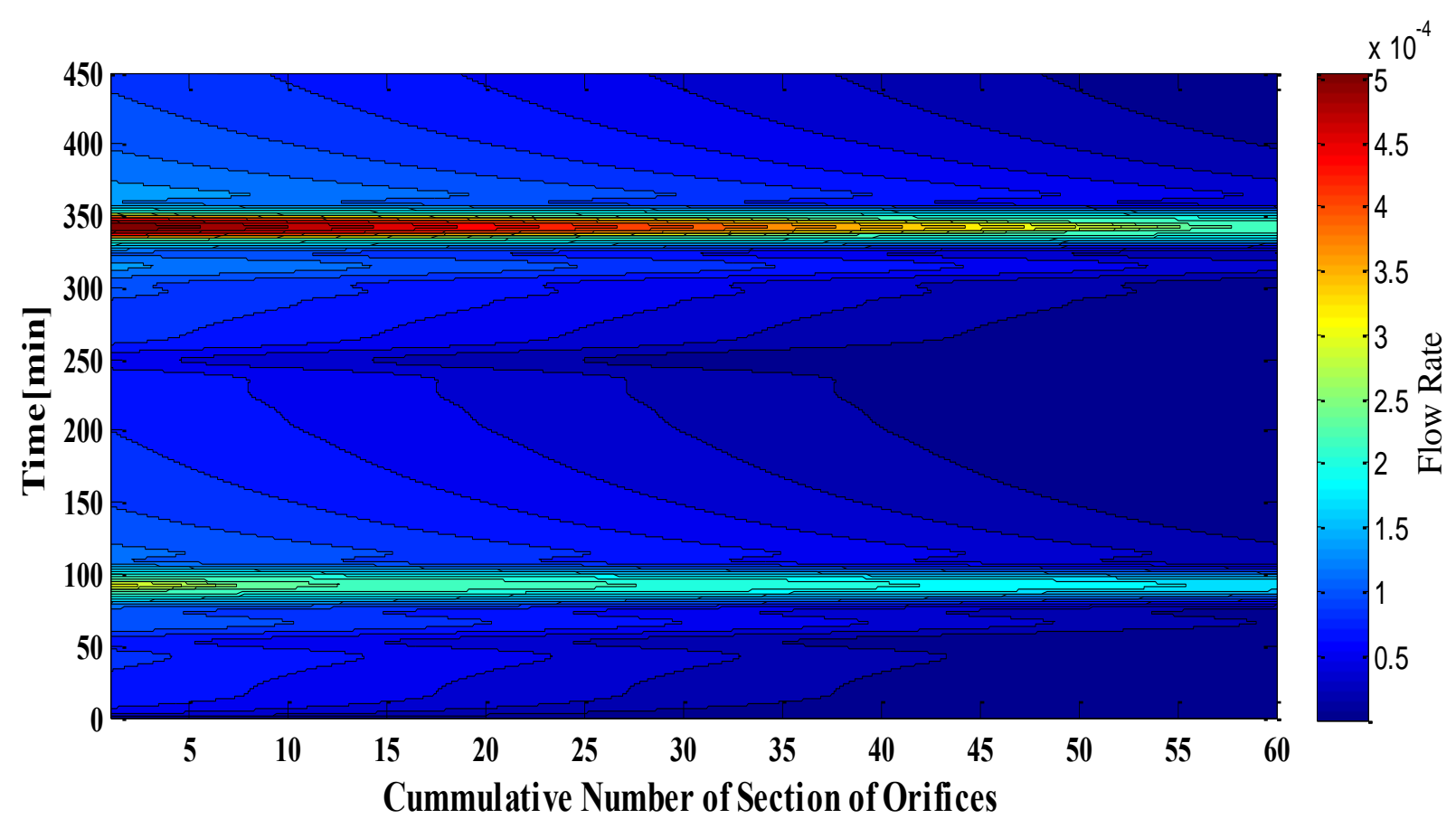

Figure 5-13 Outflow of Each Ring of Orifices along the Pipe

These contour lines with different color will show the outflow of each ring of orifices versus time. According to the legend of the figures, red part of the contour line means more outflow coming out of the orifices $\left(\mathrm{m}^{3} / \mathrm{s}\right)$ and lines will be fading down until blue color, which represent smaller outflow of the orifices. By having evenly distributed orifices and same size of orifices along the pipe, the height of the water at P1 with Chicago design storm for 2-year return periods is still not satisfactory. The desired contour line theme that is expected for these simulations is blue-red-blue from the beginning to the end of the pipe, respectively. This means that distribution pipe exfiltrate more water at the middle section of the pipe in order to use majority of the pipe length and prevent any backwater in the distribution pipe. Figure 5-14 is focused for one of the design storm such as the one with 2-years return period and the results can be illustrated as below. 


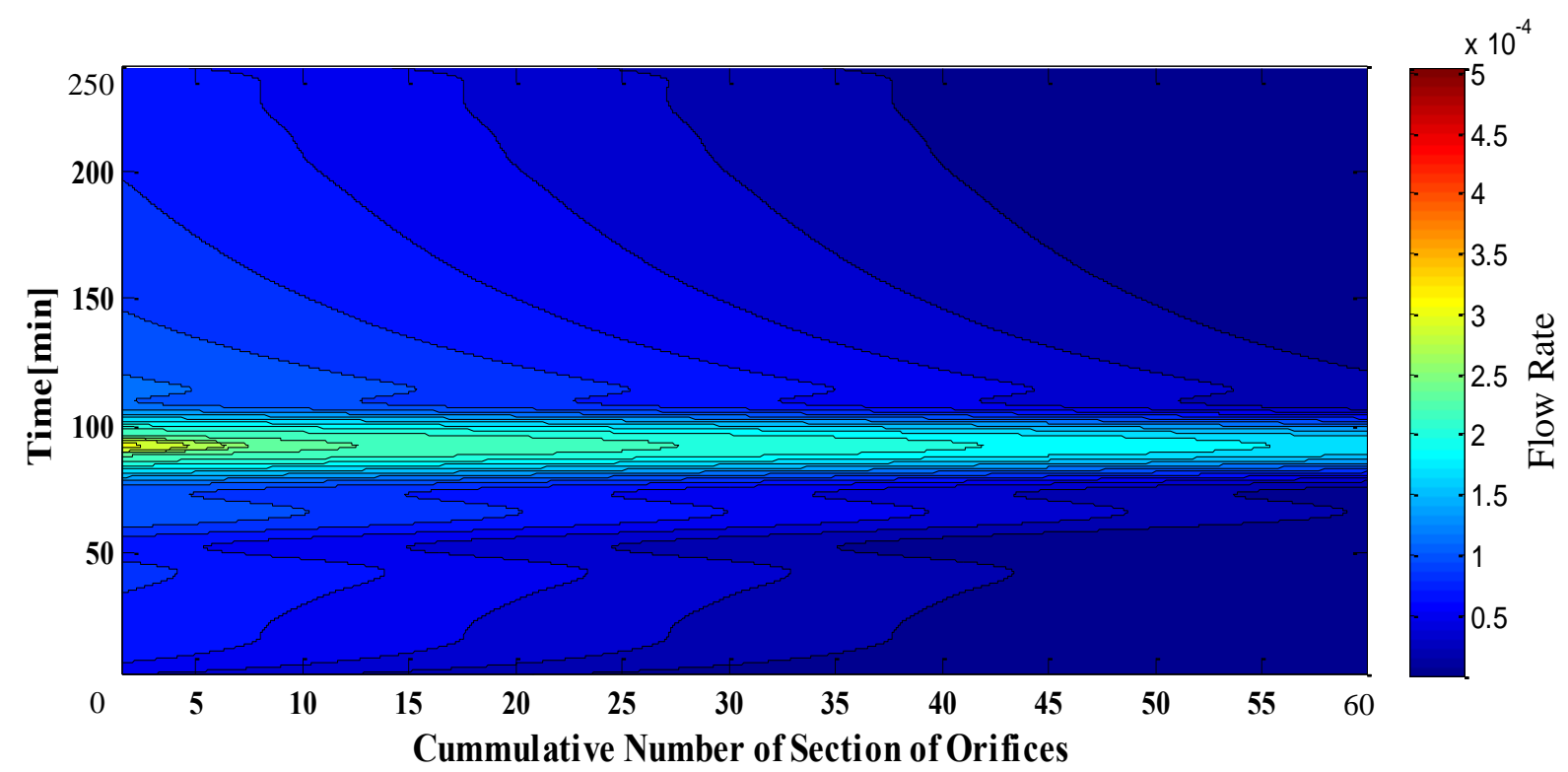

Figure 5-14 Outflow of Pipe for Chicago Design Storm of 2-yrs Return Period

Only the first 10 sections of the pipe exfiltrate a significant amount of water compared to downstream sections. At the peak of hydrograph, the upstream part of the pipe will exfiltrate more water compared to other sections.

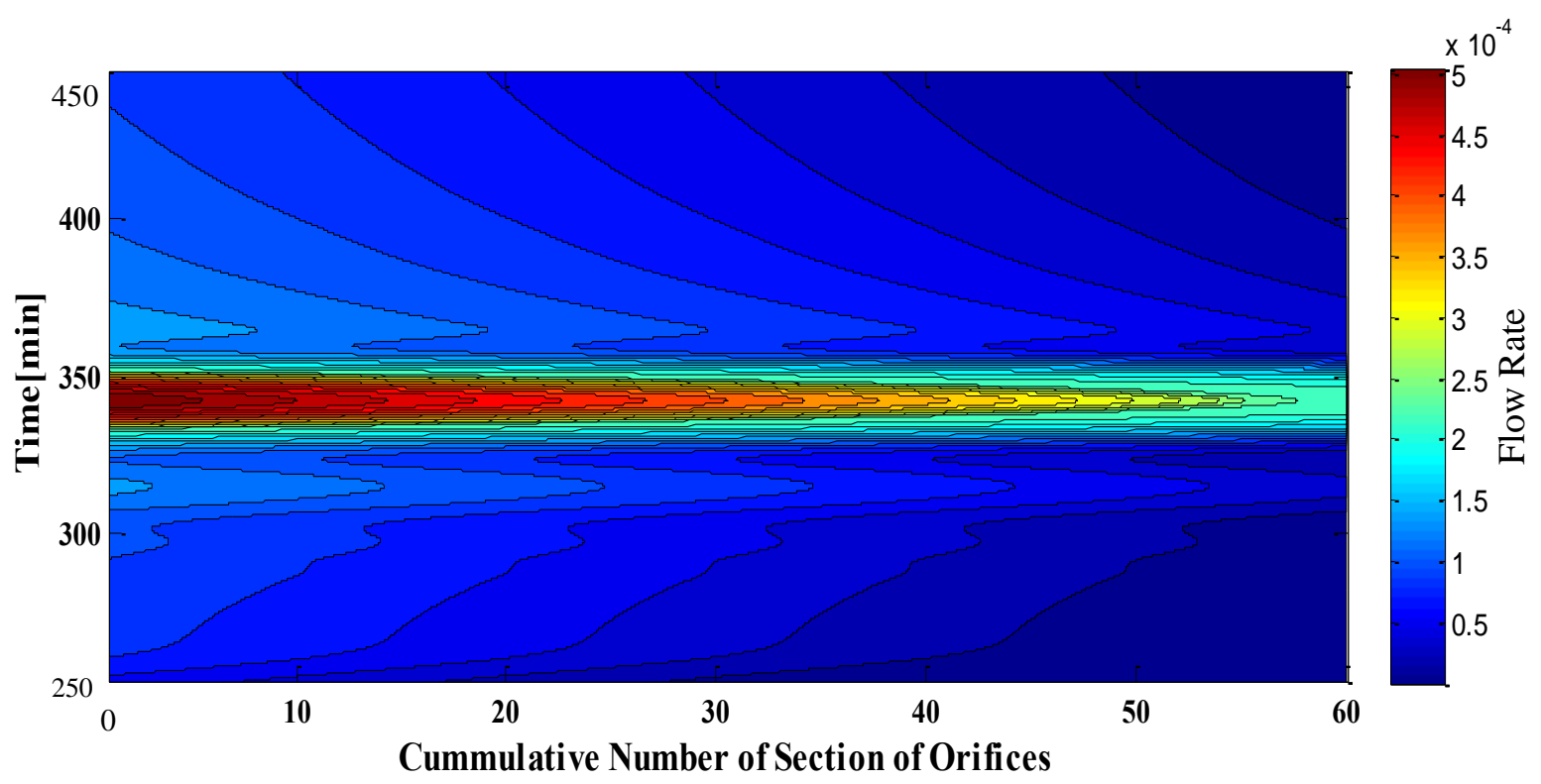

Figure 5-15 Outflow of Pipe for Chicago Design Storm of 10-yrs Return Period 
Figure 5-15 shows the results for a 10-year Chicago design storm. By comparing the outflow of distribution pipe at each section for 2-year and 10-year storms, it can be concluded that the more outflow of the distribution pipe for 10-year storm is along the length of the pipe than that of 2-year storm due to more inflow to the system. However, the distribution of water in the upper distribution pipe pattern would be in the similar pattern for each design storm.

The water exiting form the distribution pipe will enter the bioretention cell, which is the soil cell. After filling up the dead storage of the soil, the height of the water escalate in the soil. As soon as it reaches the invert elevation of orifice on the flow control pipe, it will flow inside of P2. The invert elevation of the lowest orifices of $\mathrm{P} 2$ is also assumed same as that of the distribution pipe. Therefore, the dead storage of the P2 is also at $0.02 \mathrm{~m}$. This can be seen in Figure 5-16, which shows the height of the water at the bioretention cell during the design storm.

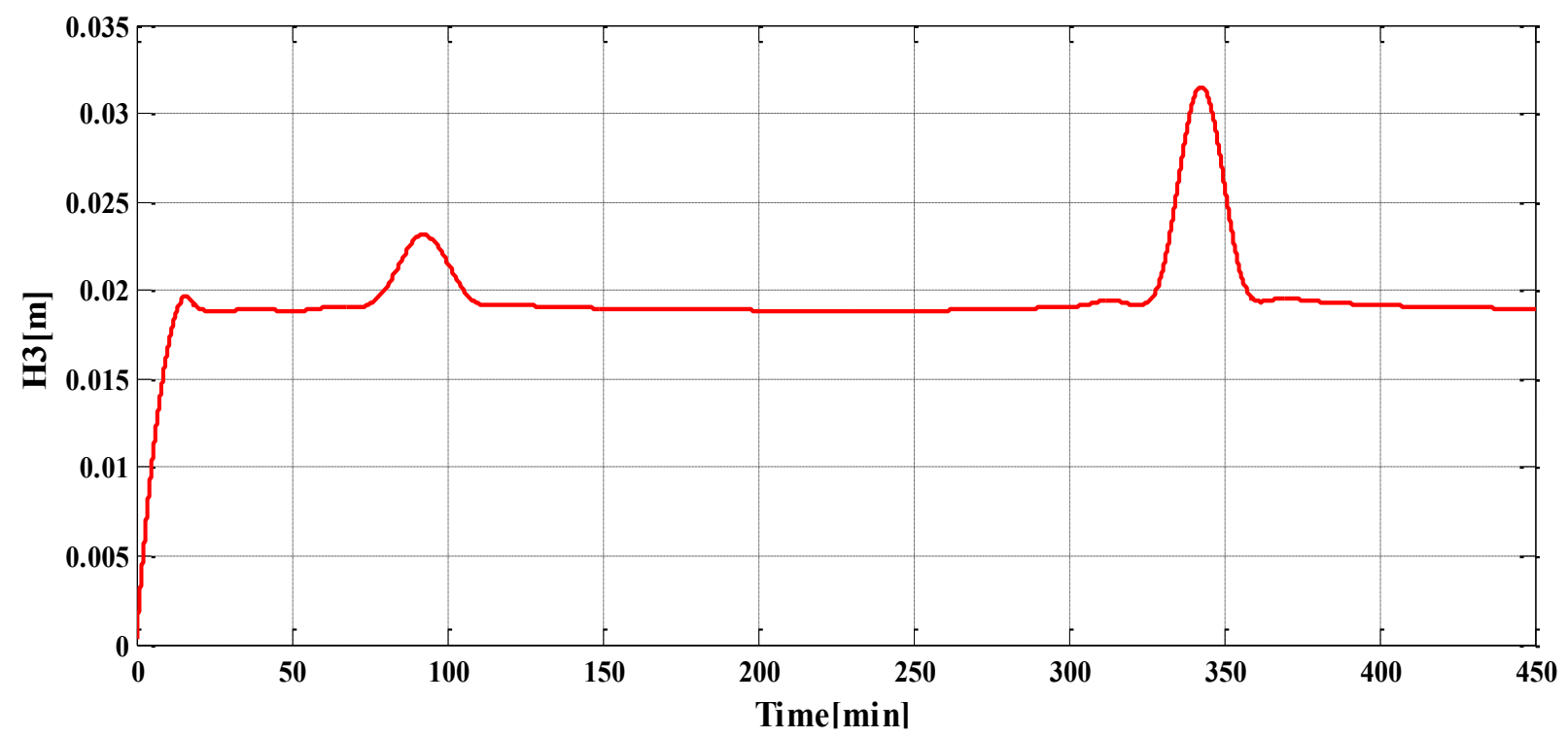

Figure 5-16 Height of Water in Bioretention Cell for two Design Storms of 2 yrs and 10 yrs

The water that reaches the invert elevation of orifices will flow inside of P2 as shown in Figure 5-17 over the 2-year and 10-year design storms. 


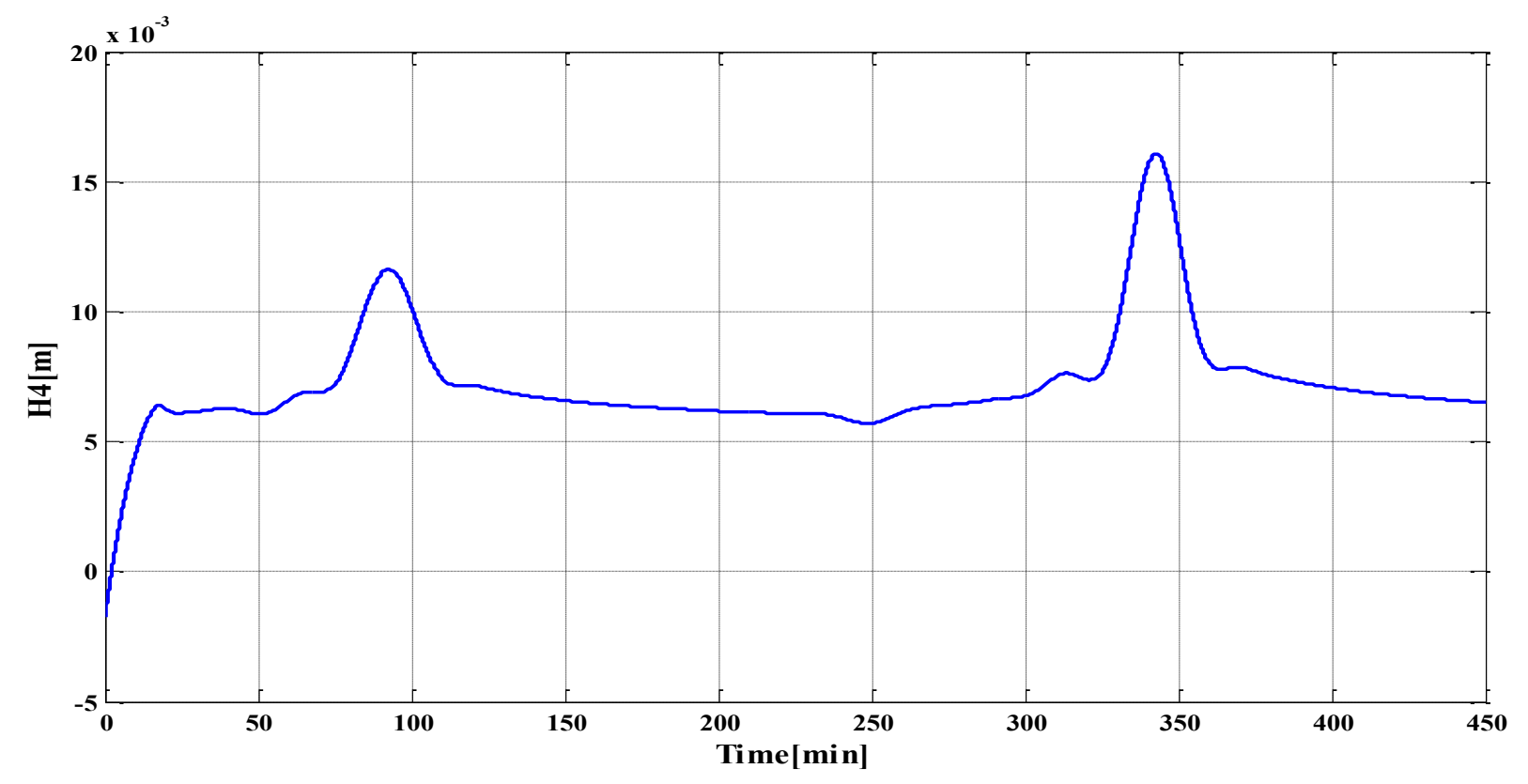

Figure 5-17 Height of Water in P2 Design Storm of 2 yrs and 10 yrs

As shown in Figure 5-17, it is clear that the height of the water at the flow control pipe starts from zero and reaches $0.005 \mathrm{~m}$. This value is smaller than the dead storage of the distribution pipe which was $0.02 \mathrm{~m}$ because of having less amount water going through the flow control pipe. Figure 5-10 and Figure 5-17 shown that the difference between the water depths at the distribution pipe and the flow control pipe. Since the percolated water from the distribution pipe will seep out of the soil cells and partially retain by soil, the water removed by the flow control pipe will be less.

\subsubsection{Case 2}

For this case, all the design parameters are the same as Case 1 except w_d_min, which is the invert elevation of orifices at the end of the distribution pipe, which mean that the same parameter values of Case 1 are used for A_Coef1, A_Coef2 for Case 2. Hence, this case focuses on the orientation of the orifices along the pipe by changing the elevation of the orifices from $\frac{D_{p 1}}{8}$ to $\frac{3 D_{p 1}}{8}$. The Matlab simulation distributes the orifices between these two elevations evenly along the pipe. By having different elevation of the orifices, the dead storage at the beginning and end of the pipe are changed. In another words, the orientation of the orifices is altered. In this case, any excess water entering the system is expected to exfiltrate from the lower elevation orifices, which is at the 
beginning of the pipe rather than the ones in higher elevation near the end of the distribution pipe. Figure 5-18 shows the exfiltration at the beginning of the distribution pipe is higher than the end of the pipe for both design storms.

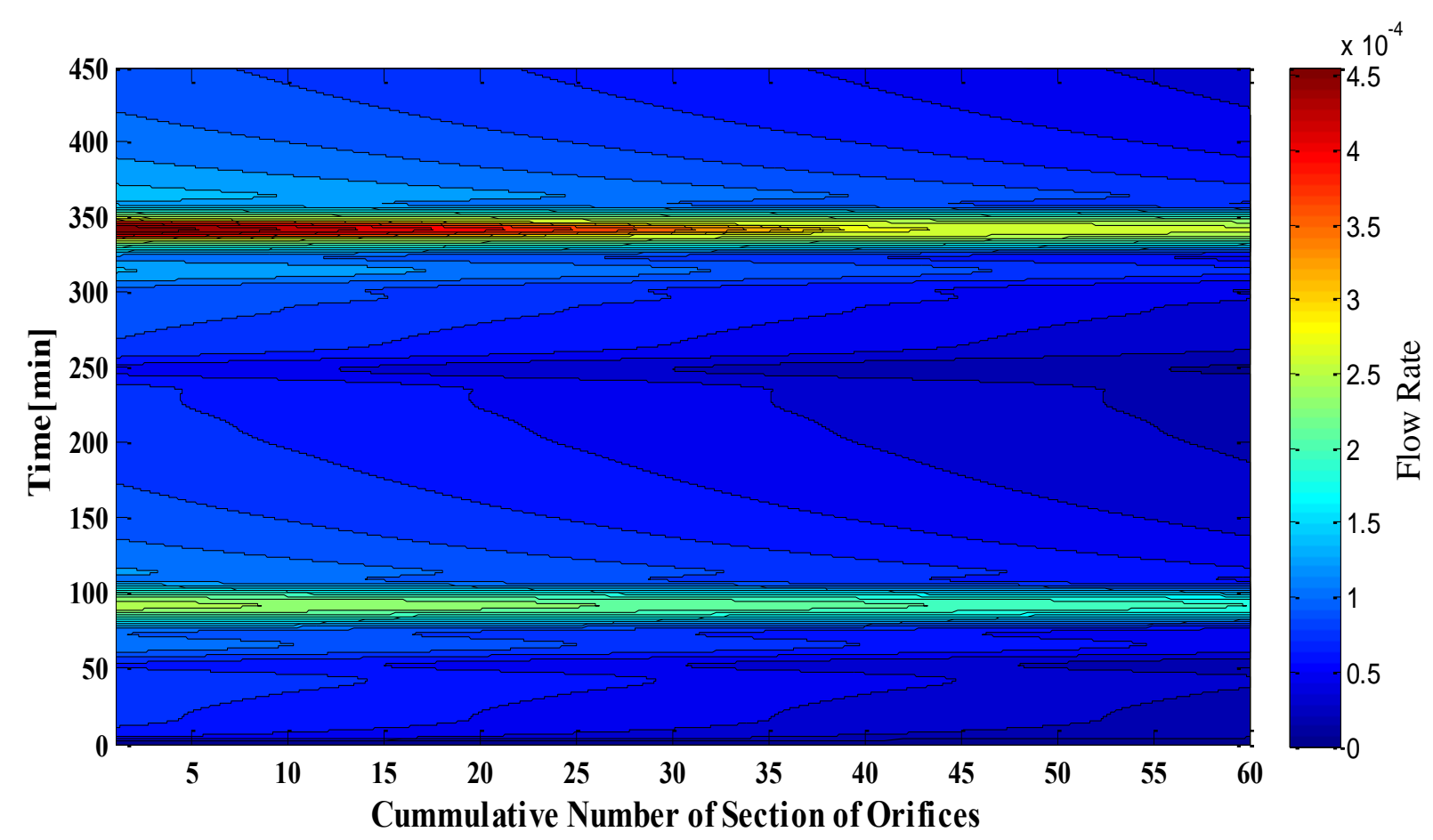

Figure 5-18 Outflow of Each Ring of Orifices along the Pipe

Figure 5-18 is showing the more detail exfiltration from distribution pipe for Chicago design storm with 2 years return period for all the 60 rings of orifices: 


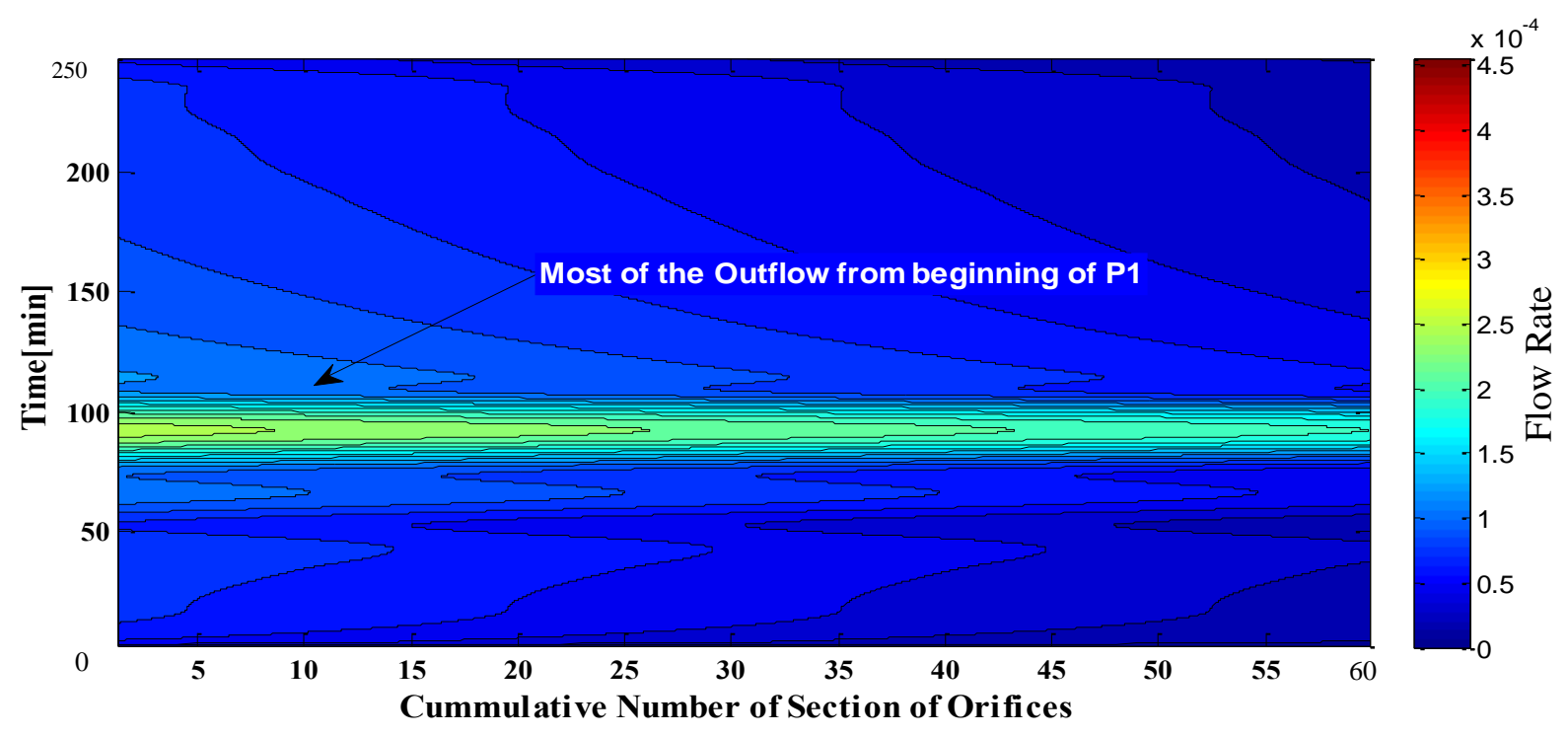

Figure 5-19 Outflow of Pipe for Chicago Design Storm of 2-yrs Return Period

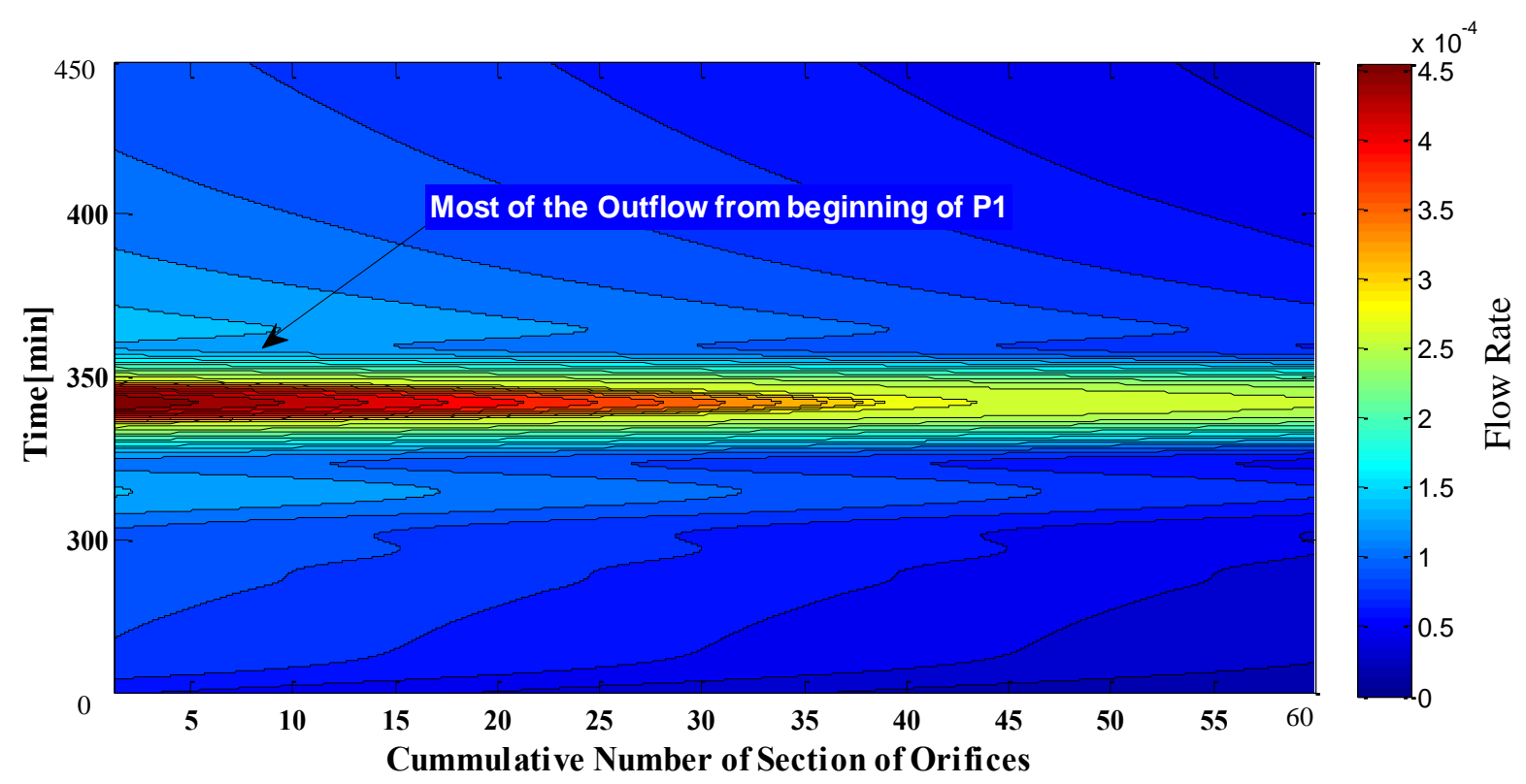

Figure 5-20 Outflow of Pipe for Chicago Design Storm of 10-yrs Return Period

By comparing Figure 5-15 and Figure 5-20, it is evident that the orifice outflow at the beginning of the distribution pipe in Case 2 is larger than that in Case 1 for a 10 -yr Chicago design storm. 


\subsubsection{Case 3}

For Case 3, the only parameter that changes is w_d_max, which is the invert elevation of orifices at the beginning of the distribution pipe. All other parameters would be similar to Case 1 . Changing w_d_max to $\frac{3 D_{p 1}}{8}$ will increase the invert elevation of orifices at the beginning compare to the end of the pipe, which is with invert elevation of $\frac{D_{p 1}}{8}$. This means that any additional water entering the system at the peak of the hydrograph, will be exiting at the end of pipe, which has the lower elevation than the beginning of the pipe.

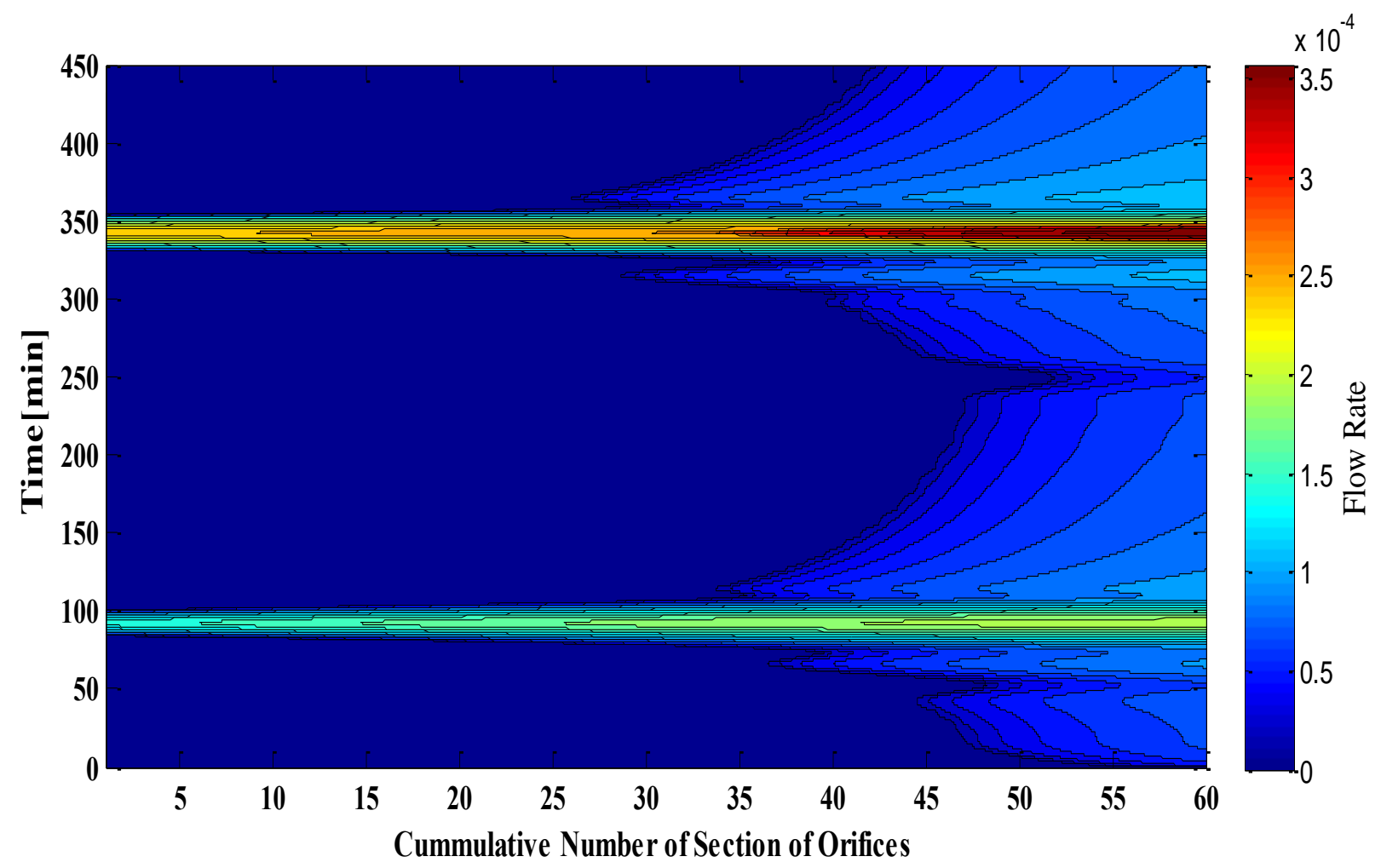

Figure 5-21 Outflow of Each Ring of Orifices along the Pipe

Figure 5-21 is showing the outflow from all the orifices along the pipe for two consecutive design storms. In this situation, there will be a chance of unintended backwater to the distribution pipe in real life situation because of not having appropriate orifices size along the pipe to exfiltrate the water fast enough near the beginning of the pipe. However, that would not be a case in this simulation. 


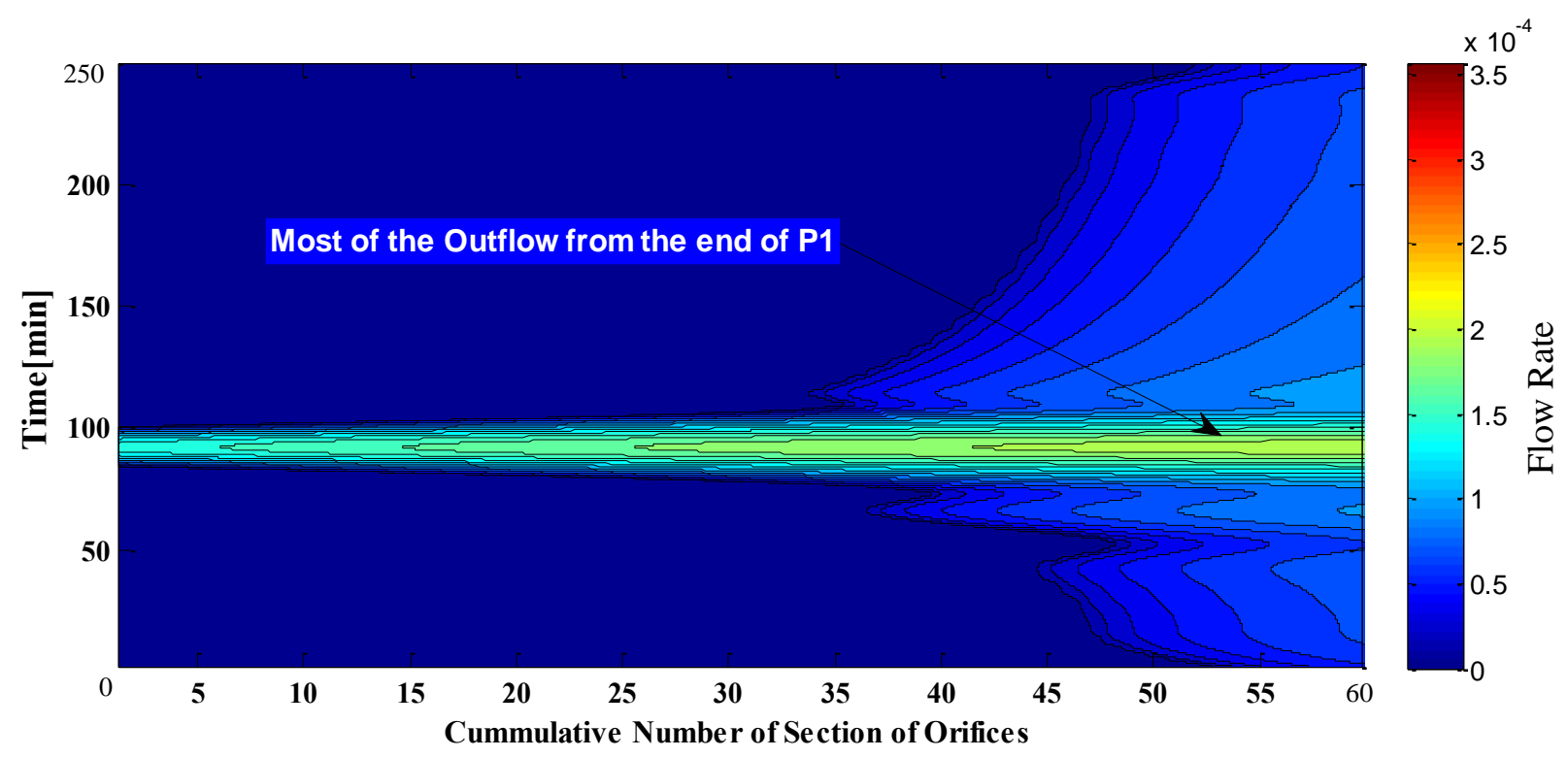

Figure 5-22 Outflow of Pipe for Chicago Design Storm of 2-yrs Return Period

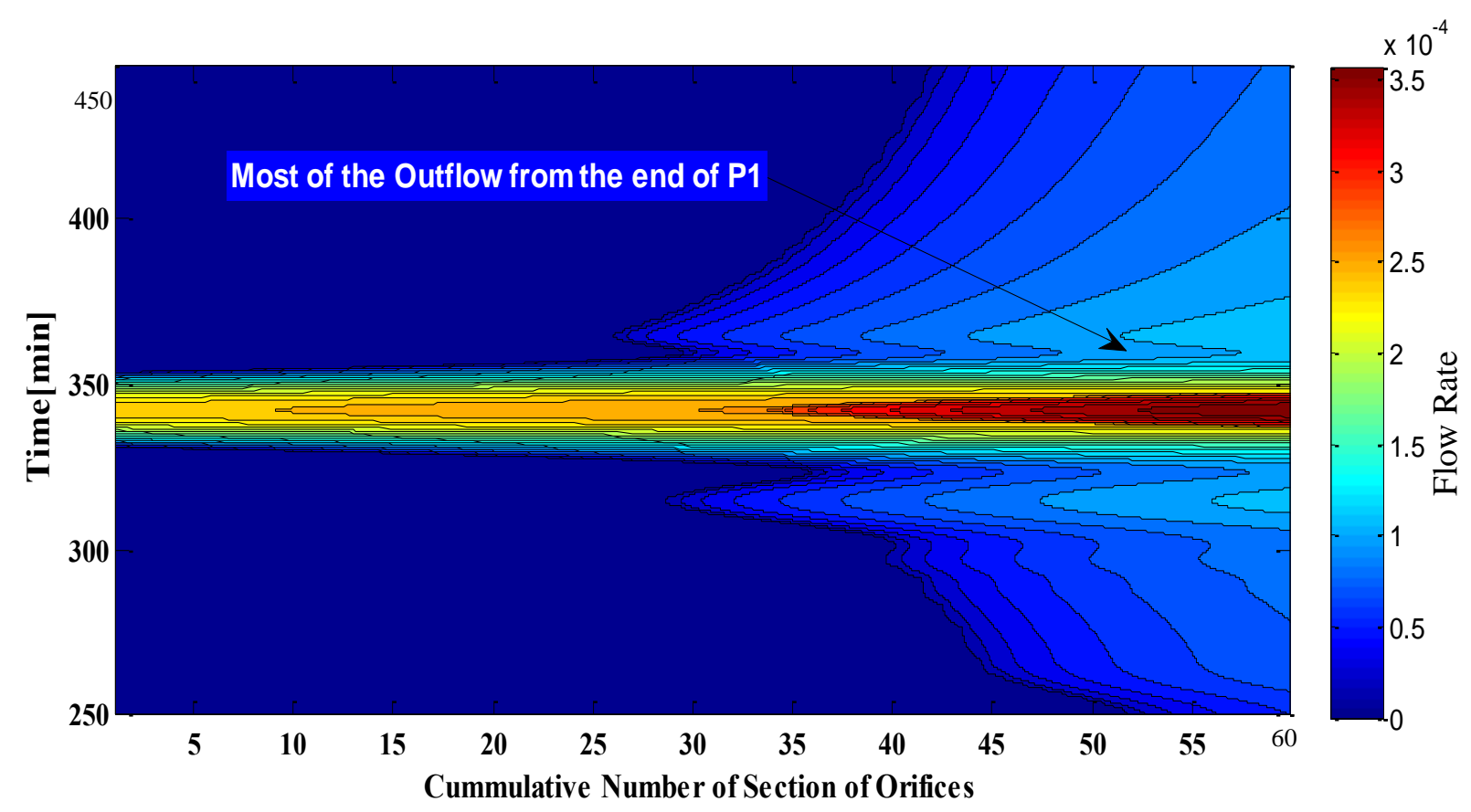

Figure 5-23 Outflow of Pipe for Chicago Design Storm of 10-yrs Return Period

Figure 5-22 and Figure 5-23 shows the outflow of P1 for the 2-year and 10-year Chicago design storms. Most of the water exits near the end of the pipe due to lower orifice invert elevation. By comparing these results with Case 1, it is noted that changing the orientation of the orifices has significant impacts on the delivery of rainfall to the bioretention cell. 


\subsubsection{Case 4}

For this case, the diameter of the pipe is $0.15 \mathrm{~m}$ and w_d_min and w_d_max have the same value as those of Case 1.Only A_Coef1 is changed and analysed.

By increasing the value of A_Coef1, the area of all the perforations along the length of the pipe is increased. As shown in Figure 5-24, the water drains faster at the beginning of the distribution pipe due to larger perforations for the 2-yr and 10-yr Chicago design storms.

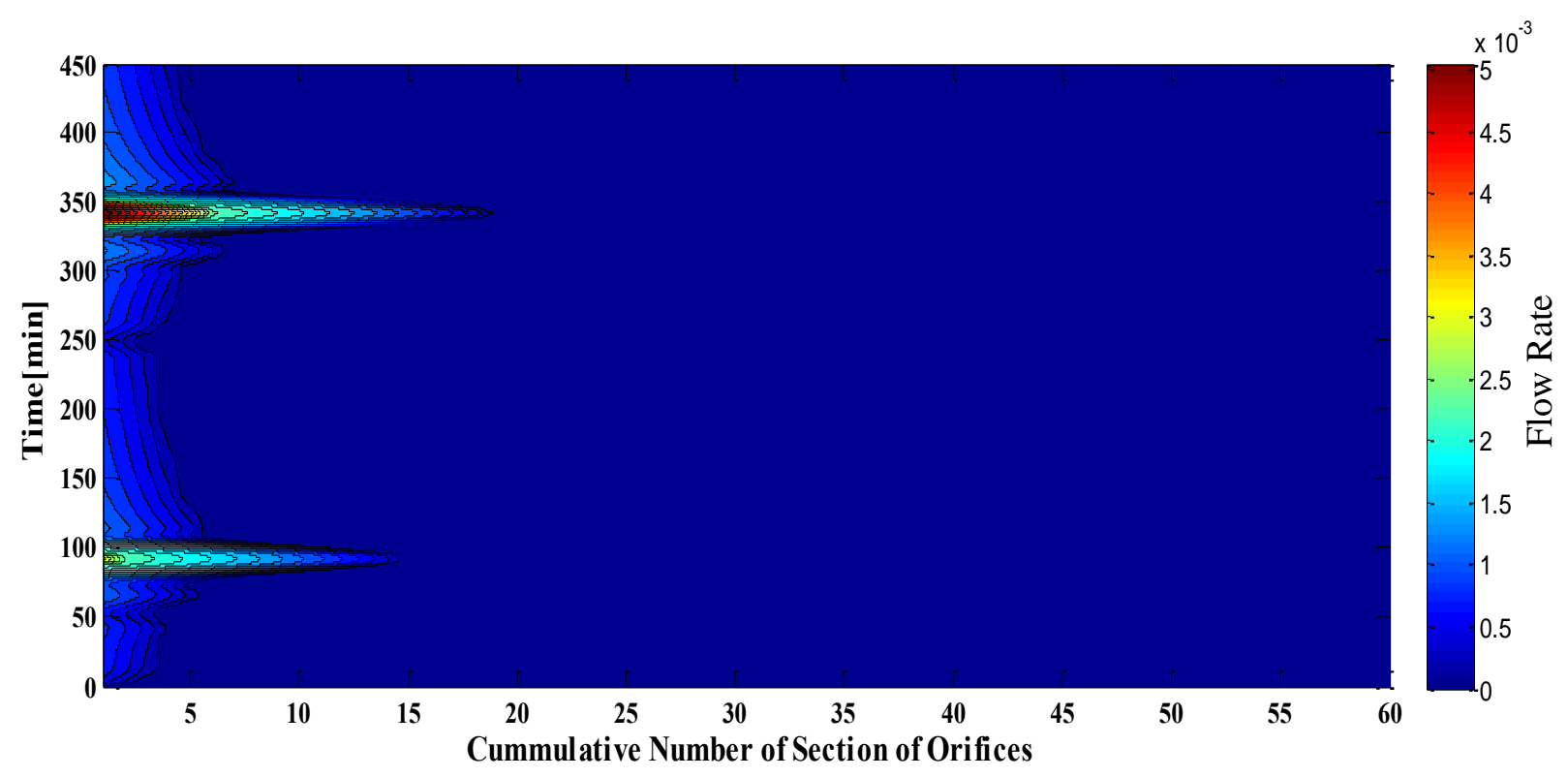

Figure 5-24 Outflow of Each Ring of Orifices along the Pipe

As shown in Figure 5-25 and Figure 5-26, the captured runoff is not evenly distributed in P1 because of the large diameter of orifices along the pipe. Even with larger amount of runoff of the 10 -yrs storm, the water hardly reaches 20 rings of orifices, resulting in the inefficiency of the system. This situation may be to the scenario that occurs at the Queensway Ave. project. That system had an overdesigned length of the pipe as well as an arbitrary diameter of the orifices resulting in the short-circuiting of the water to flow control pipe of the underground bioretention cells. 


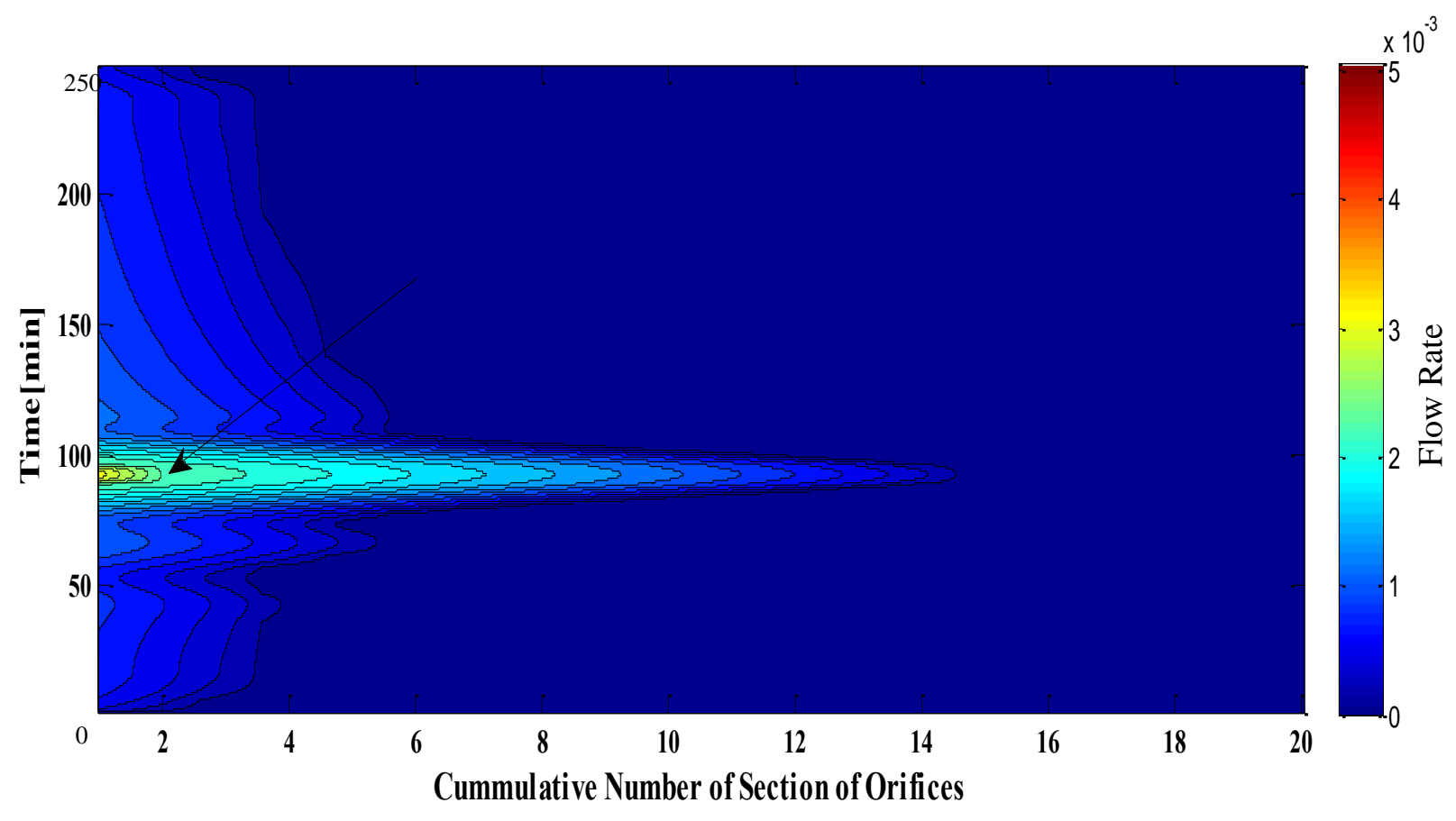

Figure 5-25 Outflow of Pipe for Chicago Design Storm of 2-yrs Return Period

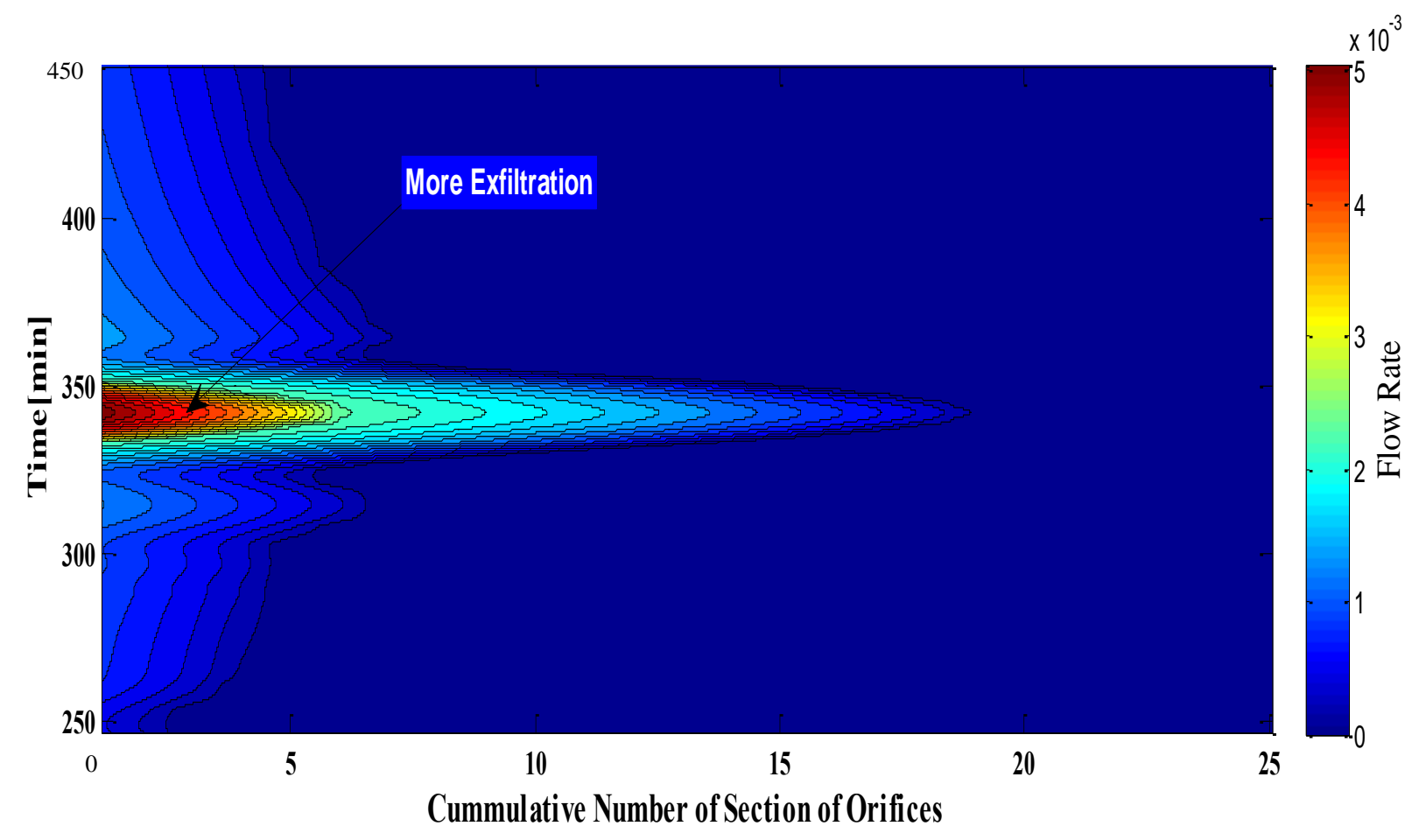

Figure 5-26 Outflow of Pipe for Chicago Design Storm of 10-yrs Return Period 


\subsubsection{Case 5}

In this simulation, the only parameter that is changed is A_Coef2. This parameter is a factor that changes the area of orifices along the pipe and is different from A_Coef1. A_Coef1 is the size of orifices along the pipe. This parameter increases the area of orifices by its value depending on the location of the ring of orifices. For this set-up, A_Coef2 is assumed $0.00002 \mathrm{~m}$. All other parameters would be similar to those of Case 1 .

After simulating this scenario, the outflow from each ring of orifices for both 2 and 10 years design storms is shown in Figure 5-27.

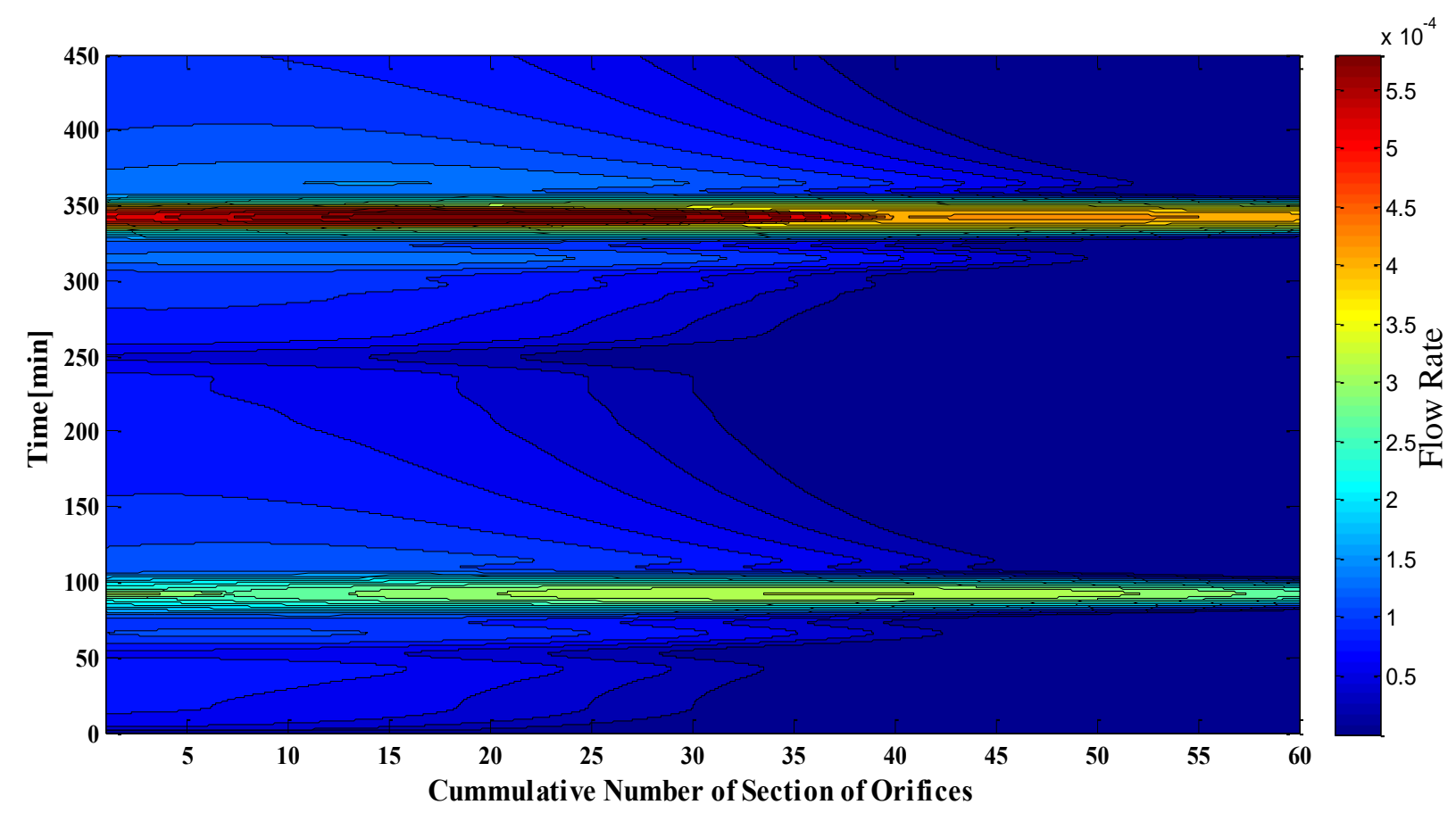

Figure 5-27 Outflow of Each Ring of Orifices along the Pipe

Figure 5-27 shows that the amount of water exiting from all rings of orifices. The increasing outflow along the pipe is expected because of the orifice's size increases along the pipe.

By looking at the color theme, it is noticed that the exfiltration increases significantly for both design storms. For the 10-yr storm, the distribution of the captured runoff along the distribution pipe is not desired theme. By increasing the area of orifices as well as the number of ring of orifices along the pipe (e.g. changing the d_s parameter, the distance between each ring of orifices), the 
captured runoff can be distributed along the pipe without backwater effect. Figure 5-28 and Figure 5-29 are the magnified versions of Figure 5-27, which show the difference between this case and Case 1.

By comparing these four cases with case 1, the effect of changing each individual parameter is known. In order to find optimal results, the combination of these parameters should be investigated by simulations, which are recommended in future works. Matlab has Genetic Algorithm function, which can be used to find the optimal combination of parameters for distributing the rainfall throughout the distribution pipe, which is the main concern of this design.

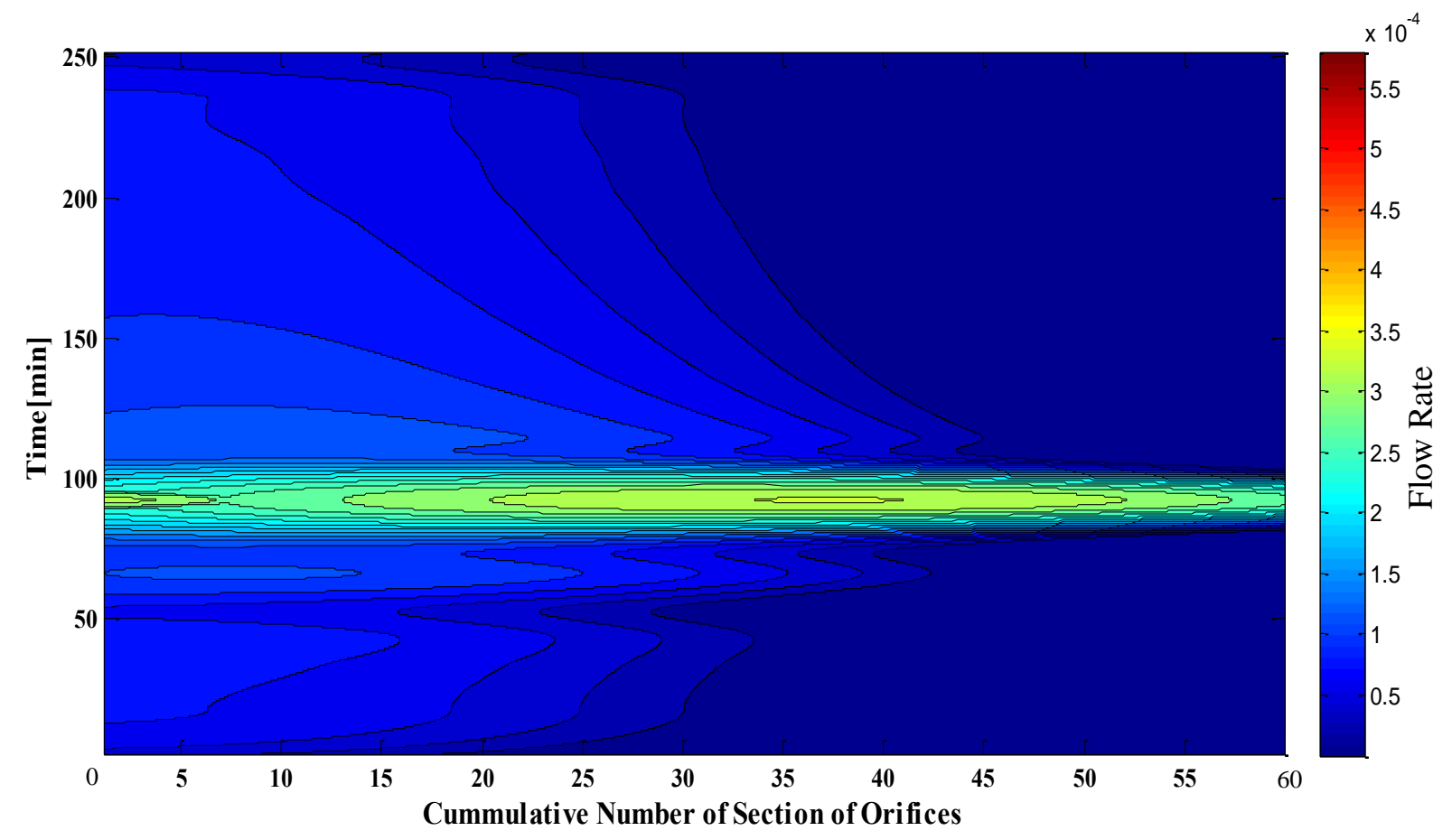

Figure 5-28 Outflow of Pipe for Chicago Design Storm of 2-yrs Return Period 


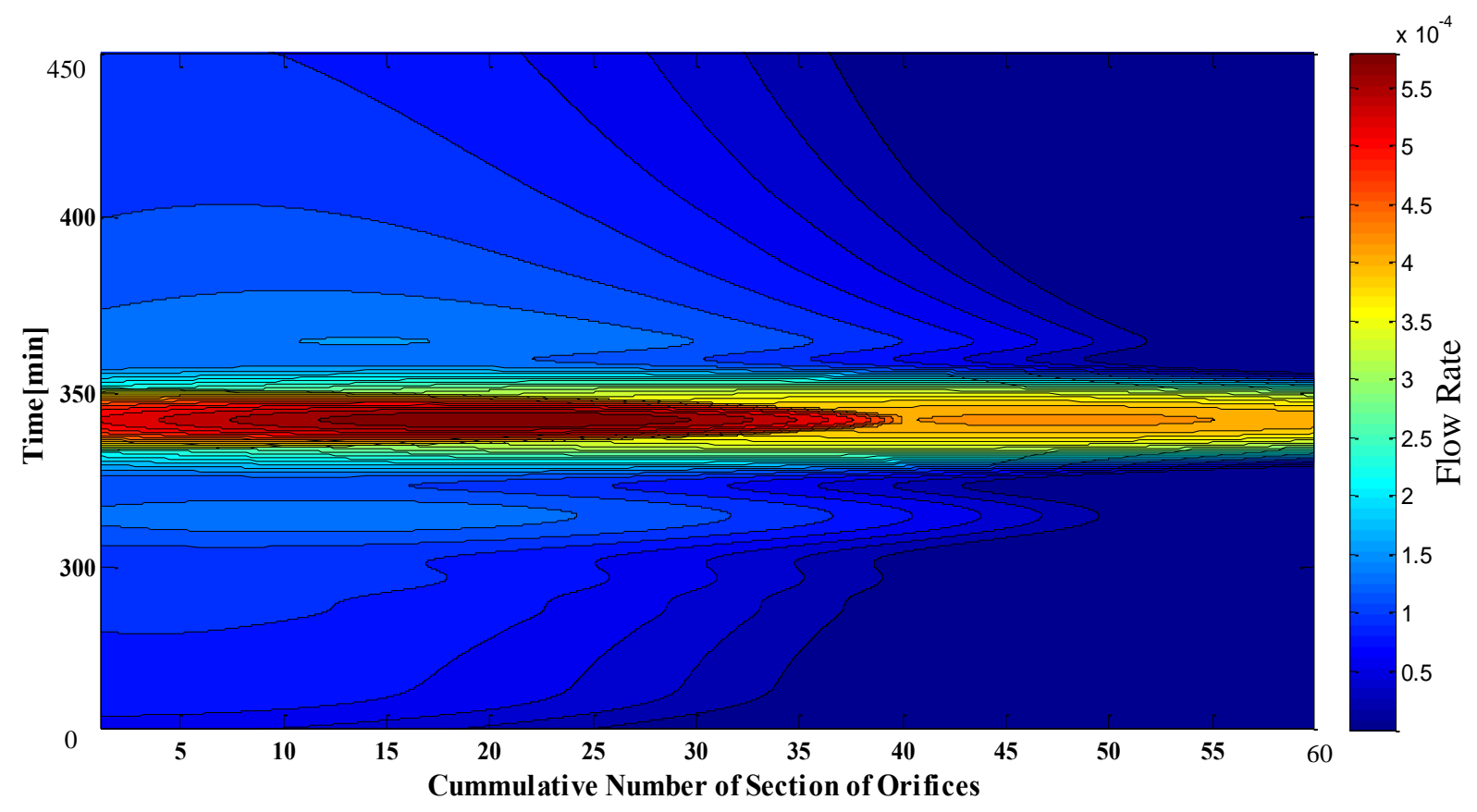

Figure 5-29 Outflow of Pipe for Chicago Design Storm of 10-yrs Return Period 


\section{Conclusions}

In order to prevent the problems caused by increased imperviousness after urbanization, LID techniques are implemented which are relatively new and not comprehensively studied. LID is an on-site design approach to preserve the pre-development hydrologic regime after implementing development in an area. Bioretention system is one of the most popular LID techniques in urban areas. Bioretention system is a water quality and quantity LID practice. A very important fact about bioretention practices is that they are unlike the traditional and conventional best management practices, which collect the volume of runoff to the end of pipe treatment facilities.

In order to understand the flow distribution of an underground bioretention system, a mathematical simulation model is developed using mass balance and hydraulic relationships. To demonstrate the model, the underground bioretention system constructed at Queensway Ave. located in the City of Toronto was used as a case study to investigate the effect of changing the design parameters of the inlet (distribution) pipe. Using this mathematical model, the flow of water in each section of the bioretention system is evaluated. An inefficient performance of the existing design is due to an over design distribution pipe and perforation orientation as well as their sizes. These parameters are selected as design variables in the case study. Therefore, one of the objectives of this study was to model the flow of captured runoff in the underground bioretention system using the mass balance equations and hydraulic relationships.

The mathematical simulation model of underground bioretention systems was developed in Matlab. A number of scenarios of the case study were investigated in detail. It is concluded that the distance between each ring of perforations along the distribution pipe and the size of the orifices determine the water profile and the amount of exfiltration from each ring of orifices along the flow distribution pipe.

Matlab simulation was used to develop the 2-year and 10-year Chicago design storms. These design storms were then used as inputs to the case study bioretention system. By changing each design variable in different design scenarios, it is concluded that the higher invert elevation of orifices at the beginning of the pipe forces the captured runoff to exit near the end of the pipe. This is contradictory to the case where the invert elevations of orifices at the end of the pipe are higher 
than those at the beginning of the pipe are. By changing the area of each orifice and factor changing area of orifices along the pipe, the diameter of orifices is increased along the distribution pipe, resulting in a faster outflow from the distribution pipe.

By comparing different scenario simulation results, the importance of a proper design and sizing of the pipe and perforation orientation and size can be identified. An objective function of maximizing the distribution of flow along the pipe can be used to select the optimum design of design variables such as pipe diameter, distance between rings of perforations, perforation sizes, and invert elevation of perforations. The optimal design of flow distribution pipe should ensure that the average outflows of each ring of orifices be considerably close to that of the average outflow for the entire distribution pipe.

This study contributes to design of distribution pipe, which is an important component of underground bioretention systems. Specifically, the size of the pipe as well as the size and orientation of orifices were design variables in this investigation. The sensitivity of each design variable with respect to flow distribution is compared, resulting in recommended design of bioretention system.

\subsection{Recommendations and Future works}

For further study, it would be valuable to analyze each section of bioretention system individually and then integrate them to maximize the bioretention system performance. Additionally, other parameters, which were assumed constant during this scenario analysis of the distribution pipe (e.g. number of orifices, number of ring of orifices) can be optimized too. Genetic Algorithm is a method of solving optimization problems and can be used to solve this kind of problem using a natural selection process, which is happening in real life such as impersonating biological evolution by Matlab.

The objective function of the Genetic Algorithm for this optimizing the characteristics of the distribution pipe can be defined as follows by assuming the $\mathrm{i}^{\text {th }}$ ring of orifices:

$$
J_{i}=\left|\left(q_{\text {total }}^{2}\right)-\left(q_{\text {ring }}^{2}\right)\right|^{\frac{1}{2}}
$$


where $\mathbf{J}$ is the objective function for the genetic algorithm, $\mathrm{q}_{\text {total }}$ is the weighted average outflow of all the orifices along the pipe, qring is the weighted average outflow of orifices in a ring of orifices. Note that the weight is added to qring by multiplying the outflow by the time that the outflow is obtained. By having more than one ring of orifices, equation 6-1 can be rewritten as follows:

$$
J=\sum_{i}^{60} J_{i}=\sum_{i=1}^{60}\left|\left(q_{\text {total }}^{2}\right)-\left(q_{\text {ring }}^{2}\right)\right|^{\frac{1}{2}}
$$

For instance, the final optimal solution for this study is a combination of decision variables, which give the smallest $\mathrm{J}$. This means that the purpose of the optimization is to have the average outflow of the entire distribution pipe equal to the average outflow of each ring of orifices. Obtaining this solution in real life cases is not impossible but it is hard to reach. Therefore, the value of $\mathbf{J}$ equal to zero will not have a physical meaning.

Other research works can focus on the design of soil cell and modeling the water percolation inside the soil. As mentioned before, studying the flow control pipe will be advantageous in order to maximize the capacity of the soil cell to absorb more rainfall for larger volume of incoming flow. As a final point, the optimization procedure for all parts of bioretention system including the distribution pipe can be expanded to improve the performance of the system significantly. 


\section{References}

[1] P.G. County, Bioretention Design Specifications and Criteria, 2007.

[2] Z. Uddin, Hydraulic design model of underground bioretention system : a source control measure for wet weather urban stormwater management, (2011).

[3] M. Clar, E. Laramore, H. Ryan, Rethinking Bioretention Design Concepts, 1993.

[4] U. States, Storm Water Technology Fact Sheet Bioretention, (1999).

[5] F. Kazemi, S. Beecham, J. Gibbs, Streetscale bioretention basins in Melbourne and their effect on local biodiversity, Ecol. Eng. 35 (2009) 1454-1465.

[6] L. Marritz, P. Cheung, Toronto Pioneer Underground Bioretention stormwater " proof of concept " Silva Cell installation, 2008.

[7] A. Roy-Poirier, P. Champagne, Y. Filion, Bioretention processes for phosphorus pollution control, Environ. Rev. 18 (2010) 159-173. doi:10.1139/A10-006.

[8] S. Paquette, Modelling of a Bioretention Cell Soil Moisture Regime in Southern Ontario, The University of Guelph, n.d.

[9] M.E. Dietz, Low Impact Development Practices: A Review of Current Research and Recommendations for Future Directions, Water. Air. Soil Pollut. 186 (2007) 351-363. doi:10.1007/s11270-007-9484-z.

[10] A.P. Davis, W.F. Hunt, R.G. Traver, M. Clar, Bioretention Technology: Overview of Current Practice and Future Needs, J. Environ. Eng. (n.d.) 109-117.

[11] U.S.E.P. Agency, Low Impact Development (LID) A Literature Review, Washington, DC, 2000.

[12] A.P. Davis, Green engineering principles promote low-impact development., Environ. Sci. Technol. 39 (2005) 338A-344A. doi:10.1021/es053327e.

[13] M.-S. Cheng, L.S. Coffman, M.L. Clar, Low-impact development hydrologic analysis, in: Urban Drain. Model., 2001: pp. 659-681. doi:10.1061/40583(275)63.

[14] E.S. Division, Bioretention Manual, Maryland, 2009.

[15] Environmental Planning group, Low Impact Development Best Management Practices Design Guide, Edmenton, 2011. 
[16] L.M. Ahiablame, B. a. Engel, I. Chaubey, Effectiveness of Low Impact Development Practices: Literature Review and Suggestions for Future Research, Water, Air, Soil Pollut. 223 (2012) 4253-4273. doi:10.1007/s11270-012-1189-2.

[17] A.O. Akan, R.J. Houghtalen, Urban hydrology, hydraulics, and stormwater quality: engineering applications and computer modeling, 2003.

[18] A. Roy-poirier, P. Champagne, A.M. Asce, Y. Filion, Review of Bioretention System Research and Design : Past, Present, and Future, J. Environ. Eng. (n.d.) 878-889.

[19] A.P. Davis, R.G. Traver, W.F. Hunt, R. Lee, R.A. Brown, J.M. Olszewski, Hydrologic Performance of Bioretention Storm-Water Control Measures, J. Hydrol. Eng. 17 (2012) 604-614. doi:10.1061/(ASCE)HE.1943-5584.0000467.

[20] A. Atchison, K. Potter, L. Severson, Design Guidelines for Stormwater Bioretention Facilities, Madison, 2006.

[21] University of Wisconsin, Design Manual for Stormwater Bioretention Facilities, Madison Wisconsin, 2006.

[22] J.J. Houle, R.M. Roseen, T.P. Ballestero, T.A. Puls, J. Sherrard, Comparison of Maintenance Cost, Labor Demands, and System Performance for LID and Conventional Stormwater Management, (2013) 932-938. doi:10.1061/(ASCE)EE.1943-7870.0000698.

[23] A.P. Davis, Field Performance of Bioretention: Hydrology Impacts, J. Hydrol. Eng. (n.d.) 91-92.

[24] H. Abida, J.F. Sabourin, M. Ellouze, ANSWAPPS: Model for the Analysis of Grass SwalePerforated Pipe Systems, J. Irrig. Drain. Eng. 133 (2007) 211-221. doi:10.1061/(ASCE)0733-9437(2007)133:3(211).

[25] C. Hinman, Bioretention Soil Mix Review and Recommendation for Western Washington, Washington DC., n.d.

[26] S.A. Trowsdale, R. Simcock, Urban stormwater treatment using bioretention, J. Hydrol. 397 (2011) 167-174.

[27] S.A. Brown, J.D. Schall, J.L. Morris, C.L. Doherty, S.M. Stein, J.C. Warner, Drainage Design Manual, Virginia, n.d.

[28] U. States, E. Protection, Agency, Storm Water Technology Fact Sheet Bioretention, Washington, D.C., 1999.

[29] B.M. Das, Fundamental of Geotechnical Engineering, Nelson a division of Thomson, California, 2005. 
[30] H. Manual, Hydraulic Design A., (n.d.) 111-212.

[31] K. Bratieres, T.D. Fletcher, A. Deletic, L. Alcazar, S. Le Coustumer, Removal of nutrients , heavy metals and pathogens by stormwater biofilters, 2008.

[32] T.M. Muthanna, M. Viklander, G. Blecken, S.T. Thorolfsson, Effects of Urbanization on Groundwater, Water Res. Volume 41 (2007) Pages 4061-407.

[33] W.C. Lucas, M. Greenway, Nutrient Retention in Vegetated and Nonvegetated Bioretention Mesocosms, J. Irrig. Drain. Eng. 134 (2009) 613-623.

[34] K.M. Debusk, N.R. Bouchard, M.S. Webb, W.F. Hunt, Watershed Retrofit and Management Evaluation for Urban Stormwater Management, 12nd Int. Conf. Urban Drain. (2011) 11-16.

[35] M. Randall, Bioretention Gardens for the Removal of Nitrogen and Phosphorous from Urban Runoff, Bioretention gardens are stormwater management practices that offer numerous water quantity and quality benefits. However, previous studies have reported inconsistent removal of nitrogen and phosphorous in these systems. The first phase of this research i, 2011.

[36] X. Chen, Effectiveness of a Bioretention Cell Treating Stormwater Runoff in Northeastern Kansas BY, University of Kansas, 2010.

[37] H. Li, A.P. Davis, Water Quality Improvement through Reductions of Pollutant Loads Using Bioretention, J. Environ. Eng. 135 (2009) 567-576. doi:10.1061/(ASCE)EE.19437870.0000026 .

[38] C. Hsieh, A.P. Davis, Evaluation and Optimization of Bioretention Media for Treatment of Urban Storm Water Runoff, J. Environ. Eng. 131 (2006) 1521-1531.

[39] T.M. Muthanna, M. Viklander, G. Blecken, S.T. Thorolfsson, Snowmelt pollutant removal in bioretention areas, Water Res. 41 (2007) 4061-4072.

[40] A.O. Akan, Preliminary Design Aid for Bioretention Filters, (2013) 318-323. doi:10.1061/(ASCE)HE.1943-5584.0000554.

[41] M.B. James, R.L. Dymond, Bioretention Hydrologic Performance in an Urban Stormwater Network, (2012) 431-436. doi:10.1061/(ASCE)HE.1943-5584.0000448.

[42] A. Dussailant, K. Cozetto, K. Potter, Green Ampt model of a rain garden and comparison to Richards equation model, Sustain. World. (2003) 891-900.

[43] Z. He, A.P. Davis, Process Modeling of Storm-Water Flow in a Bioretention Cell, (2011) 121-131. doi:10.1061/(ASCE)IR.1943-4774.0000166. 
[44] W. Heason, R.G. Traver, A. Welker, Hydrologic Modeling of a Bioinfiltration Best Management Practice, J. Am. Water Resour. Assoc. (n.d.) 1329-1347.

[45] E. Canada, N.I.R. Team, Environment Canada, (2013). http://climate.weather.gc.ca.

[46] M. Gómez, B. Russo, Hydraulic Efficiency of Continuous Transverse Grates for Paved Areas, J. Irrig. Drain. Eng. (n.d.) 225-230.

[47] L.W. Mays, Water Resources Engineering, 2005th ed., John Wiley \& Sons, 2005.

[48] M.R. Lindeburg, U.S. Department of the Interior Bureau of Reclamation. Water Resources Research Laboratory: Water Measurement Manual, 8th Editio, Engineer In Training Reference Manual. Professional Publication, Washington DC, 2001.

[49] T. of Ajax, Town of ajax design criteria section c stormwater management and storm drainage, n.d.

[50] R.H. Hawkins, R. Jiang, D.E. Woodward, A.T. Hjelmfelt, Runoff Curve Number Method: Examination of the Initial Abstraction Ratio, J. Am. Water Resour. Assoc. 42 (n.d.) 629643.

[51] M. Gómez, B. Russo, Comparative study among different methodologies to determine storm sewer inlet efficiency from test data ., J. Irrig. Drain. Eng. (2005) 21-26.

[52] M.A. Abdulwahid, S.F. Dakhil, N.K. Injeti, Numerical Investigation of the Turbulent Flow Parameters Distribution in a Partly Perforated Horizontal Wellbore, Eur. Sci. J. vol.9, No. (n.d.).

[53] F.E.M. Agency, Technical Manual: Plastic Pipe Used in Embankment Dams, n.d.

[54] A. Ahadi, S. Van Varenbergh, M.Z. Saghir, Measurement of the Soret coefficients for a ternary hydrocarbon mixture in low gravity environment., J. Chem. Phys. 138 (2013) 204201. doi:10.1063/1.4802984.

[55] S.R.S. Manickam, Dimensionless Design Charts for Exfiltration in Storm Sewers, n.d.

\section{Appendix A}

\section{Matlab Function for Numerical Analysis}


In this section, the Matlab functions used to model the flow of water in different portions of the bioretention system.

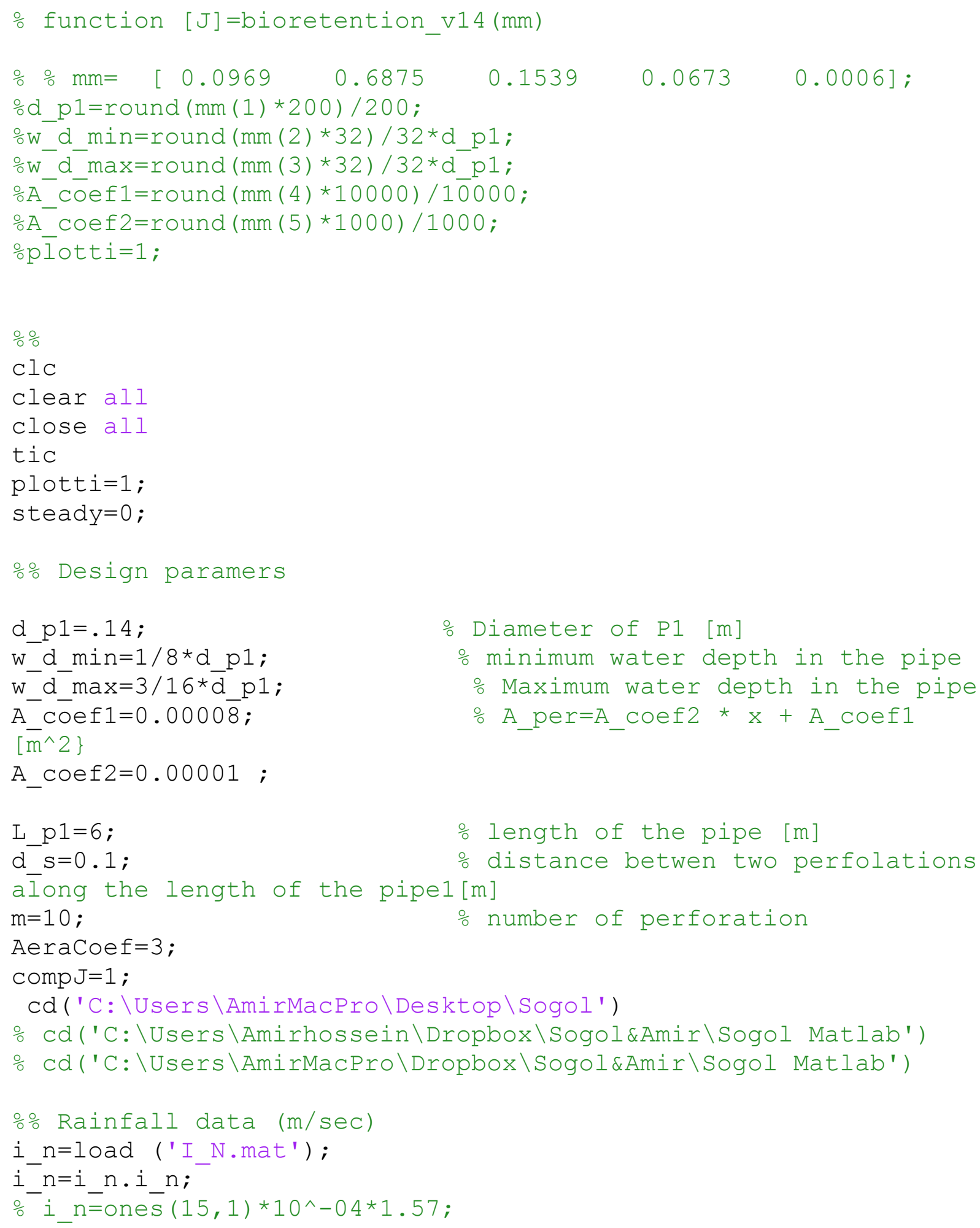




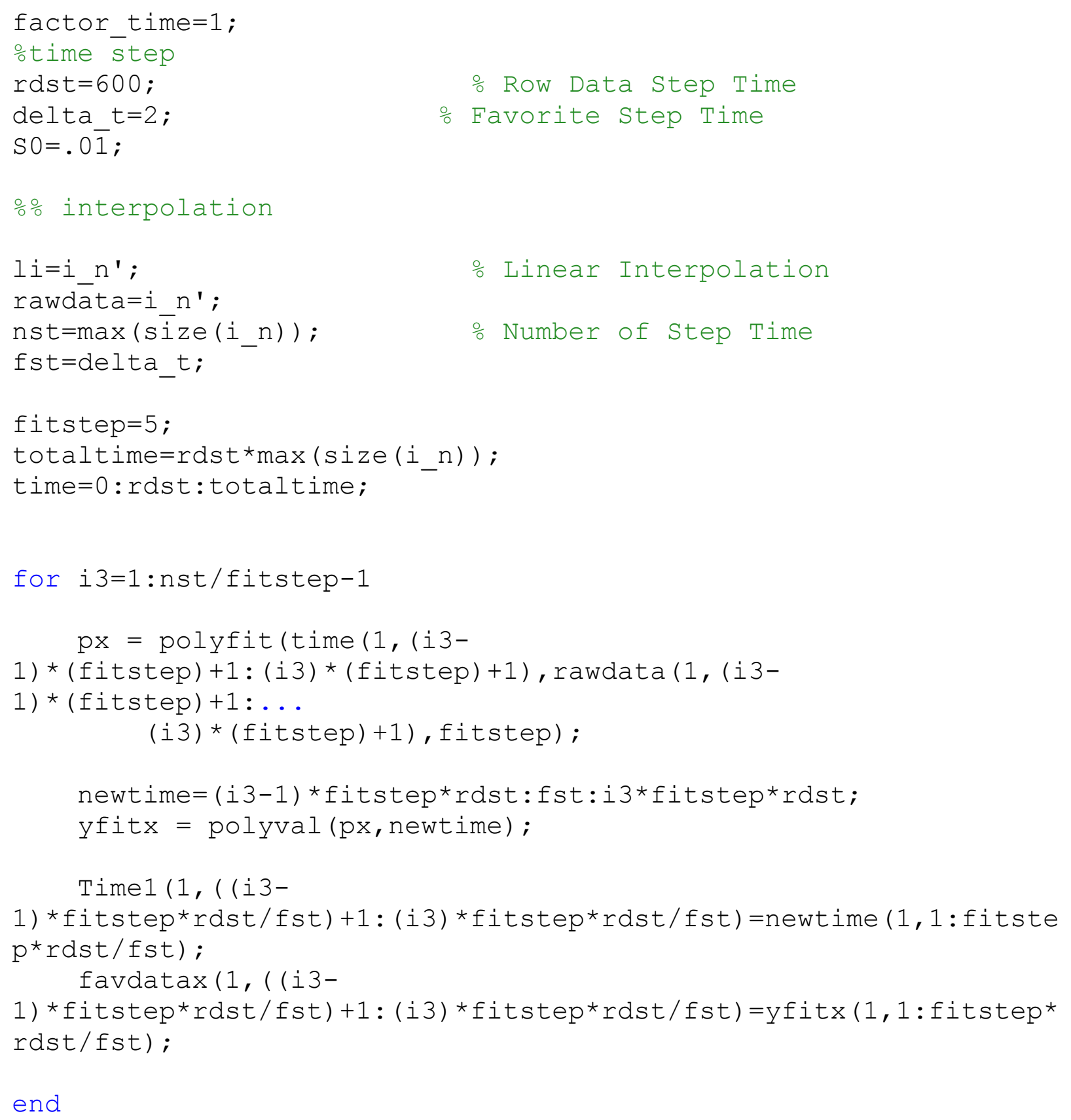




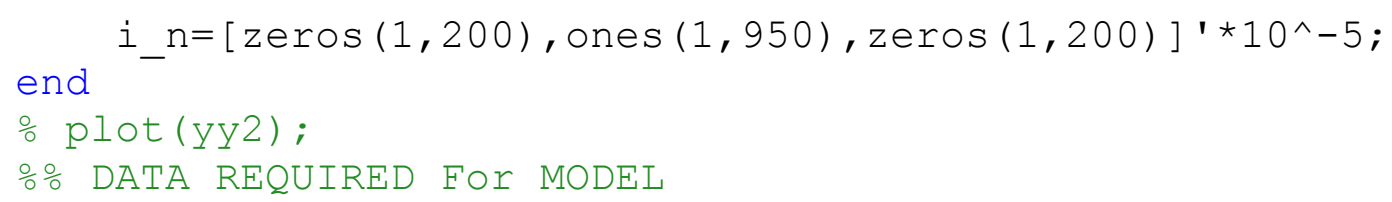


di_max $=((2 * \mathrm{pi} /(\mathrm{m} / 2-1))-2 *$ theta_max $) /(\mathrm{m} / 2-2) ;$ oAlgebraic series $a+\overline{(} n-1) d$

di_min $=((2 * \mathrm{pi} /(\mathrm{m} / 2-1))-2 *$ theta_min $) /(\mathrm{m} / 2-2)$; \%Algebraic series sum: $n / 2(2 a+(n-1) d)$

di=di_max: $-\left(d i \_m a x-d i \_m i n\right) /(n-1): d i \_m i n ; \%$

L_s $=\overline{0}: d_{-} s:$ L_p $1 ; \quad--\quad$ ontocations of the

perfolation sections $[\mathrm{m}]$

A_per = A_coef2 $*$ L_s + A_coef1;

A_per2=AeraCoef*max $(\max ($ A_per $))$;

응 Heighs calculations

o heights at $t=0$, boundary situation

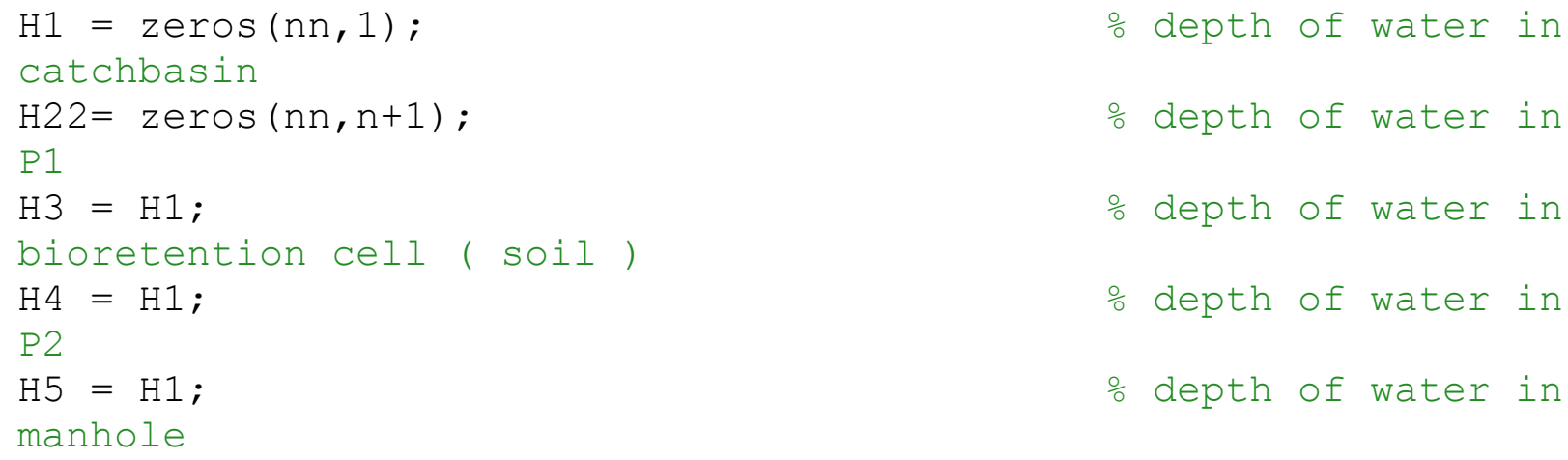


elseif $\mathrm{H} 1(\mathrm{kk}, 1)<\mathrm{d} \_\mathrm{pl} \& \& \mathrm{H} 1(\mathrm{kk}, 1)>=\mathrm{w}$ d_min

$\mathrm{f} 1=\mathrm{C}(\mathrm{X}) \mathrm{aa} 2 * \mathrm{X}(1)-\mathrm{aa} 2 * \mathrm{H} 1(\mathrm{kk}, 1)-\bar{a} \mathrm{a}{ }^{*} \mathrm{i} \_n(\mathrm{kk}+1,1)-$ $\mathrm{aa} 4 * i \_n(k k, 1)+\operatorname{aal} *\left(\mathrm{X}(1)-\mathrm{w}_{-} \mathrm{d} \_\mathrm{min}\right) \wedge 1.5+\mathrm{aal}{ }^{\star}(\mathrm{H} 1(\mathrm{kk}, 1)-$ w_d_min)^1.5;

else

$\mathrm{f} 1=\mathrm{a}(\mathrm{X}) \mathrm{aa} 2 * \mathrm{X}(1)-\mathrm{aa} 2 * \mathrm{H} 1(\mathrm{kk}, 1)-\mathrm{aa} 4 * \mathrm{i} n(\mathrm{kk}+1,1)-$ $\mathrm{aa} 4 * i \_n(\mathrm{kk}, 1)+\mathrm{aa} 1 * \mathrm{~d} \_\mathrm{p} 1 / 2 *\left(\mathrm{X}(1)-\mathrm{d} \_\mathrm{p} 1 / 2\right)^{\wedge} 0.5+$

$\mathrm{a} a 1 * \mathrm{~d} \_\mathrm{p} 1 / 2 *(\mathrm{H} 1(\mathrm{kk}, 1)-\overline{\mathrm{d}} \mathrm{p} 1 / 2)^{\wedge} 0.5$;

end

options = optimset('Display', 'off');

$\mathrm{H} 1(\mathrm{kk}+1,1)=\mathrm{fsolve}(\mathrm{f} 1, \mathrm{H} 1(\mathrm{kk}, 1)$, options $)$;

if $\operatorname{imag}(\mathrm{H} 1(\mathrm{kk}+1,1)) \sim=0$

$\mathrm{H} 1(\mathrm{kk}+1,1)=\mathrm{H} 1(\mathrm{kk}, 1)$;

end

$\mathrm{H} 1(\mathrm{kk}+1,1)=\mathrm{abs}(\mathrm{H} 1(\mathrm{kk}+1,1))$;

\%응 Distribution Pipe1

$\mathrm{H} 22(\mathrm{kk}+1,1)=\mathrm{H} 1(\mathrm{kk}+1,1)$;

theta_wet=zeros $(n, 1)$;

for $i=1: n \quad \frac{\circ}{0}$ calcualtion of the hight of the

perfolation holes

for $j=1: m / 2-1$

thetha $(i, j)=j / 2 *(2 * \operatorname{theta} 0(i)+\operatorname{di}(i) *(j-1))$;

$\mathrm{H} h(i, j)=\mathrm{d} \_\mathrm{p} 1 / 2 *(1-\cos ($ thetha $(i, j)))$;

$\mathrm{D}_{-} \mathrm{h} 1=\max \left(\left[\overline{0}, \mathrm{H} 22(\mathrm{kk}, i)-\mathrm{H}_{-} \mathrm{h}(i, j)\right]\right)$;

D_h2 $=\max \left(\left[0, \mathrm{H} 22(\mathrm{kk}+1, i)-\mathrm{H}_{-} \mathrm{h}(i, j)\right]\right)$;

Q_h_s $=2 * d e l t a \_t / 2 * A \_p e r(i) * C \_d *(2 * g) \wedge 0.5 *\left(D \_h 2 \wedge 0.5+D \_h 1^{\wedge} 0.5\right)$;

$\circ \overline{\mathrm{Q}}$ for two parallel holes

if $j==m / 2$

Q_h_s=delta_t/2*A_per $(i){ }^{*} C_{-} d^{*}(2 * g) \wedge 0.5 *\left(D \_h 2 \wedge 0.5+D \_h 1^{\wedge} 0.5\right) ;$

$\circ \overline{\mathrm{Q}}$ for one $\bar{h} \mathrm{ole}$

end

end

Q_h $(k k, i)=Q \_h(k k, i)+Q \_h \_s$;

Q_t $(k k, 1)=Q \_t(k k, 1)+Q \_h(k k, i)$;

$\mathrm{H} \overline{2} 2(\mathrm{kk}+1, i+\overline{1})=\left(\left(\mathrm{aa} 1 * \mathrm{H} \overline{2} 2(\mathrm{kk}+1, i)^{\wedge} 1.5+\mathrm{aa} 1 * \mathrm{H} 22(\mathrm{kk}, \mathrm{i})^{\wedge} 1.5-\right.\right.$ Q_h $\left.\left.(k \mathrm{k}, i)-\operatorname{aal} * \mathrm{H} 22(\mathrm{kk}, i+1)^{\wedge} 1.5\right) / \operatorname{aal}\right)^{\wedge}(2 / 3)$;

\% heighRatio=H22 (kk+1, i)/d_p1;

\% Hydro rad= (-.017*heighRatio^2) $+(.6739 *$ heighRatio $)+.0004$;

if $\mathrm{H} 22(\overline{\mathrm{k}} \mathrm{k}+1, i+1)==0$

alpha=0; 


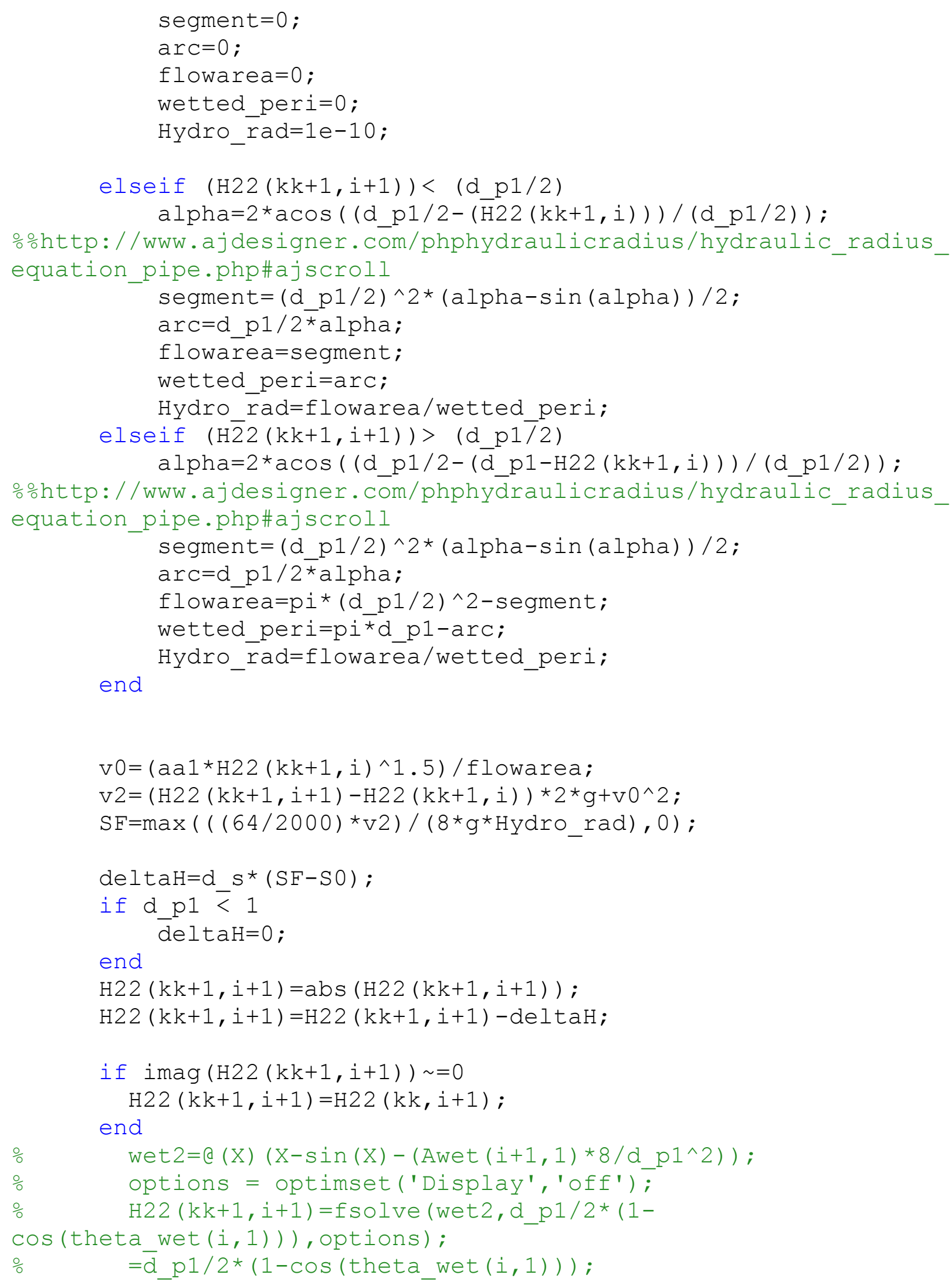


end

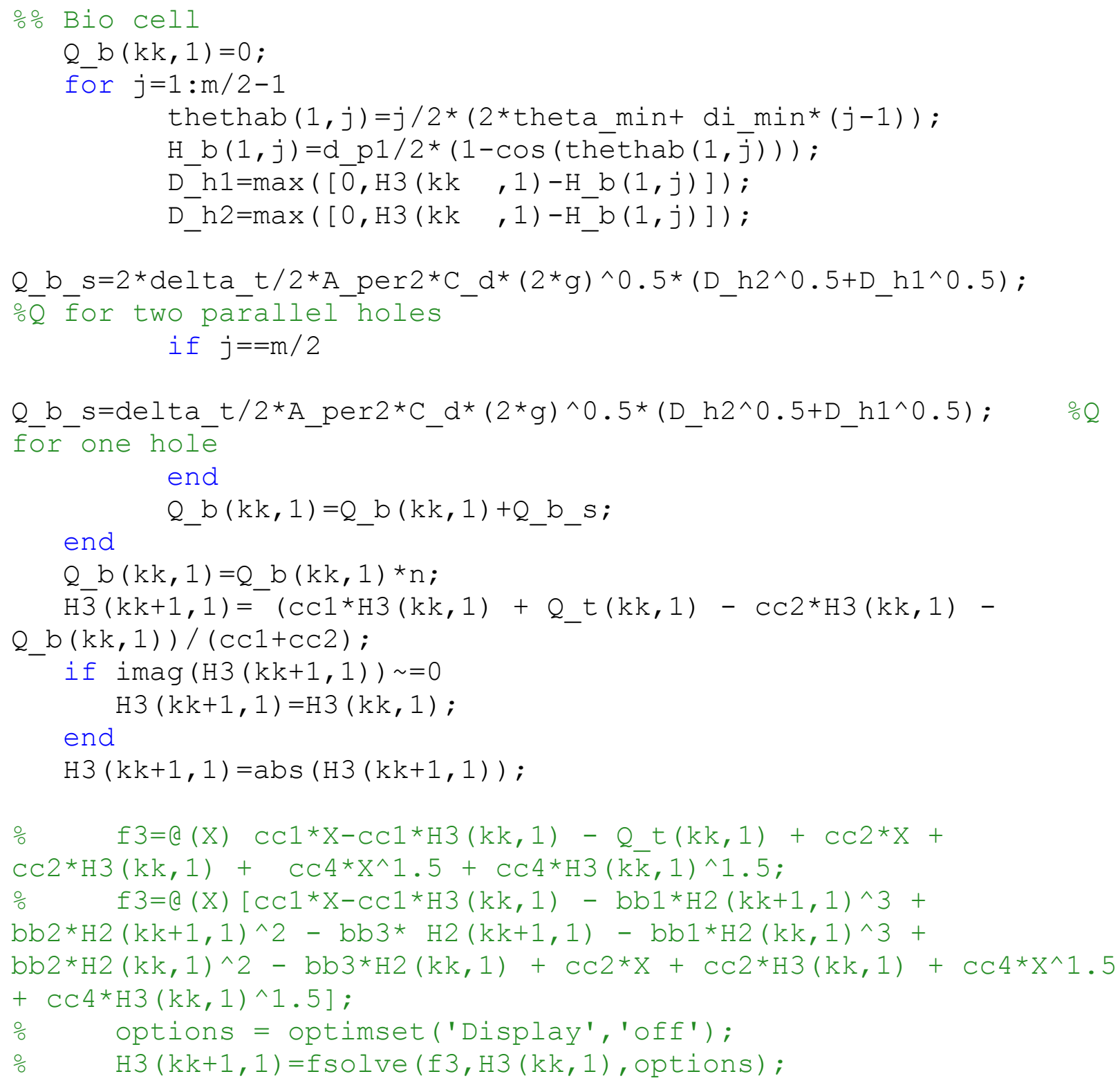




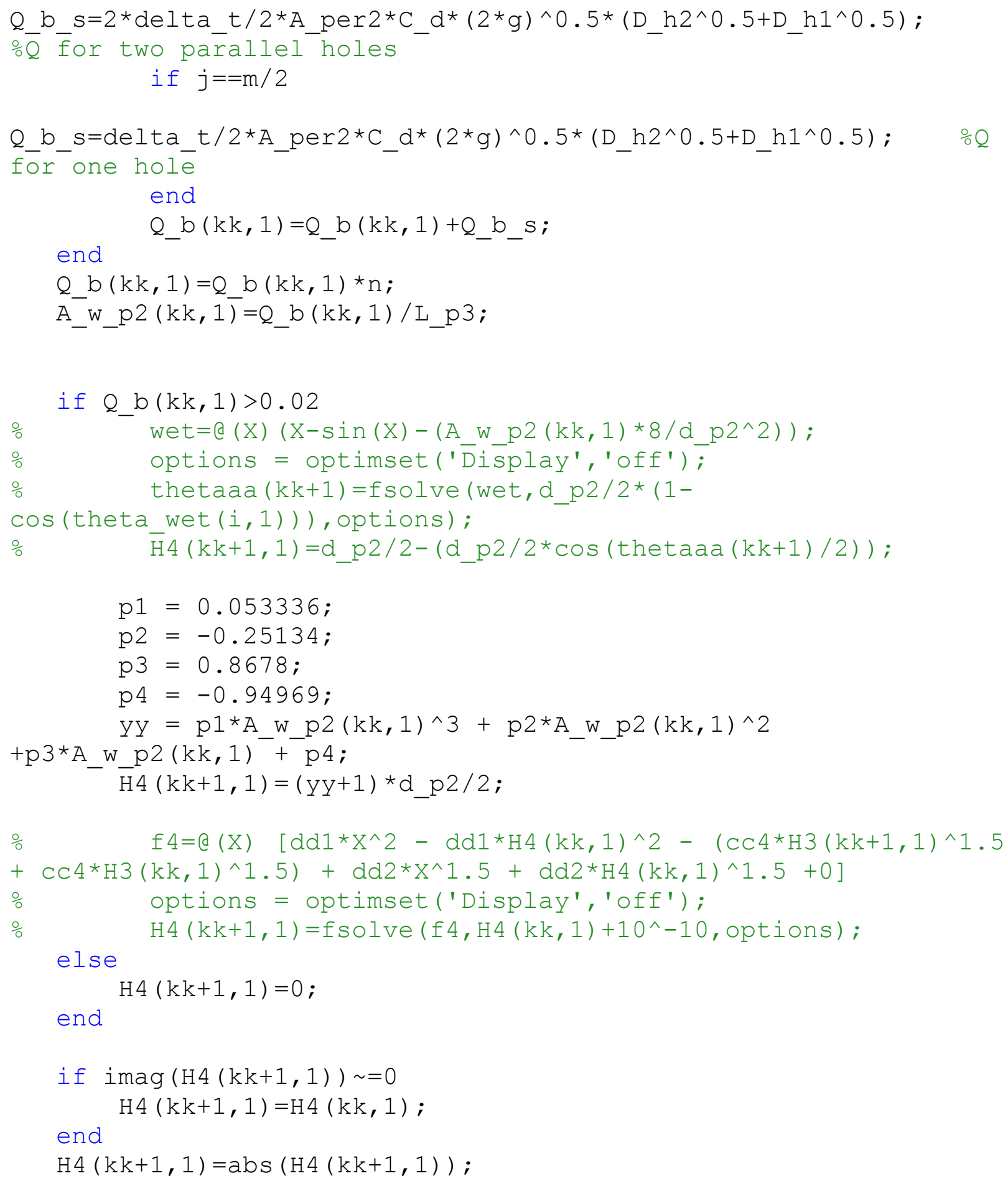




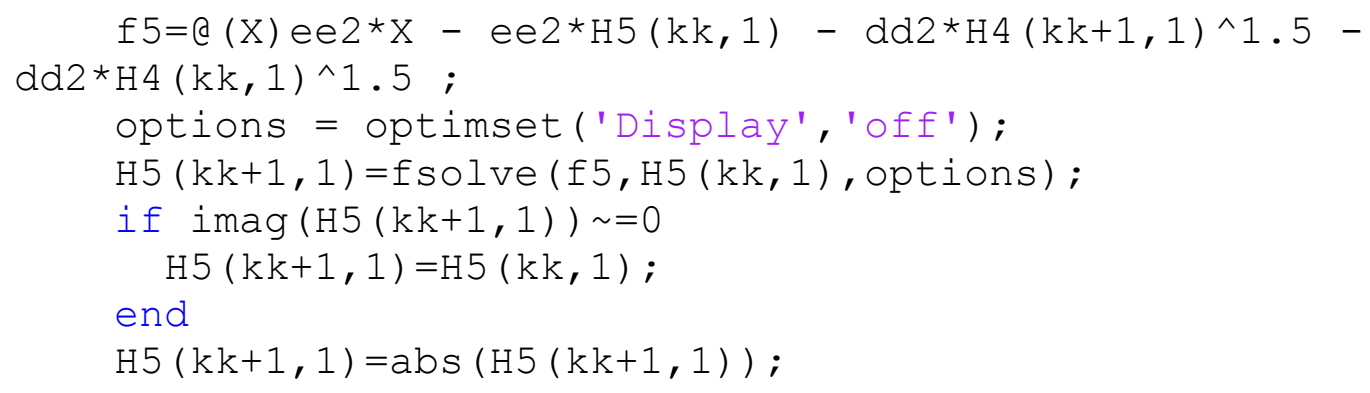




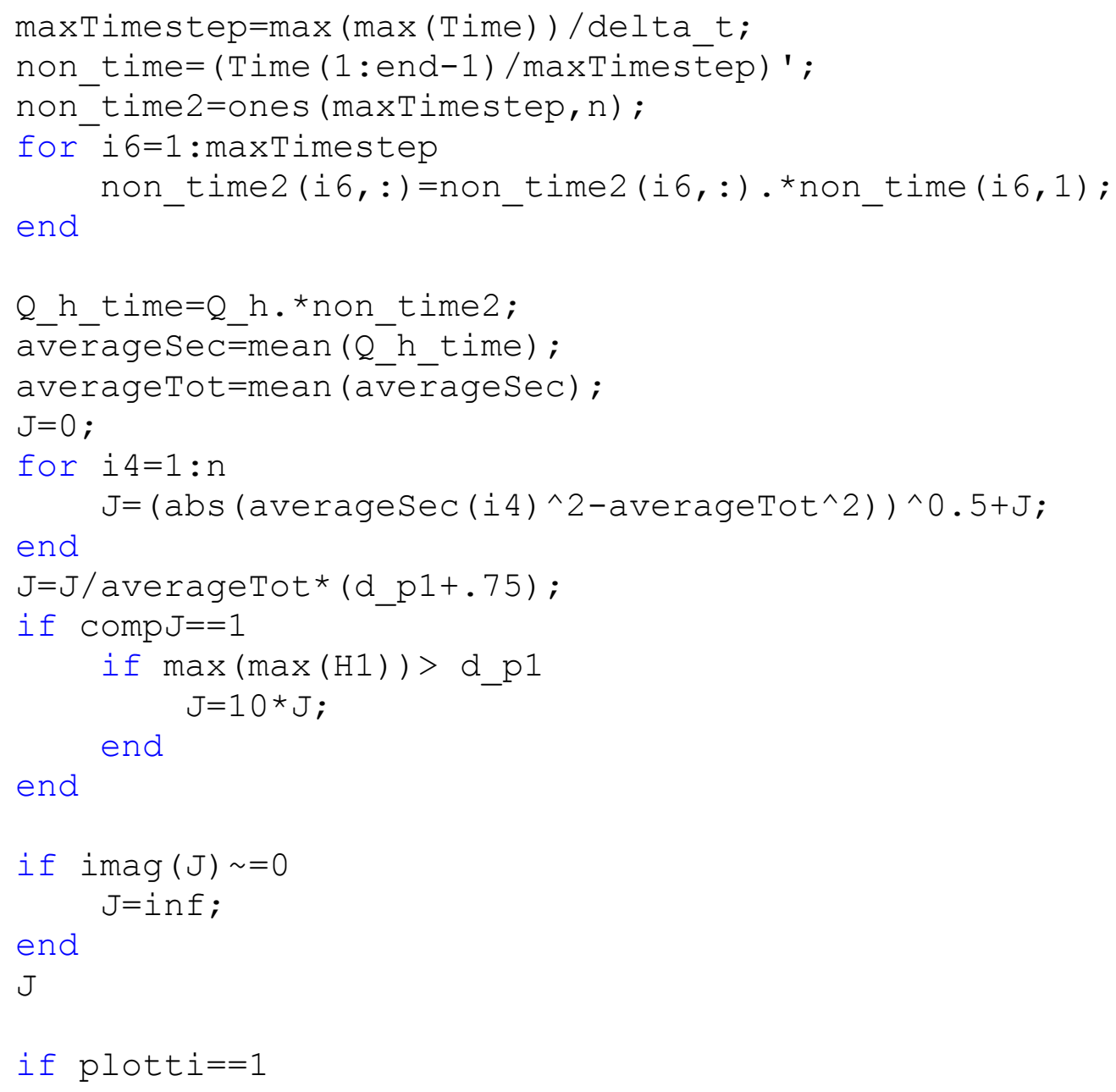




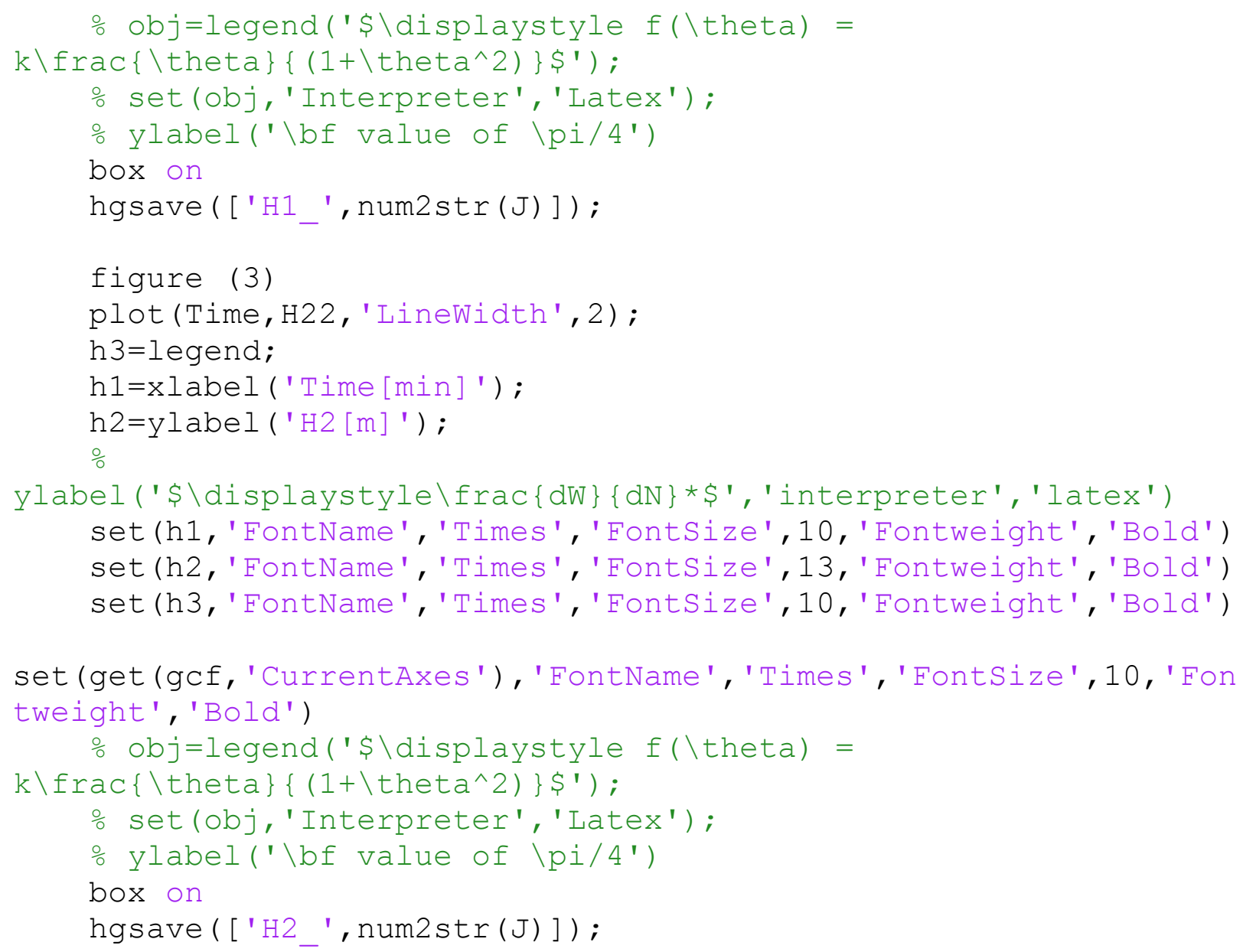


o set (obj, 'Interpreter', 'Latex') ;

\% ylabel ('\bf value of \pi/4')

box on

hgsave (['H3_', num2str (J) ]);

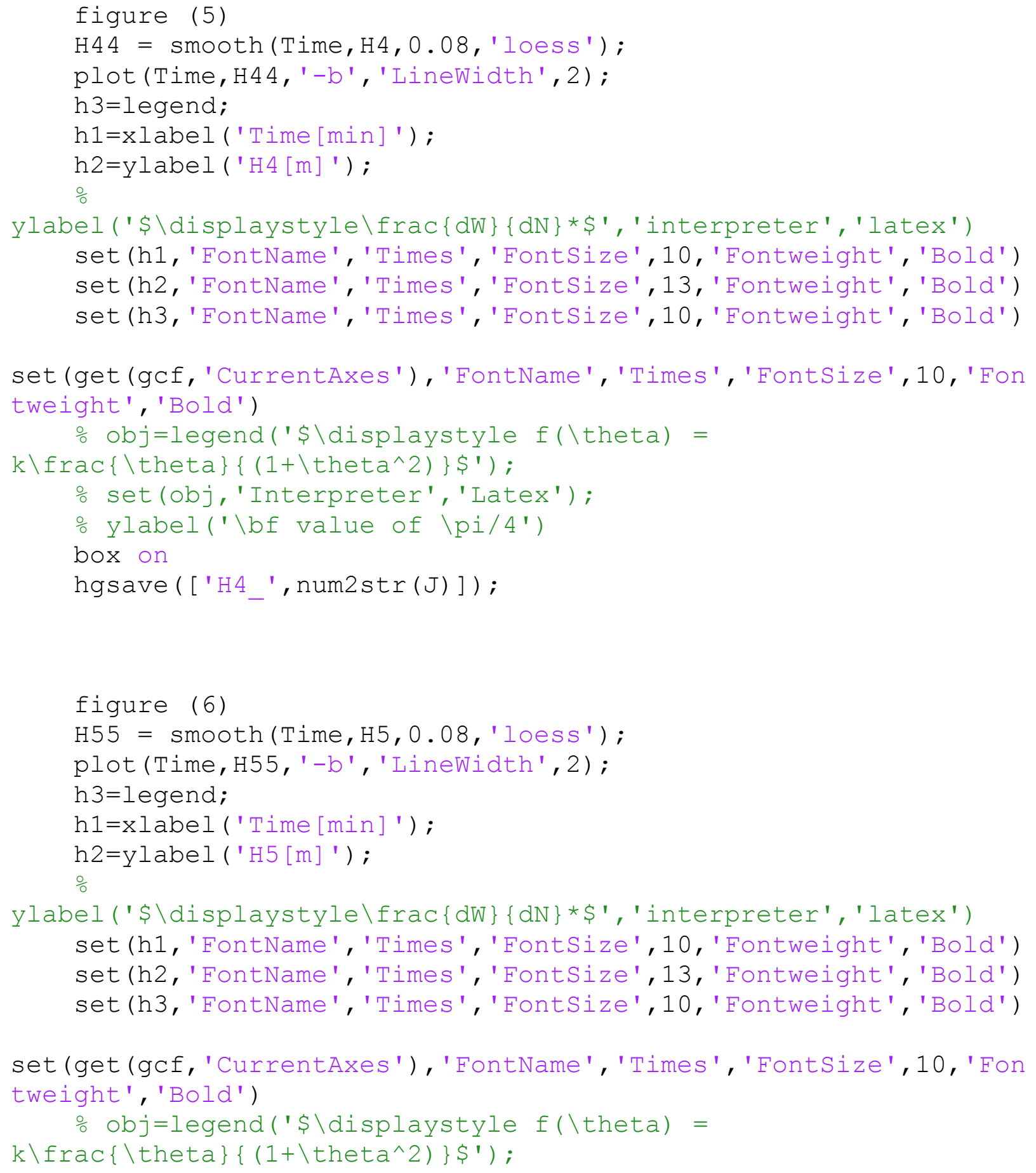




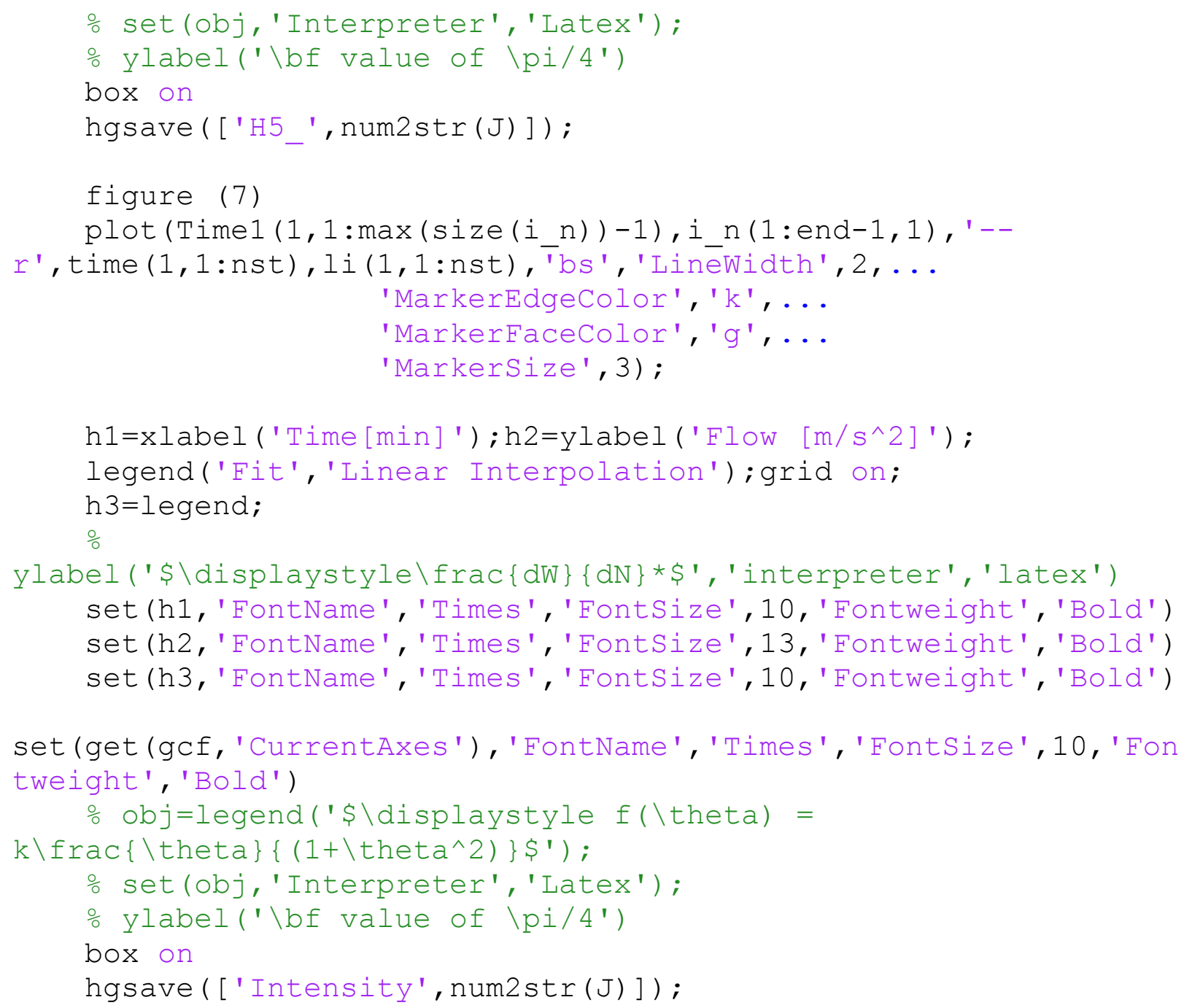




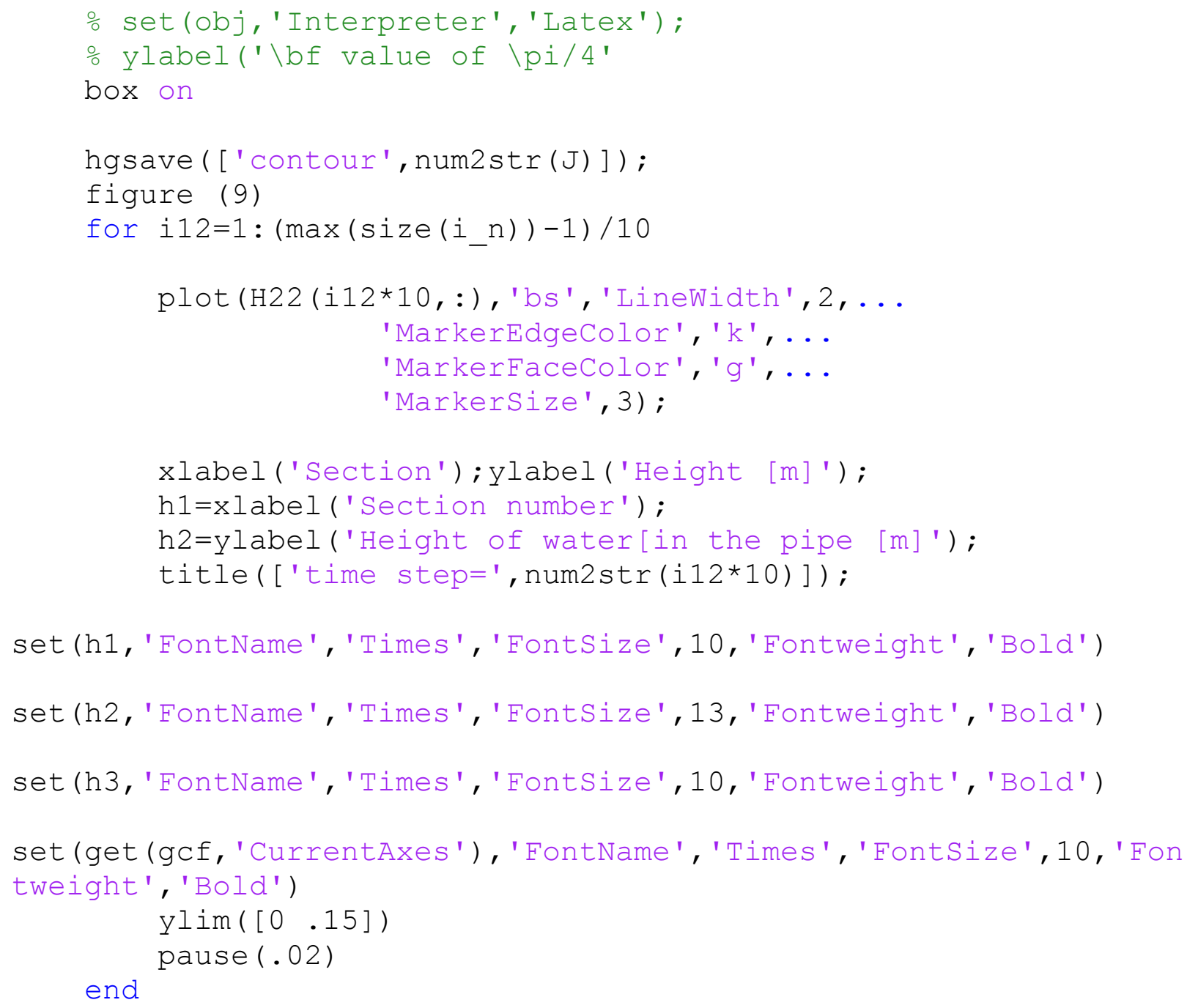

end

toc 